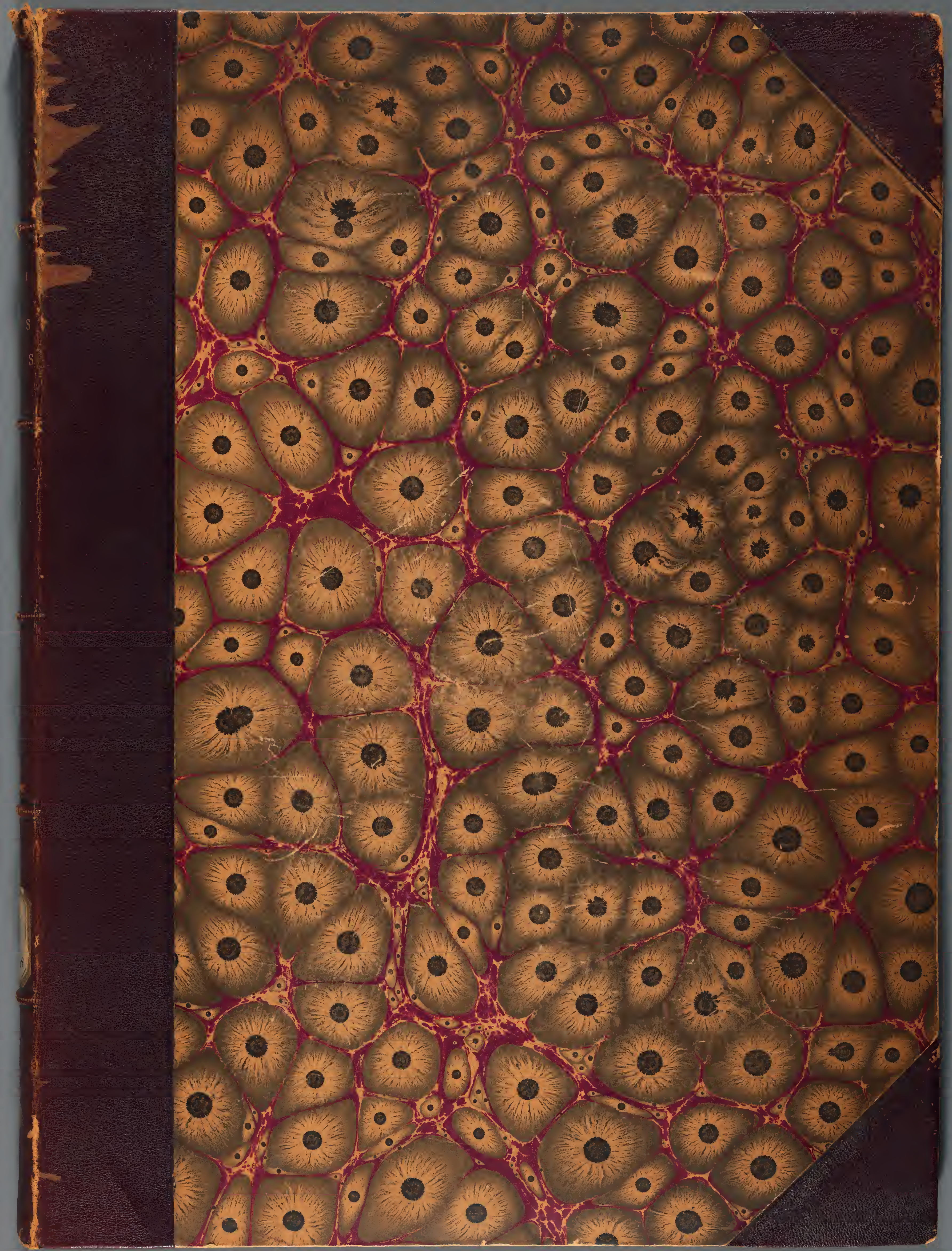






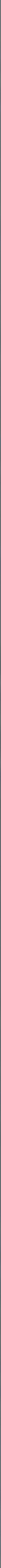




\title{
HORTUS CANALIUS
}

SEU

\section{PLANTARUM RARIORUM,}

QUAE IN HORTO BOTANICO ILLUSTRISSIMI, AC EXCELLENTISSIMI JOSEPHI MALABAILA COMITIS DE CANAL

COLUNTUR,

\section{ICONES ET DESCRIPTIONES.}

\author{
AUCTORE \\ Igraz
$I G N$. Fridrich
$I R I D . T A U S C H$,
}

M. C. botalices olconomico - technicae prof. eXtraORd, Pl. SOC. LitT, SOdALI.

TOMUS PRIMUS.

$P \quad R \quad A^{\psi} G \quad A \quad E$.

LX TYPO-ET LITHO-GRAPIIA THEOPIILI HAASE.

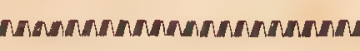

MDCCCXXIII. 


\section{Herbarium}

Rem herbariam heic libare lubet, quae quondam paucarum plantarum erat scientia; hodie vero copia detectorum evasit omnium amplissima.

Linne in praefat. ad Species plantarum. 




SUAE. CAES. RE G.MAJESTATIS CONSHLIARIUS INTUMUS ACTUALIS ET CAMERARIUS, ORDINIS REG. SARDINIENSIS STT. MAURITI ET LAZA. RI LQUES, SOCIETATIS CAES. REG. PATRIAE OECONOMICAE IN REG vo BoHEMIAE PRAESES, ET PLURIUM SOCIETATUM LITTERARI ARUM SODALIS. 



\title{
ILLUSTRISSIMO AC EXCELLENTISSIMO
}

\author{
DOMINO DOMINO
}

\section{JOSEPHO MALABAILA COMITI DE CANAL,}

SUAE CAESAREO-REGIAE APOSTOLICAE MAJESTATIS CONSILIARIO INTIMO ACTUALI, ET CAMERARIO, ORDINIS R. SARDINIENSIS STI. MAURITII ET LAZARI EQUITI, CIVI PRAGENSI HONORARTO, SOCIETATIS C. R. PATRIAE OECONOMICAE IN REGNO BOHEMIAE PRAESIDI, ACADEMIAE R. SCIENTIARUM TAURINENSIS, SOCIETATIS C. R. OECONOMICAE VINDOBONENSIS, ET STYRIACAE, OECONOMICAE IN SAXONIA, AGRARIAE CRACOVIENSIS MEMBRO, SOCIETATIS C. NATURAE STUDIOSORUM MOSCOVIENSIS, LITTERARIAE CRACOVIENSIS, OECONOMICAE IN BAVARIA, NEC NON OECONOMICAE C. R. MORAVO-SILESIACAE MEMBRO HONORARIO etc, etc. 


\section{VIR ILLUSTRISSIME AC EXCELLENTISSIME!}

Innumeris illis, qui Te venerentur, non solum adnumerari audeo, quin imo princeps eorum considerari velis remisque adlaboro. Quapropter occasio, venerationem profundam Nomini Tuo testificandi, nec avidius a me exspectari, nec cupidius arripi potuit.

Tanta enim Tua sunt, tamque ampla de patria, civibus, et scientiis merita, ut omnes Temet excellentissimis carae patriae viris accenseant, et unanimi veneratione prosequentur, imo et qua indigenum omni jure considerent. Juvenili aetate in rebus militaribus reipublicae dicata, provectioribus annis in vitam privatam redibas, nec ullam ommittebas occasionem commune bonum omnimode promovendi, et vestigia ab omnibus aestimati parentis Tui, Ludovici Malabaila Comit is de Canal regis Sardiniae in aula Austriaca legati, secutus scientiis indulgendi.

Hac ratione magna Tibi merita parasti eo, quod instituti pro pauperibus, et orphanotrophei solertissime curam gesseris, quod proprium institutum pro viduis famulorum creaveris, quod innumeros hominum erioxylon tractando, et nuperius syrupum e rapa Betae coquendo accupatos sustentaveris; partim illis hortum egregium in villa urbi adjacente fundando victum suppeditasti, in quibus, siquidem civium salus diu noctuque ante oculum Tibi versabatur, nullis unquam sumptibus pepercisti.

Hortum, cujus hospitales umbras omnes urbis nostrae incolae avide quaerunt, et quem singulari sollicitudine, et solertia exornasti, non solum animis civium restaurandis, verum etiam scientiis dedicari voluisti; siquidem jam anno 1791 proprium hortum botanicum, et plura ampla viridaria ibidem fundasti, ibique cathedram Botanices philosophicae erexisti, in quo munere clarissimi viri 
Franciscus Wilibaldus Schmidt, Mikan, Nowodworsky, et Pohl excelluerunt.

Te auctore, et fautore benevolo clarissimus Schmidt, in quo sacrum scientiarum fervorem accendisti, primum historiae naturalis in regno Bohemiae museum in Tuo horto publice instruxit; Te auctore eo adductus est, ut plura rerum ibidem collectarum nonnullis elaboratis publici juris facere potuit; Te auctore primam Bohemiae Floram, quae plurimis sui temporis palmam praeripit, elucubravit; Te auctore Hortum Canalium iconibus 400 illustratum perfecit: quibus continuandis invida Parca obicem posuit. Tu o indefesso fervore, quo civibus prodesse semper voluisti, qua praeses c. r. societatis oeconomicae non solum necessitatem scientiae botanicae pro oeconomo probe perspexisti, et ab anno 1813 scientiam botanicam ad doctrinam, quo majorem attigit perfectionis gradum, praeprimis oeconomico - technicam extendisti, verum etiam nuper elapsis annis eos, qui inter ceteros excelluerunt, ad accendendum eorum pro re botanica fervorem, praemiis donasti.

Verum tamen non solum unam horti partem scientiae botanicae destinabas; sed etiam in villa huic juncta pro societate oeconomica nova instituebantur experimenta, novaeque perutiles adhibebantur, et publice ostendebantur machinae, et nuperius circa 700 specierum fructuum horaeorum in usum consortii pomologici alebantur, quo praecipue eorum species in patria nostra innotuerunt.

Tua de scientia botanica merita tum in nostra, tum in exteris regionibus ab omnibus agnoscuntur, ita ut clarissimus Sprengel in historia Botanices Tui cum laude mentionem faciat, et cla- 
rissimus Hoffmann nomen Tuum in regno plantarum proprio genere „Malabaila“" dicto aeternae posterum memoriae tradiderit.

Quodsi etiam licitum sit, viro tot, tantisque meritis excellenti majores suos alta mente respicere; tamen nunquam fecisti, semperque singulari liberalitate, et humanitate excelluisti, quibus sincerum omnium amorem, et aestimationem Tibi vindicasti.

Quamvis autem de solo paterno, et scientiis quam optime meritus sis; tamen Fautor Excellentissime! ea, quibus me cumulasti, beneficia omnia illa exsuperant, ita ut cuncta enumeraturo verba deficerent. Ab eo enim tempore, quo arenam academicam intravi, et praelectiones botanicas audivi, quae hujus studii amorem potenter in me excitarunt, nullum Te generosiorem, et liberaliorem fautorem cognovi, Tuaeque inprimis benevolentiae in acceptis habeo, quod cursum academicum absolvere, et omne a studiis mihi concessum tempus lustrationibus in patria nostra botanicis vovere mihi licuerit. Nunquam destitisti nova mihi favoris, amorisque Tui stabilire exempla, meque ab anno 1815 ad cathedram Botanices oeconomico - technicae evexisti. Quas grates Tibi debeam, cum omnia, quaecunque habeam, a Tua singulari in me benevolentia, et sapientibus auspiciis ceu fonte proveniant, verbis exprimere imparem me sentio, quapropter occasionem, grati animi specimen publice manifestandi, ardentissimis exoptabam votis. Rogo itaque Faut or Excellentissime! ut primitias laborum meorum, quae ex Tua segete progerminant, qua exiguum aeternae venerationis in Te meae, gratique animi specimen suscipias, mihique ignoscas, si hasce Tua mihi prae omnibus aestimanda, et cuique bono profecto grata imagine con- 
decorem. Quodsi primo illi lucubrationum mearum fructui, cui maturando fomitem in me primus excitasti, aliquantum arriseris, felicissimum me depraedicabo, atque indefessus pergam, tramitem mihi a Te assignatum prosequi, ut scopum mihi praefixum, Tuis satisfecisse votis, attingam. Indulge precibus meis, Illustrissime ac Excellentissime! mihique, ut semper fecisti, favere perge.

Laborum Tu orum fructus aeterne prosint, atque celebrentur, uti gloria, quam nullus unquam erodet temporis dens, nulla unquam obliterabit vetustas. Quem enim virum tanta decorant merita, hujus encomia Horatius his canit verbis:

Illum aget penna metuente solvi

Fama superstes.

Tuus

devinctissimus

Ign. Frid. Tausch. 


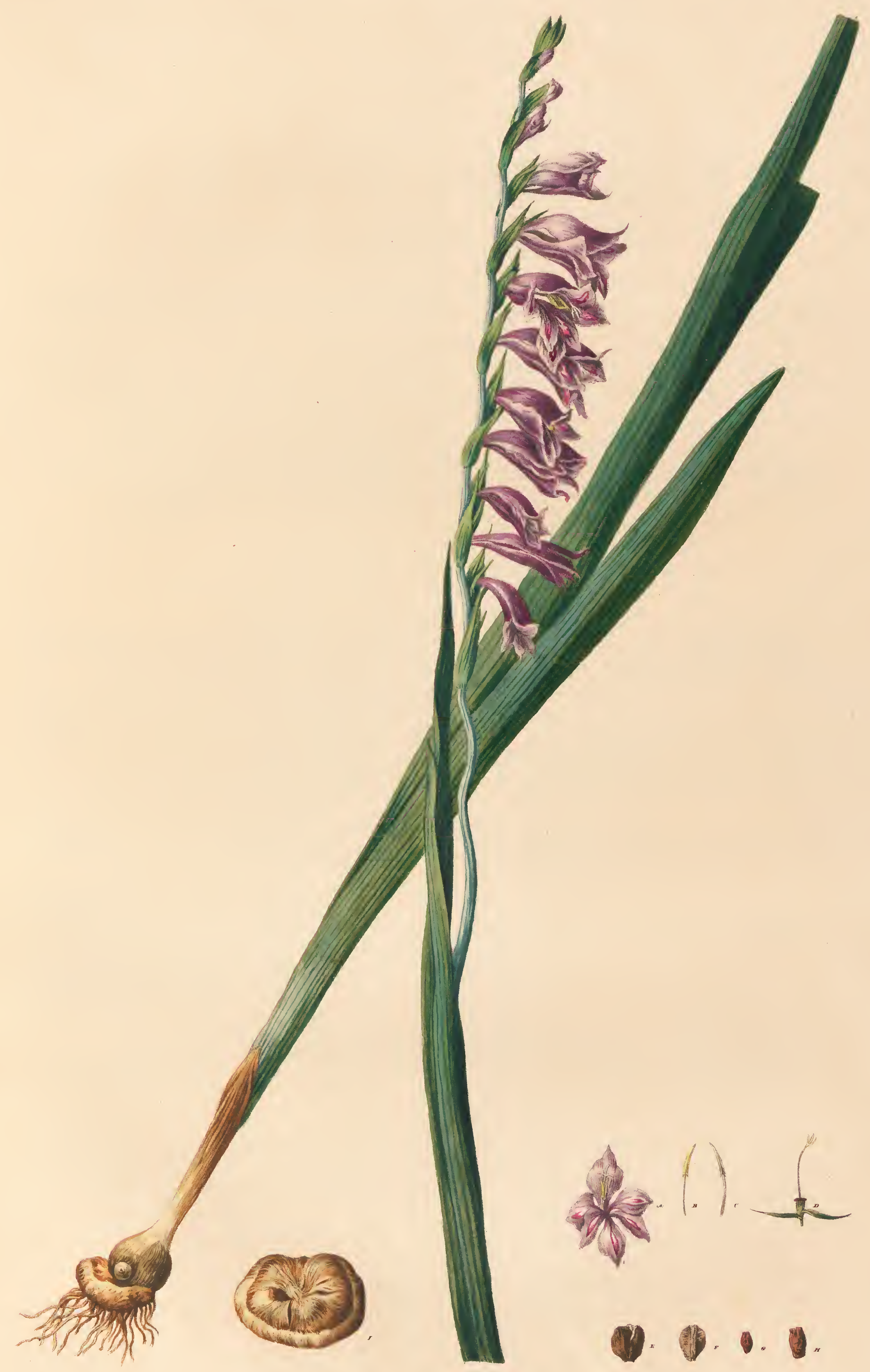

GLADIOLUS IMBRICATUS . 


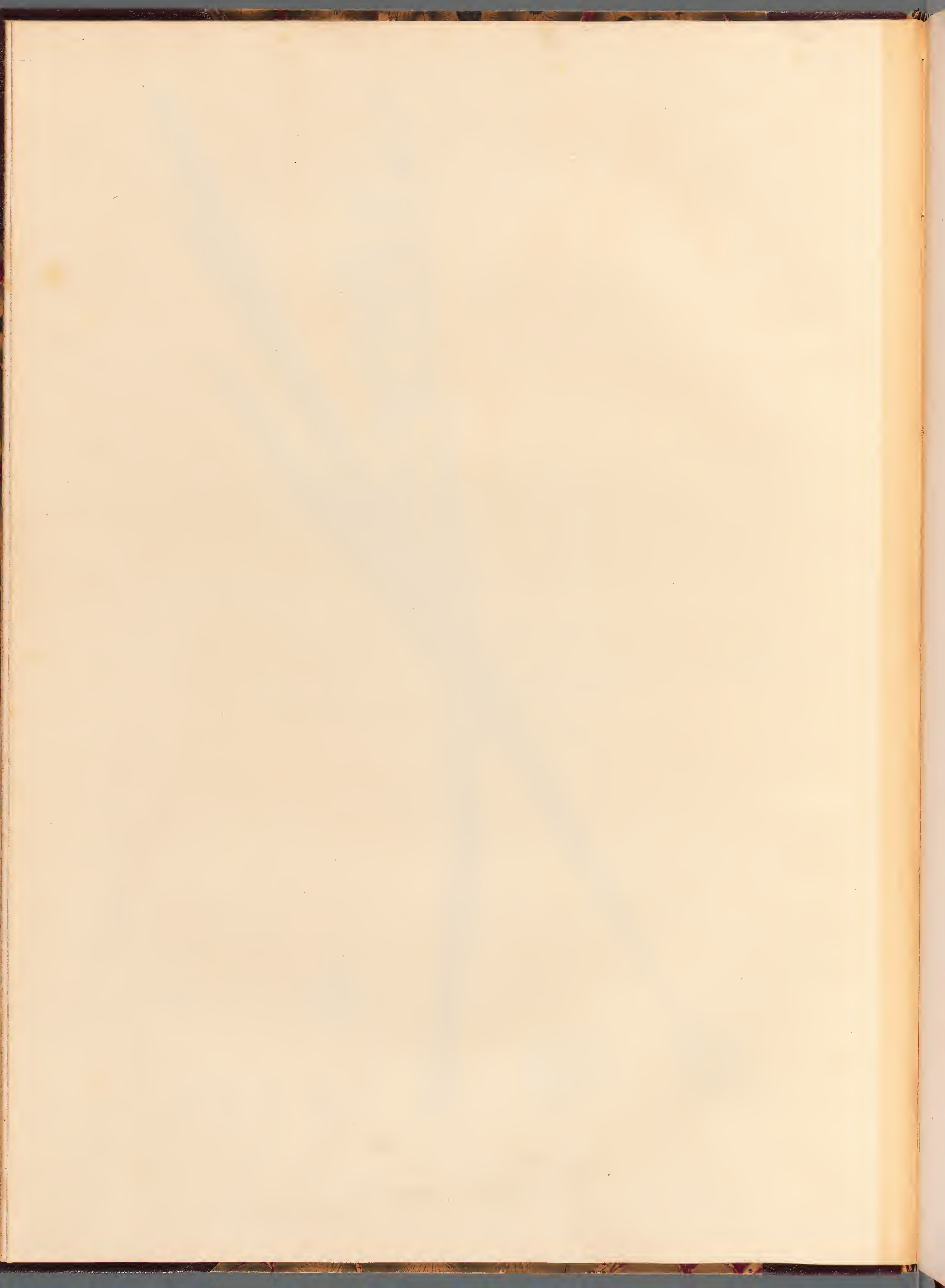




\title{
GL A D I O L U S I M B R I C A T S.
}

\author{
G L A D I O L U S. Linne. Aiton.
}

Classis, et Ordo.

Triandria: Monogynia. Linne gen. pl. Monocotyledoneae: Irideae. Jussieu gen. pl.

Character generis.

Fructificatio. Spatha uniflora, bivalvis. Perigonium superum, tubo curvato, limbo sexpartito ringente, laciniis inaequalibus. Stamina tria adscendentia sub labio superiore. Antherae erectae. Germen inferum. Stylus filiformis. Stigmata tria. Capsula trilocularis, trivalvis, polysperma. Semina alata.

Vegetatio. Herbae. Caulis simplex. Folia alterna, disticha, vaginata, subulata, aut compressa (tetragona vel ensata). Bulbus vertice sobolifer. Flores spicati, coronarii.

\section{G L A D I O L U S I M B R I C A T U S.}

Differentia specifica, et Synonymia.

G. floribus spicatis, confertis, secundis, subnutantibus; perigonii laciniis undulatis, acutis, unguiculatis, basi hiantibus: labio inferiore quinquepartito: tubo spatha acuta breviore; foliis ensatis; bulbo deplanato.

Gladiolus floribus uno versu dispositis minor. Bauh. pin. 4,1 ?

Gladiolus imbricatus. Linne spec. pl. edit. III. p.52. Willd. spec. pl.I. p. 212. Roem. et Schult. syst. veget. I. p. 407. Marsch. a Bieberstein Fl. taur. caucas. suppl. p. 38. Cent. pl. ross. II. t. 6o. (ex suppl.). Tausch ind. pl. hort. Canal. 1821. Schult. Mant. I. p. 289.

Gladiolus rossicus. Pers. syn. pl. I. p. 46. excluso synonymo Jacq.

Gladiolus tenuis. Marsch. a Bieberstein Fl. taur. caucas. I. p. 29. Besser enum. pl. Volhyn. p. 4.

Gladiolus galiciensis. Besser Fl. galic. I. p. $5^{1}$.

Gladiolus neglectus. Schultes obs. bot. p. 14. Oestr. Flor. I. p. 102. Roem. et Schult. syst. veget. I. p. 418. Presl Fl. czech. n. 59.

Gladiolus Marschalli. Poiret Enc. meth. suppl. II. p. 789 .

Dichtblühende Siegwurz.

$$
\text { Locus natalis, et tempus. }
$$

Crescit in Bohemia in prato silvatico ad Zbirow; in horto colitur sub Dio, et fructificat Junio. $\delta^{*}$.

$$
\text { Descriptio. }
$$

Vegetatio. Radix biennis, bulbosa. Bulbus deplanatus, difformis, fibroso-tunicatus, badius, testis 2-3 suborbicularibus albis carnosis coadunatis testaceus, basi radicatus, vertice sobolifer; sobolibus 1-zimpositis, et fructificatione peracta ipsiis; marcescens, abolescens. Caulis centralis, basi sobolem fovens, simplex, erectus, gracilis, striatus, glaucus, foliosus, versus apicem flexuosus nudus, basi vaginis 1-2 fuscescentibus tectus. Folia caulina $4-5$ disticha, ensiformia, basi vaginata, stricta, nervosa, vix glaucescentia. Spica florum terminalis. Flores sessiles, alterni, conferti, secundi, subnutantes. 
Fructificatio. Spatia unitlora, bivalvis, valvis herbaceis, acutis, tubo perigonii subaequalibus. Perigonium: (calyx Juss. corolla Linn.) superum, basi tubulosum; tubo incurvo; limbo profunde 6-partito, ringente; labio superiore simplici, inferiore 5-partito ; laciniis omnibus spathulatis, acutis, undulatis, basi unguiculatis, hiantibus. Color floris ex purpureo in violaceum vergens, laciniis labii inferioris macula lanceolata albida, purpureo-limbata pictis. Stamina 3, orificio tubi inserta, sub labio superiore adscendentia. Filamenta filiformia, glabra, antheris longiora. Antherae erectae, lineares, sagittatae, biloculares. Germen inferum, trigonum. Stylus filiformis. Stigmata 3, incrassata, revoluto-patentia. Capsula parva, coriacea, trilocularis, trivalvis, valvis medio septiferis, polysperma. Semina alato-tunicata, fusca, tenuissime punctata.

Observatio. Planta spontanea nil nisi magnitudine a culta recedit. Spontaneae bulbus magnitudine nucis avellanae, sobolis magnitudine pisi majoris; caulis brevior, gracilior, minus foliosus, foliis angustioribus; flores minores, vix ultra sex, fere imbricati.

\section{Diagnosticon.}

Gladiolus imbricatus proximus est G. communi, ita ut in plerisque Floris sub illo partim subintelligendus sit. Differt autem a G. communi, cujus differentia specifica: G. floribus spicatis, distantibus, secundis, subnutantibus; perigonii laciniis obtusis, unguiculatis, basi hiantibus; labio inferiore tripartito; tubo spatha acuta multo breviore; foliis ensatis; bulbo orbiculari-depresso; bulbo deplanato, difformi, caule graciliore, (in culta saltem) quidquam altiore, foliis angustioribus, floribus minoribus, confertis, labio, et laciniis perigonii, colore in violaceum vergente, spatha breviore, capsula duplo minori, denique fructificatione spatio 14, dierum serius peragente.

$$
\text { Critica. }
$$

Gladiolum imbricatum Linne ab illius tempore a nemine repertum, et e sola differentia specifica clarissimis autoribus cognitum cum nostro convenire, e sequentibus concluditur: 1. E loco natali, quem Russiam citeriorem Linne dicit. Invenitur vero non solum in Russia, sed etiam in regionibus Russiae adjacentibus, imo et in omni Europa septentrionali. 2. E serie systematica, et differentia specifica. Linne proximum posuit Gladiolo communi, floribusque imbricatis distinxit a priori floribus distantibus designato. 3. E comparatione differentiae specificae cum aliis ejusdem generis, qua evincitur, patrem Linne hic floribus imbricatis forte e specimine unico, misere exsiccato, pressove desumptis solum confertos intellexisse, cum aliis speciebus floribus vere imbricatis gaudentibus, quibus et G. imbricatus a clarissimis autoribus consociari solet, nempe G. spicato, et alopecuroidi (Watsoniae Aiton) exquisite tantum ,flores spicatos“ tribuit.

$$
\text { Explicatio Tabulae. }
$$

A. Limbus perigonii bilabiatus. B. Stamen a facie. C. Stamen a tergo. D. Pistillum perigonio abscisso, et spathae valvis explanatis instructum. E. Capsula. F. Valvula capsulae dissepimento. G. Semen. H. Idem magnitudine auctum.

I. Bulbus fructificatione peracta ipsius, eradicatus, absque sobole. 


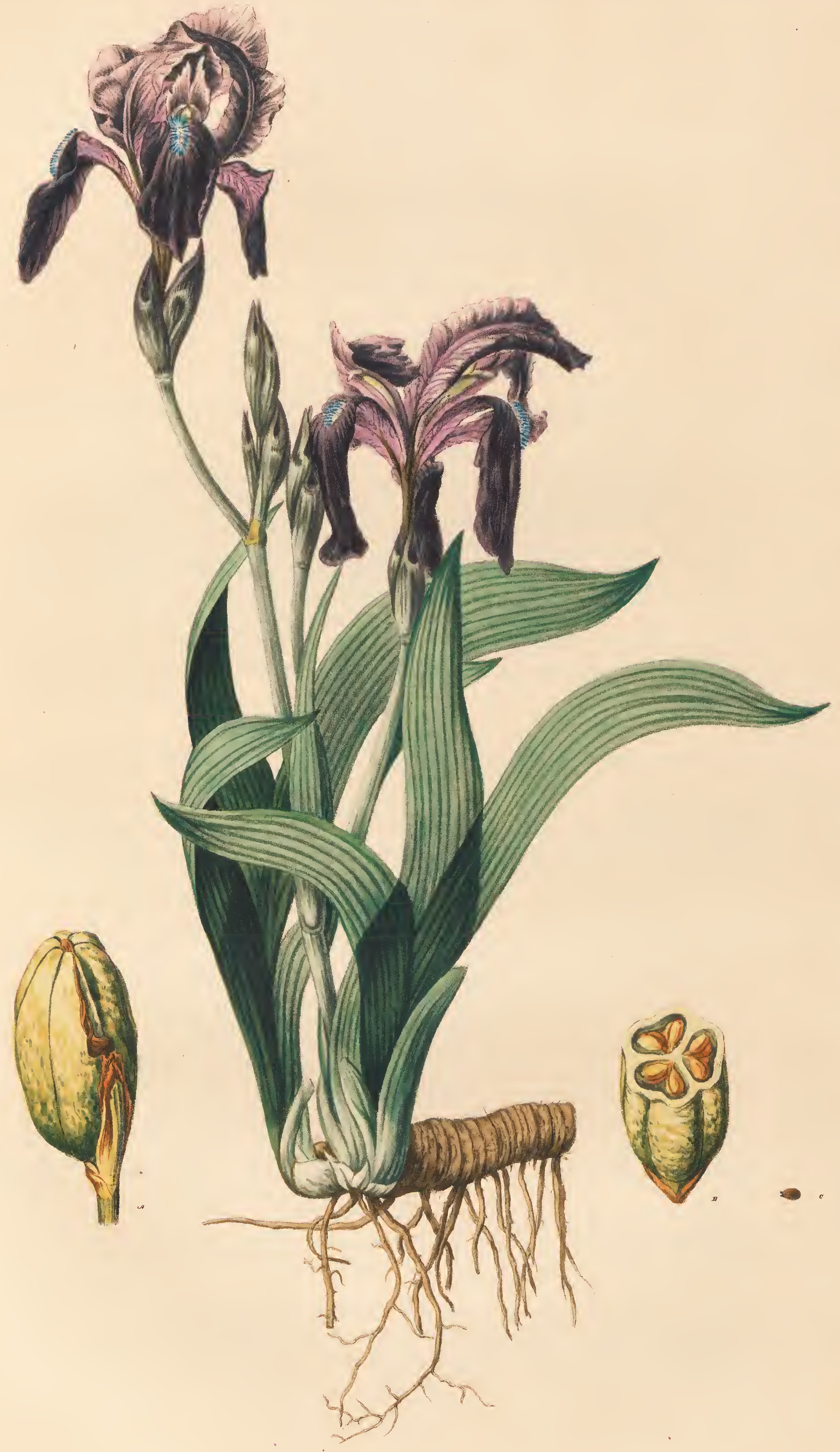

IRIS FALCATA 


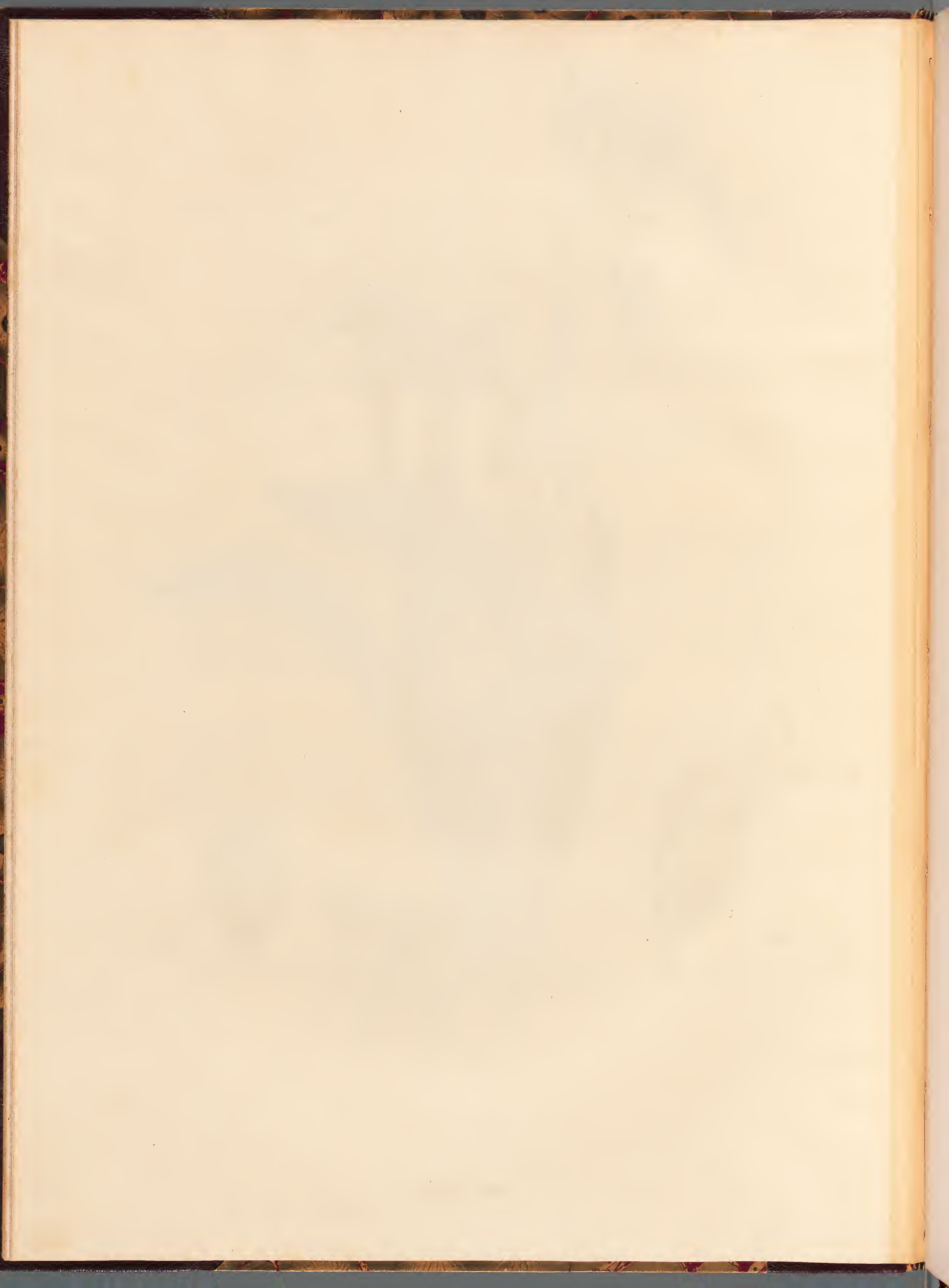




\section{R I S $\begin{array}{llllllll} & \mathrm{F} & \mathrm{A} & \mathrm{L} & \mathrm{C} & \mathrm{A} & \mathrm{T} & \mathrm{A} \text {. }\end{array}$}

\section{I $\quad \mathbf{R} \quad$ I $\quad$ S. Linne.}

Classis, et Ordo.

Triandria: Monogynia. Linne gen. pl. Monocotyledoneae: Irideae. Jussieu gen. pl.

Character generis.

Fructificatio. Spatha uni-multiflora, bivalvis. Perigonium superum, tubo recto, limbo sex-partito, laciniis tribus exterioribus reflexis, aut patentissimis, basi staminiferis, tribus interioribus erectis. Stamina tria. Antherae oblongae, rectae. Germen inferum, oblongum. Stylus brevis. Stigmata tria, petaliformia, oblonga, bifida, dorso unilamellata, et staminibus incumbentia. Capsula trilocularis, trivalvis, polysperma.

Vegetatio. Herbae scapigerae, aut raro basi trunco caulescentes. Radix bulbosa, aut tuberosa, aut raro fibrosa. Folia alterna, disticha, vaginata, canaliculata, aut subulata, aut compressa (ensata vel tetragona). Flores terminales, coronarii.

$$
\text { Divisio generis. }
$$

In Iride, fructificatione, et vegetatione aestimata, sequentes sectiones discerni possunt:

I. Pogiris. Perigonii laciniae exteriores deflexae, barbatae. Stigmata erecto-patentia. Capsula obtusa, coriacea, dehiscens. Semina rotundata. Folia ensata (gladiata), stricta. Tủber vermicularis, annulatus, nudus, carnosus.

a. Laciniae perigonii concolores. e. g. I. falcata, pumila.

b. Laciniae perigonii discolores. e. g. I. germanica, variegata.

II. Lophiris. Perigonii laciniae exteriores deflexae, plicato-cristatae, (an et nudae?). Stigmata erecto-patentia. Capsula .. Semina .. Folia ensata, laxa. Truncus saepe basilaris. Radix fibrosa, saepe stolonifera. e. g. I. cristata, chinensis. Huc quoque plures I. imberbium Linne referendae.

III. Limniris. Perigonii laciniae exteriores deflexae, nudae. Stigmata erecto-patentia. Capsula obtusa, lignosa, ore dehiscens. Semina compressa, angulata. Folia ensata. Tuber vermicularis, annulatus, comosus. (Caulis fistulosus plantarum aquaticarum). e. g. Iris Pseudacorus, sibirica.

IV. Xyridion. Perigonii laciniae exteriores patentissimae, nudae. Stigmata patentia. Capsula subulato-rostrata, ore dehiscens. Semina compressa, angulata. Folia ensata. Tuber vermicularis, nodosus, annulatus, squamosus. e. g. I. spuria, ochroleuca.

V. Spathula. Perigonii laciniae exteriores patentissimae, nudae. Stigmata patentia. Capsula obtusa, coriacea, dehiscens. Semina rotundata. Folia ensata. Tuber vermicularis, nodosus, annulatus, squamosus. e. g. I. graminea, foetidissima.

VI. Xiphion. Perigonii laciniae exteriores deflexae, nudae. Capsula .. Semina. . Folia canaliculata, aut subulata, aut tetragona. Bulbus tunicatus, aut fibrosus, aut tuber exannulatus. e. g. I. Xiphium, Sisyrinchium, tuberosa. 


\section{R I S F A L C A T A.}

\section{Differentia specifica, et Synonymia.}

Pogiris: concolor; scapo basi furcato, multifloro, folia falcato-gladiata superante; spatha herbacea, subcompressa, pruinosa; laciniis perigonii oblongis, integris, undulatis; tubo germine cylindrico longiore; capsula oblonga.

Iris bohemica $\beta$ latifolia Tausch ind. pl. hort. Canal. anno 1821.

Sichelförmiger Bart-Schwertel.

\section{Locus natalis, et tempus.}

Locus natalis assignari nequit; colitur autem multis jam annis in horto, ubi nomine I. pumilae reperimus. Fructificat ineunte Maio. 4.

$$
\text { Descriptio. }
$$

Vegetatio. Radix perennis, tuberosa. Tuber repens, vermicularis, depressus, articulatus, annulatus, nudus, inferne radicatus, basi marcescens, abolescens, apice frondescens, progignansque, carnosus, fuscescens, intus albus, odoratus, sapore subfervido. Scapus terminalis, intrafoliaceus, e foliorum vaginis egrediens, erectus, subaphyllus, subcompressus, nodosus, glaucus, basi furcatus; ramo inferiore pedunculum radicalem referente; superiore multifloro, pedunculis alternis, ad ramificationes vaginatis, vagina infima subfoliosa. Folia fasciculata, fasciculis basi vaginis tectis; terminali fructificante, 2 plerumque lateralibus sterilibus, soboliferis, articulosque tuberis gignentes. Folia in fasciculis alterna, 5-5, disticha, falcato-gladiata, apice recurva, saepeque versa, basi vaginata, nervosa, subglaucescentia, scapo breviora, anthesi peracta autem latiora, longioraque.

Fructificatio. Spatha uni-, suprema bi-flora, basi subinflata, apice compressa, bivalvis; valvis subaequalibus, herbaceis, coerulescentibus, pruinosis, lacunosis, tubo perigonii brevioribus. Perigonium suaveolens, superum, basi tubulosum; tubo recto, germine duplo longiore, e viridi coerulescente ; limbo profunde 6-partito, inaequali ; laciniis oblongis, integris, undulatis, basi angustatis (unguiculatis), concoloribus, laete violaceis, basi venis e flavo-fuscis pictis; exterioribus 3 deflexis, barbatis, barba albida, basi flava; interioribus erectis, unguibus distantibus. Stamina 3, laciniis perigonii exterioribus basi inserta. Filamenta subulata, glabra. Antherae oblongae, basi emarginatae, sessiles, erectae, biloculares, albae. Germen inferum, oblongum, 6-striatum. Stylus terminalis, brevis. Stigmata 3, petaliformia, oblonga, apice bifida, dentataque, dorso lamella transversali ; erecto-patentia, lamellaque staminibus incumbentia, perigonii laciniis dilutiora. Capsula oblonga, 6-sulcata, obtusa, coriacea, dehiscens, 3-locularis, 3-valvis, valvis medio septiferis, polysperma, columna centrali triangulari, seminifera. Semina oblonga, rugosa, fusca.

$$
\text { Diagnosticon. }
$$

Iris falcata differt a maxime affini I. bohemica Schmidt, foliis latioribus, magis falcatis, scapo multifloro brevioribus ; spatha subcompressa, nec inflata; laciniis perigonii oblongis, nec ellipticis; barba apice alba, nec coerulea; germine, et capsula oblonga, nec trigona.

$$
\text { Explicatio Tabulae. }
$$

A. Capsula oblonga, ante dehiscentiam subherbacea. B. Eadem transversim dissecta. C. Semen. 


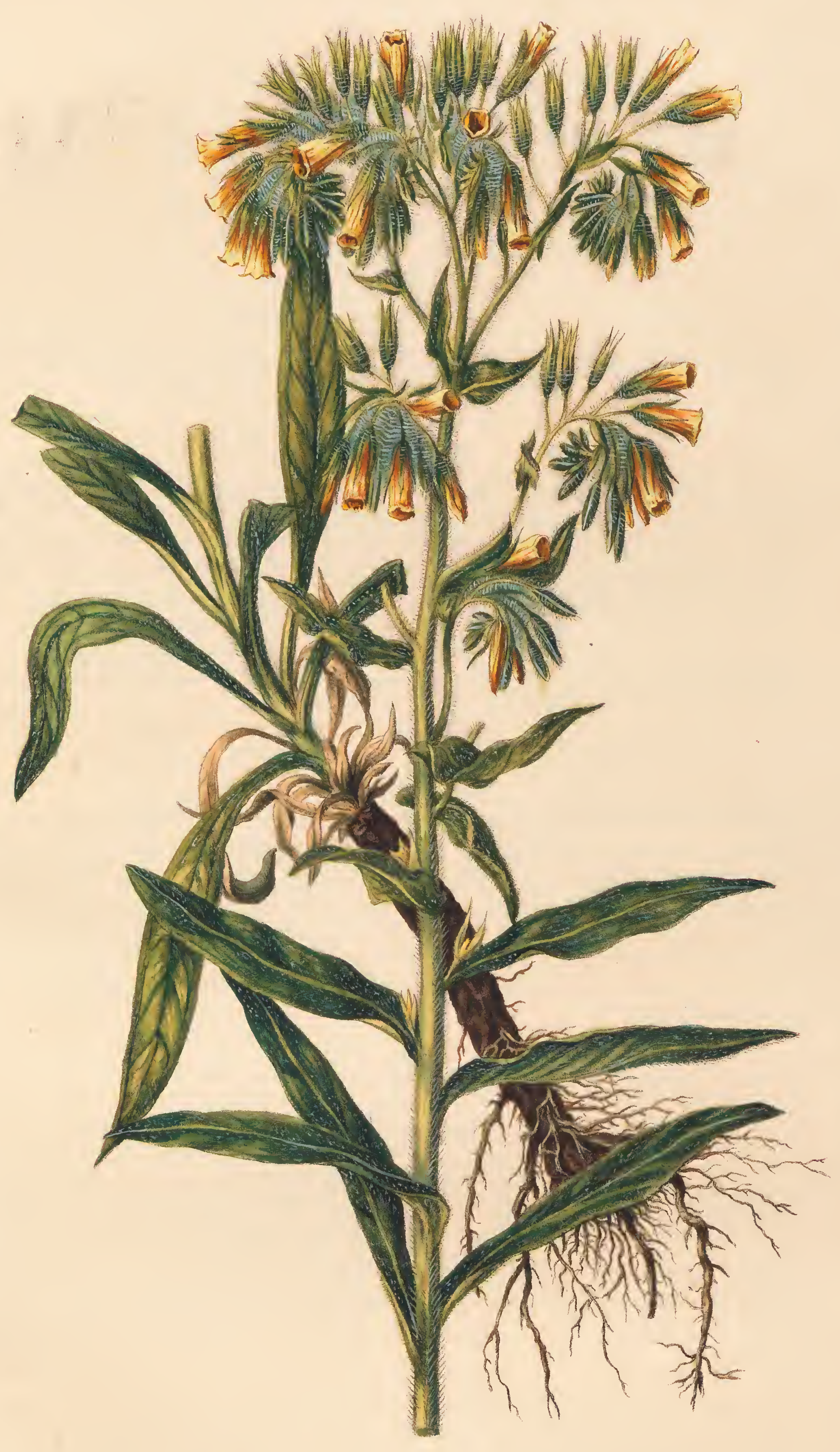

1. *. 1. W. . . . . 



\title{
O N O S M A G I G A N T E U M.
}

\author{
O N O S M A. Linne. \\ Classis, et Ordo
}

Pentandria: Monogynia. Linne gen. pl. Dicotyledoneae: Borragineae, Gymnotetraspermae (Echieae). Jussieu gen. pl.

\section{Character generis.}

Fructificatio. Calyx quinquepartitus, laciniis lanceolatis, erectis. Corolla tubuloso-ventricosa, subpentagona, limbo quinquedentato, fauce nuda. Stamina quinque. Antherae sagittatae, erectae, basi cohaerentes. Germen quadrilobum, superum. Stylus filiformis, vix exsertus. Stigma emarginatum. Nuculae (caryopsides osseae) quatuor, triangulares, nitidae, jaspideae, basi plana, exumbilicata receptaculo affixae.

Vegetatio. Herbae, foliis alternis, confertis, pilis rigidis basi tuberculatis, aut stellatis vestitae. Flores subspicati, aut racemosi, foliosi, pedunculis fructiferis erectis.

\section{Divisio generis.}

In novissima Asperifoliarum monographia clarissimi Lehmann quaedam Onosmati interveniunt species pedunculis fructiferis nutantibus, quae ab Onosmate separandae, genusque proprium, Onosmodium Nobis a Purshia Sprengel (Onosmodium Michaux) bene discernendum constituunt. Hocce excepto Onosma ex inflorescentia subdividitur :

A. Flores subspicati e. g. O echioides.

B. Flores racemosi e. g. O giganteum.

\section{O N O S M A G I G A N T E U M.}

$$
\text { Differentia specifica, et Synonymia. }
$$

O. floribus subtubulosis racemosis nutantibus; pedunculis calycibusque pilis elongatis patenti-hirsutissimis; foliis oblongo-lanceolatis appresse stellato-hirsutis, floralibus amplexicaulibus; caule erecto apice ramosissimo.

Onosma giganteum. Lam. illustr. gen. no. 1840. Pers. synops. pl. I. p+ 162. Roem. et Schult. syst. veg. IV. p. 63. Lehmann Asperifol, no. 264. (exclus. synon. Marsch. a Bieb. et Pall.).

Riesen-Lotwurz.

$$
\text { Locus natalis, et tempus. }
$$

Crescit in aridis Palaestinae, ubi specimina quaedam seminibus donata, e quibus nostrum enatum est, a cl. Sieber lecta fuere. Colitur in frigidario, et fructiticat Julio. đo. 


$$
\text { Descriptio. }
$$

Vegetatio. Radix biennis, rhizomatoidea. Rhizoma perpendiculare, cylindricum, basi ramosissimum, radiculis radicellatis; rimosum, fusco-nigrum, intus albidum, (non tingens); radiculae, et radicellae laeves, flavo-fuscescentes. Caulis intrafoliaceus, erectus, apice ramis floriferis paniculatus, striatus, foliosus, hirsutus. Folia oblongo-lanceolata : caulina alterna, conferta ; inferiora, et radicalia in petiolum attenuata, superiora sessilia, floralia amplexicaulia ; omnia integerrima, rugosa, basi subtrinervia, nervo medio dorso subcarinata, facie sulcata, appresse-hirsuta, pilis e fasciculo pilorum brevium stellato prodeuntibus. Flores racemosi, nutantes, post anthesim erecti. Racemi saepe conjugati, ante anthesim revoluti. Pedunculi longitudine calycis, pilis densissimis, elongatis, rigidis, patentissimis albo-hirsuti.

Fructificatio. Calyx inferus, tubulosus, 5-partitus, laciniis lineari-lanceolatis, elongatis, erectis; una cum pedunculo vestitus, persistens. Corolla tubulosa, subventricosa, pentagona, ad limbum subconstricta, limbo brevissimo 5-dentato reflexo, fauce nuda, calyce tertia parte longior, flava, glabra. Stamina 5, corollae inserta. Filamenta subulata. Antherae sagittatae, basi cohaerentes, biloculares, apice membranaceae bidentatae, erectae, inclusae, aut corollam subexcedentes. Germen superum, 4-lobum. Stylus filiformis, supra medium articulatus, inter germinis lobos enascens, albidus, corollam vix excedens. Stigma emarginatum. Fructus: singulo germinis lobo, lobis autem 2-3 nonnunquam abortivis, nucula (caryopsis ossea) triangularis, acuta, basi plana exumbilicata, receptaculo plano triangulari inserta, nitida, laevis, livida, fusco-maculata.

Observatio I. Planta spontanea differt a culta altitudine, et ramositate majori, ita ut prioris fragmenta superiora ramosissima caulem crassitie fere digiti exhibeant, giganteaque sui generis dici possit; porro pedunculis densius hirsutis, magis candicantibus, et rigiditate pilorum non solertius explorata lanatis. Planta exsiccata offert folia pilis elongatis hirsutissima, fere canescentia, quae in viva obscure viridia cernuntur.

Observatio II. Onosmodium, in quo typus Onosmatis in Cynoglosseis, aeque ac in Colsmannia, uti e descriptione liquet, in Lycopsideis apparet, sequentem exhibet characterem: Fructificatio. Calyx 5-partitus, laciniis lanceolatis, erectis. Corolla tubuloso-ventricosa, limbo 5-dentato, fauce nuda. Stamina 5. Antherae sagittatae, erectae. Germen 4-lobum, superum. Stylus filiformis, exsertus. Stigma obtusum. Nuculae 4, triangulares, tuberculosae, basi lateris interni exumbilicati receptaculo affixae. Vegetatio. Herbae, aut suffrutices, saepe ramosissimae. Folia pilis rigidis, basi tuberculatis, aut stellatis. Flores axillares, racemosi, nudi, aut foliosi, pedunculis fructiferis nutantibus. Huc spectat $\mathrm{O}$. orientale, syriacum, rostellatum, micranthos; an et fructiosum, divaricatum, et echinatum?

$$
\text { Explicatio Tabulae. }
$$

A. Corolla tubuloso-ventricosa, pentagona. B. Eadem fissa antheris basi cohaerentibus. C. Eadem fissa, una cum staminibus explanata. D. Stamen magnitudine auctum a facie. E. Idem a tergo. F. Calyx fissus pistillo. G. Pistillum lobis? germinis foecundatis, increscentibus, 2 vero oppositis abortivis. H. Nucula (e planta spontanea desumpta) latere externo, I. Eadem latere interno. K. Apex folii magnitudine auctus a facie. L. Idem a tergo. 


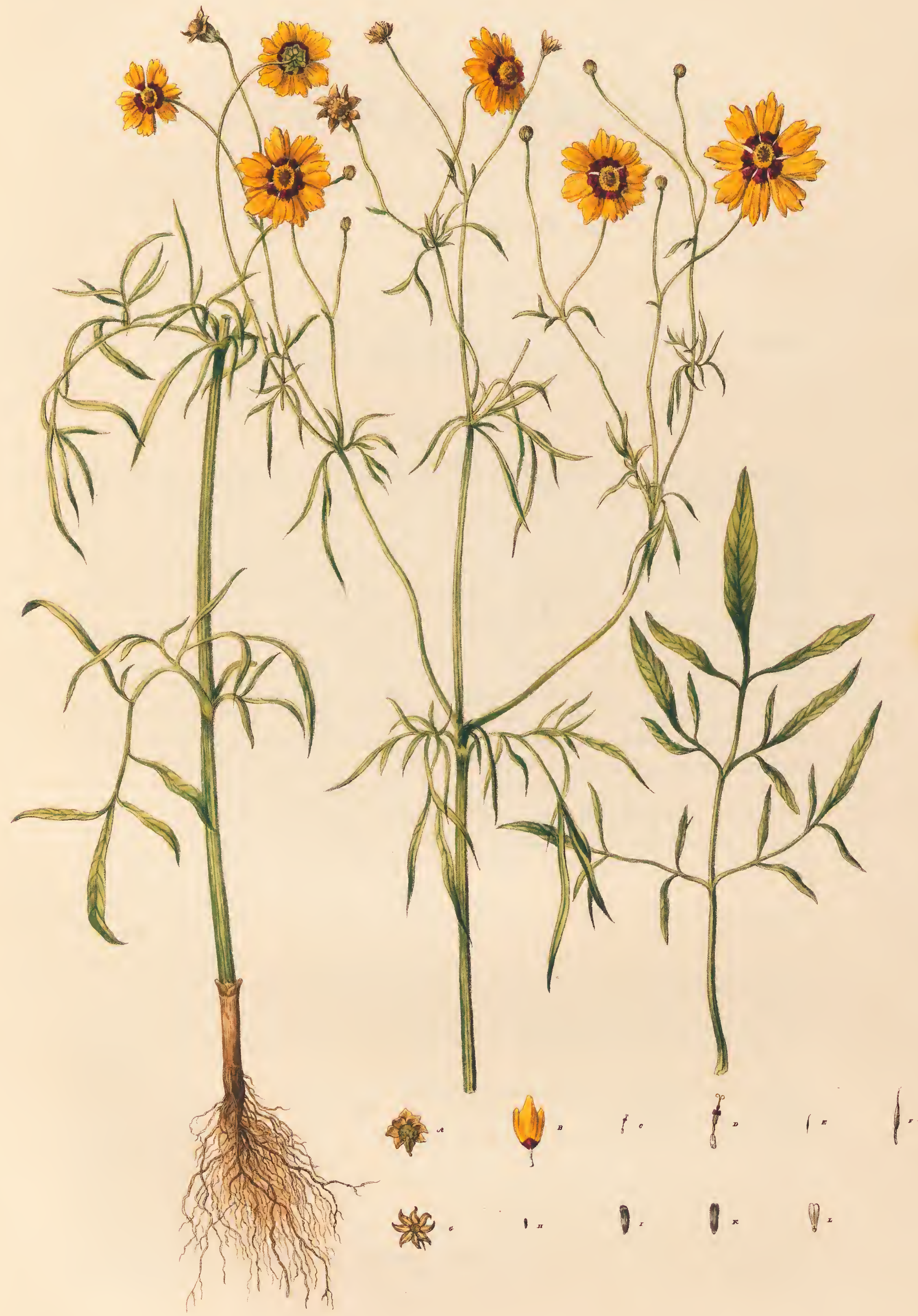

DIPLOSASTERA TINCTORIA. 



\title{
D I P L O S A S T E R A T IN C T O R I A.
}

\author{
D I P L O S A S T E R A.
}

Classis, et Ordo.

Syngenesia: Polygamia, frustranea. Linne gen. pl. Dicotyledoneae: Compositae, Corymbiferae (Heliantheae). Jussieu gen. pl.

\section{Character generis.}

Fructificatio. Calyx communis turbinatus, octopartitus, coloratus, basi squamis octo minimis calyculatus. Corolla composita, radiata. Flosculi radii octo, foemineae: corollula ligulata; ligula apice latiore, trifida, basi melisphragide picta. Flosculi disci numerosi, hermaphroditi: corollula tubulosa, quinquefida; calyculo margine vix prominulo. Stamina hermaphroditis quinque; filamentis capillaribus, brevibus; antheris in tubum cylindricum connatis. Pistillum hermaphroditis : germen inferum, compressum; stylus filiformis, longitudine staminum; stigma bifidum; foemineis : germen magis dilatatum, abortivum, absque stylo, et stigmate. Caryopsis singulis hermaphroditis monosperma, oblonga, compressa, hinc convexa, inde concava protuberantia longitudinali ab apice ad basin, aptera, apice integra, nuda. Pappus nullus. Receptaculum convexum, paleaceum, paleis acuminatis, deciduis. Cotyledones planae; corculum rectum, minimum; radicula infera. Ex his character generis essentialis sequentibus evincitur:

Calyx communis turbinatus, octopartitus, calyculo minimo, octophyllo basi cinctus. Corollulae radii octo, apice dilatatae, trifidae, basi melisphragide pictae. Caryopsides compressae, integrae, apterae. Pappus nullus. Receptaculum paleis deciduis, acuminatis.

Vegetatio. Herba annua, erecta, ramosa. Folia opposita, verticillataque pinnatisecta.

Observatio. Diplosastera pluribus characteribus congruit cum Coreopsi, generi in libris polymorpho, et in plura dividendo, de quibus hic Coreopsim, qua typum normalem, et Chrysomeleam Diplosasterae simillimam adducimus, eorumque characteres essentiales comparandi causa proponimus, et quidem

Coreopsis: Calyx communis simplex, octopartitus, bracteolis octo linearibus auctus. Corollulae radii octo, integrae. Caryopsides compressae, emarginatae, margine alatae. Pappus bicornis. Receptaculum paleis persistentibus apice dilatatis. e. g. C. tripteris, verticillata.

Chrysomele a (Coreopsoides Moench): Calyx communis duplex, uterque octopartitus. Corollulae radii octo, apice subtrifidae, unicolores. Caryopsides compressae, ovatae, cymbaeformes, emarginatae, margine alatae. Pappus bicornis. Receptaculum paleis deciduis acuminatis. e. g. C. auriculata, lanceolata. 


\title{
D I P L O S A S T E R A T I N C T O R I A.
}

\author{
Synonymia.
}

Coreopsis tinctoria. Enum. sem. hort. Berol. anno 1822.

Färbender Doppelstern.

$$
\text { Locus natalis, et tempus. }
$$

Diplosasterae semina nomine Espuelarde Cabalero ex America boreali communicata fuerunt; ubi spontanea invenitur. Fructificat in horto Julio, Augusto. $\odot$.

\section{Descriptio.}

Vegetatio. Radix annua, fibrosa, radiculis subaequalibus, confertissimis, flavofuscis. Caulis erectus, cylindricus, striatus, medullaris, foliosus, ramosus, ramis oppositis, verticillatisve, ad pedunculos usque pluries subdivisis. Folia opposita, aut verticillata, petiolata, laxa, sub-bipinnatisecta, segmentis distantibus, patentibus, linearibus, basi attenuatis decurrentibus, integerrimis, uninerviis, concocoloribus; terminalibus elongatis. Folia primordialia simplicia, ovata, aut pinnatisecta, segmentis ovatis. Integra glaberrima. Flores terminales, corymbosi, pedunculis elongatis, unifloris, subnutantibus.

Fructificatio. Flos compositus, synanthereus. Calyx communis fusco-flavescens. Corollulae radii aureae, basi melisphragide aurantiaco dentato pictae, ligulae lobo medio nonnunquam dentato. Corollulae disci, antheraeque atro-fuscae. Caryopsides nigrae, tenuissime rugosae, apice cicatriculatae, et abhinc sub microscopio subemarginatae. Cetera in charactere generico.

$$
\text { Etymologia. }
$$

Diplosastera dicta est ex oюr $\lambda_{\text {oos }}$ duplus, et агия stella, cum melisphragides stellam pictam in radio stellato praesentent; tinctoria, cum flores pigmentum rubrum praebeant.

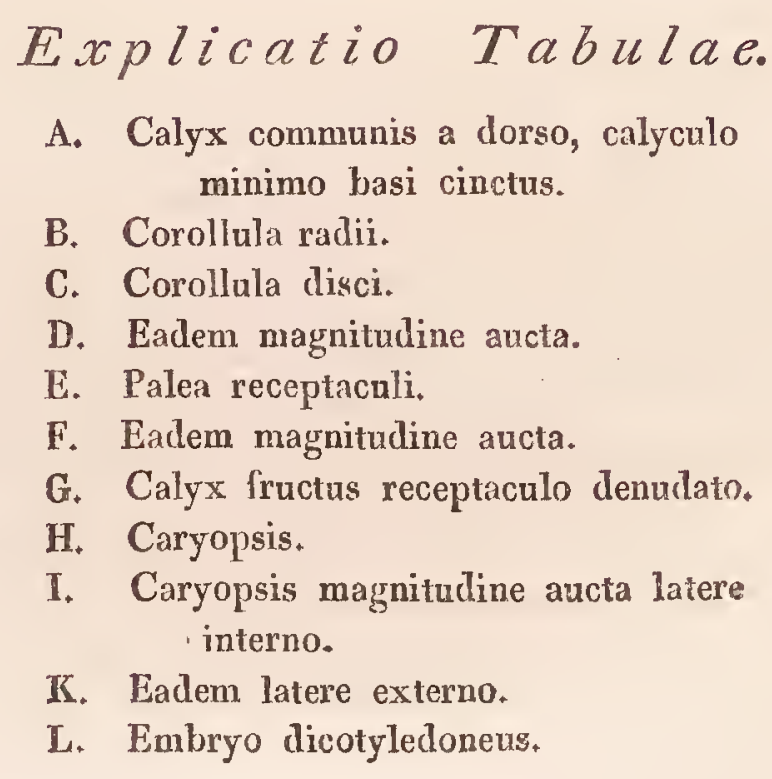




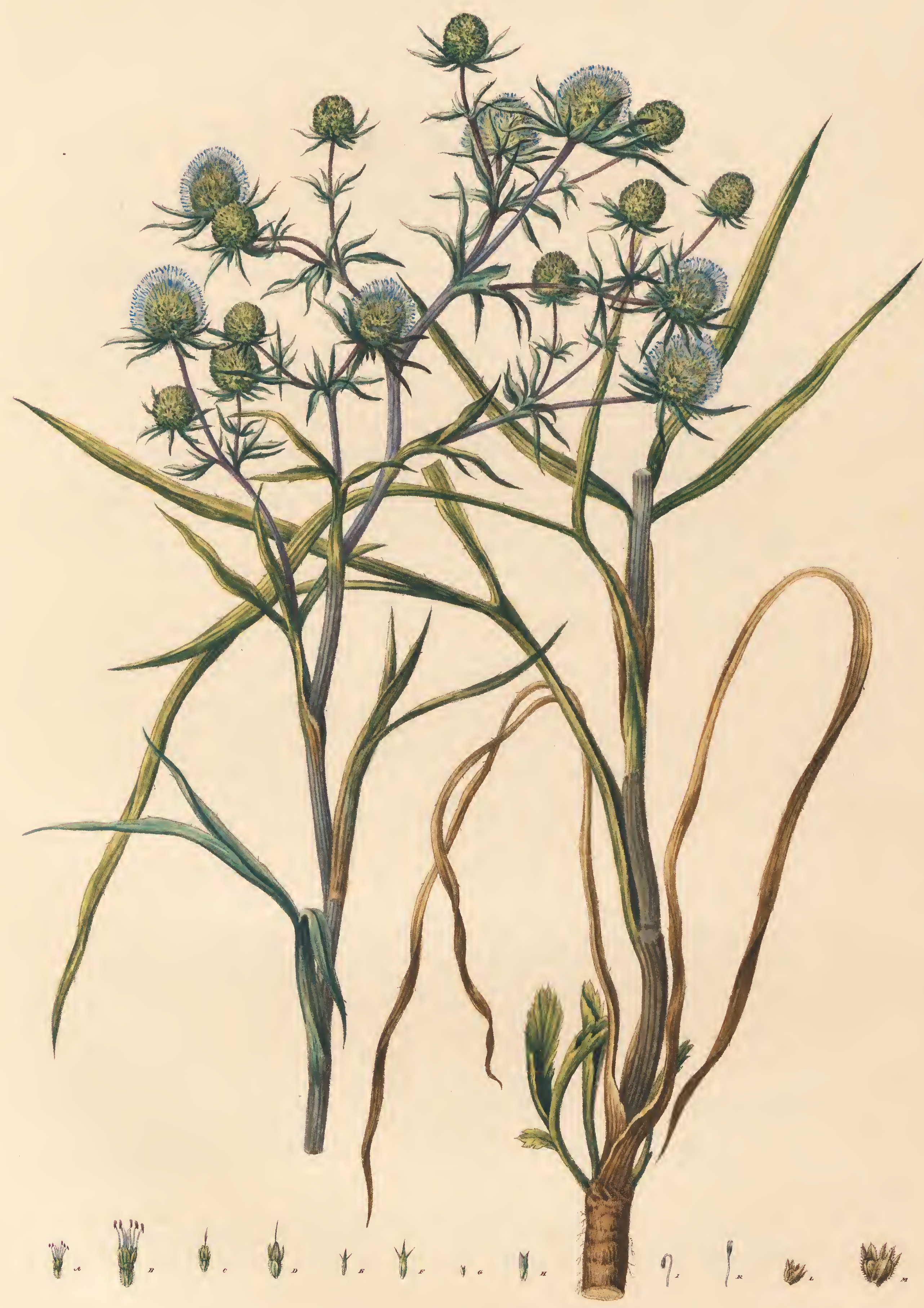

ERYNGIUN TERNATUM. 


\title{
E R Y N G I U M T E R N A T U M.
}

\author{
E R Y N G I U M. Linne. \\ Classis, et Ordo.
}

Pentandria: Digynia. Linne gen. pl. Dicotyledoneae: Umbelliferae, Anomalae

(Compositae). Jussieu gen. pl.

\section{Character generis.}

Fructificatio. Flos compositus, chorisanthereus (umbella flosculis in receptaculo sessilibus capitata). Calyx communis (involucrum) simplex, polyphyllus, pungens. Receptaculum conicum, paleaceum, paleis persistentibus. Flosculi paleis discreti. Calyculus pentaphyllus, superus. Corollula pentapetala, aequalis, petalis inflexo-emarginatis. Stamina quinque, libera. Germen inferum, angulatum, paleaceum. Styli duo. Fructus: caryopsides duae, connexae, ab apice secedentes, calyculo coronati.

Vegetatio. Herbae, apice saepe coerulescentes. Folia rigida, vaginantia, integra, aut divisa, saepe margine spinosa; floralia nonnunquam verticillata. Flores dichotomo-corymbosi, aut raro solitarii, globosi, aut cylindrici.

\section{Divisio generis.}

Eryngium genus admodum naturale vix divisionem admittens e sola vegetatione subdividitur; et quidem

A. Nervi foliorum paralleli. e. g. E. aquaticum.

B. Nervi foliorum ramosi: his

a. Caulis foliosus; folia petiolis marginatis. e. g. E. ternatum.

b. Caulis foliosus; folia infima petiolis nudis. e. g. E. planum.

c. Caulis foliosus; folia infima petiolis nudis, articulato-fïstulosis. e. g. E. corniculatum.

d. Caulis subnudus; folia petiolis nudis. e. g. E. gracile.

\section{E R Y N G I U M T E R N A T U M.}

\section{Differentia specifica, et Synonymia.}

E. caule folioso; petiolis marginatis; foliis ternatis (trisectis), radicalibus saepe integris : omnibus lineari-lanceolatis, ramoso-nervosis, remote ciliatis ; floribus globosis; foliolis calycinis patentibus, subintegerrimis; paleis tricuspidatis.

Eryngium trifolium. Prosp. Alpin. exot. p. 152. Parkins. theatr. p. 987. Moris. hist. III. p. 167 . sect. 7 . t. $3^{6}$. f. 24 .

Eryngium orientale foliis trifidis Tournef. cor. p. 23. ?

Eryngium ternatum. Poiret enc. meth. suppl. IV. p. 293. Delaroche hist. Eryng. p. 65. Roem. et Schult. syst. veg. VI. p. 319.

Eryngium Tournefortianum. Com. a Sternberg. Syllog. pl. nov. 17. p. $3^{2}$.

Gedreyte Männertreu.

$$
\text { Locus natalis, et tempus. }
$$

Crescit rarissime in collibus asperis Cretae, unde cl. Sieber specimina, seminaque, e quibus nostrum enatum est, attulit. Colitur in frigidario, fructificat Julio. 4 . 


$$
\text { Descripio. }
$$

Vegetatio. Radix perennis, rhizomatoidea. Rhizoma perpendiculare, fusiforme, basi subramosum, hinc inde radiculatum, fuscescens, intus album, vertice squamis fuscis tecium. Caulis intrafoliaceus, erectus, nodosus, striatus, glaber, foliosus, apice ramosus, coloratus, colore e cyaneo in violaceum vergente. Folia: radicalia integra lineari-lanceolata, primordialia lanceolata; remote ciliata, ante evolutionem serrata, ramoso-nervosa, basi in petiolum canaliculatum membranaceum angustata: caulina alterna, remota, ternata (trisecta); lateralibus decurrentibus, brevioribus, et saepe uno, alterove abortiente; petiolo canaliculato, basi vaginante; ceterum radicalibus simillima, nonnisi angustiora, longioraque. Folia radicalia nonnunquam ternata, et caulina infima integra, et ciliae foliorum in adulta planta saepe evanescentes. Flores terminales, dichotomo-corymbosi, globosi, pedunculis nudis, aut subfoliosis.

Fructificatio. Flos compositus, chorisanthereus (flosculis antheris liberis). Calyx communis simplex, foliolis 6 - 10 linearibus, rigidis, mucronatis, integerrimis, aut apice, vel basi dente uno, alterove spinoso-dentatis, florem excedentibus, facie coerulescentibus. Receptaculum conicum, paleaceum, paleis persistentibus, lanceolatis, carinatis, apice spinoso-z-partitis, flosculis longioribus. Flosculi conferti, paleis distincti, completi, hermaphroditi. Calyculus superus, persistens, 5-phyllus, foliolis oblongis, uninerviis, mucronatis. Corollula aequalis, 5-petala, petalis inflexo-emarginatis, calyculo vix longioribus, laete coeruleis, basi albicantibus. Stamina 5. Filamenta capillaria, petalis duplo longiora, ante anthesim nutantia. Antherae liberae, oblongae, incumbentes, versatiles, biloculares, laete coeruleae, ante anthesim purpurascentes. Germen inferum, angulatum, paleaceum, bipartibile. Styli 2 , filiformes. Stigmata simplicia, vix incrassata. Fructus : caryopsides 2, connatae, ab apice secedentes, ovatae, compressae; dorso carinatae, striatae, paleaceae; commissura excavatae, sub-z-costatae, absque axi; apice calyculo coronatae, ex. flavo-fuscescentes.

Observatio. Planta spontanea fructifera caulem spithama vix longiorem floribus 3 terminatum, et foliola vix longitudine digiti exhibet, iconique Alpinianae bene respondet.

$$
\text { Critica. }
$$

Planta nostra non solum iconi, sed etiam descriptioni Alpinianae convenit, et auctor ,flores 2, aut plures, latos, rotundos, purpureos" dicens forte colorem ex antheris ante anthesim omnino purpurascentibus deprompsit; alias assumi deberet; petala coerulea, quae illust. Comes a Sternberg in speciminibus ex eodem semine enatis alba observavit, quoque purpureo ludere colore, qui lusus in plantis non raro occurrit.

Synonymum Tournefortianum dubie adposuimus, cum a cl. Delaroche e folio in herbario Vaillantiano asservato E. amethystino affinis species dicta sit.

$$
\text { Explicatio Tabulae. }
$$

A. Flosculus integer. B. Idem magnitudine auctus. C. Flosculus dinidiatus. D. Idem magnitudine auctus. E. Palea receptaculi. F. Eadem magnitndine ancta. G. Petalım. H. Idem magnifudine auctum. I. Stamen ante authesim nutans.

K. Stamen sub anthesi. L. Caryopsides fructus ab apice separatae. M. Eaedem magnitudine auctae. 


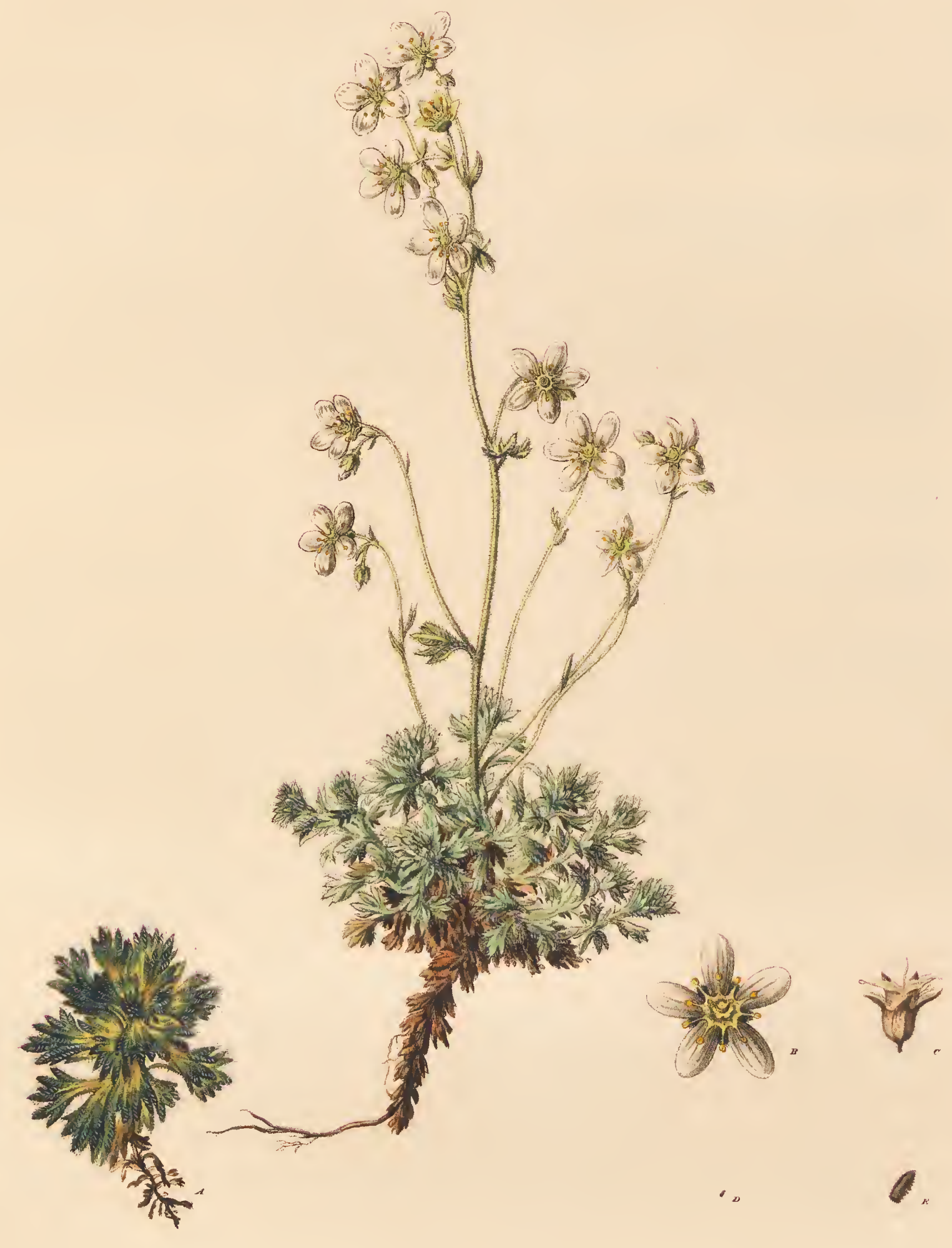

Saxifraga Steindandi. 


\title{
S A X I F R A G S T E I N M A N N I.
}

\author{
S A X I F R A G A. Linne.
}

Classis, et Ordo.

Decandria: Digynia. Linne gen. pl. Dicotyledoneae: Saxifrageae. Jussieu gen.pl.

Character generis.

Fructificatio. Calyx adhaerens quinquefidus, aut liber quinquepartitus. Petala quinque. Stamina decem. Germen inferum, aut superum. Styli duo. Stigmata capitata. Capsula bilocularis, birostris, inter apices dehiscens, polysperma, semiinfera, seu infra calyce cincta, aut supera.

Vegetatio. Herbae, saepe stoloniferae, raro trunco basi suffrutescente. Folia alterna, aut raro opposita, integra, aut partita, interdum omnia radicalia. Flores paniculati, aut corymbosi, aut raro solitarii, ante anthesim nutantes. possunt:

$$
\text { Divisio generis. }
$$

Ex fructificatione, et vegetatione sequentes Saxifragae sectiones statui

I. Porphyrion. Calyx adhaerens, erectus. Semina angulata, laevia. Caulis foliosus, stoloniferus. Folia opposita, integra, minima, coriacea, e.g. S. oppositifolia.

II. Aizonia. Calyx adhaerens, erectus. (Petala saepe punctata). Semina oblonga, tuberculosa. Caulis foliosus, stoloniferus, stolonibus folioso-rosulatis, aut imbricatis. Folia alterna, angusta, integra, coriacea, enervia.

a. Folia obtusa (lingulata)+ e. g. S. Aizoon, caesia.

b. Folia acuta (linearia, aut subulata). e. g. S. tenella, Burseriana.

III. Dactylites. Calyx adhaerens, erectus. Semina oblonga, tuberculis asperrima. Caulis foliosus, saepe stoloniferus, stolonibus folioso-rosulatis. Folia alterna, incisa, palmatave, aut raro integra, subherbacea, nervosa.

a. Perennes; stoloniferae. e.g. S. Steinmanni, hypnoides, sedoides.

b. Annuae, aut biennes; exstoloniferae. (Petala saepe emarginata). e. g. S. Ponae, tridactylites, petraea.

c. Bulbosae; (exstoloniferae). e. g. S. cernua, rivularis, granulata.

IV. Micranthes. Calyx adhaerens, ore reflexo. Semina oblonga, laevia. Caulis subnudus. Folia oblonga, radicalia. Stolones nulli. Flores parvi, saepe glomerati, paniculati, aut capitati. e. g. S. pensilvanica, nivalis.

V. Hydatica. (Robertsonia Haw. et Diptera Borkh.). Calyx liber, reflexus. Petala unimaculata, (punctata). Filamenta apice dilatata. Semina subsphaerica, tuberculis asperrima. Caulis subnudus, paniculatus, 'saepe stoloniferus. Folia alterna, suborbicularia, aut cuneata; radicalia, aut in stolonibus rosulata.

a. Folia subcrassa, radicalia. Stolones nulli. e. g. S. punctata, erosa.

b. Folia subcrassa, radicalia. Petala elongata, nonnunquam inaequalia. Flagella reptantia. e. g. S. cuscutaeformis, sarmentosa.

c. Folia coriacea. Stolones folioso-rosulati. e. g. S. umbrosa, cuneifolia.

VI. Arabisa. Calyx liber, reflexus. Petala bimaculata, longe unguiculata, nonnunquam inaequalia. Filamenta subulata. Semina oblonga, striata. Caulis subnudus, corymbosus, stoloniferus. Folia alterna, cuneiformia, subherbacea, in stolonibus rosulata. e. g. S. stellaris, leucanthemifolia. 
VII. Hirculus. Calyx liber, reflexus. Semina oblonga, (laevia?). Caulis foliosus, stoloniferus. Folia alterna, angusta, nervosa. e. g. S. Hirculus.

VIII. Cotylea. (Miscopetalum Haw.). Calyx liber, erectus. Semina oblonga, tuberculosa. Caulis foliosus, paniculatus. Folia alterna, suborbicularia, subcrassa, enervia. Stolones nulli. e. g. S. rotundifolia.

IX. Eropher on. (Bergenia Moench). Calyx liber, erectus. Semina angulata, laevia. Caulis nudus, paniculatus, trunco basi suffrutescente, folioso. Folia alterna, suborbicularia, coriacea. e. g. S. crassifolia.

\section{S A X I F R A G A S T E I N M A N N It \\ Differentia specifica, et Synonymia.}

Dactylites: glanduloso-villosa, canescens; stolonibus brevibus erectiusculis; foliis confertis cuneatis palmato-tri-quinque-fidis, laciniis obtusis; caule multifloro erecto; petalis oblongis obtusis.

Saxifraga Steinmanni. Tausch ind. pl. hort. Canal. anno 1821.

Steinmanns - Finger-Steinbrech.

$$
\text { Locus natalis, et tempus. }
$$

Crescit in Bohemiae rupibus basalticis ad Albim prope Aussig, ubi eam cl. Chemiae technicae Professor Steinmann de Flora Bohemiae indaganda, augendaque meritissimus primus observavit, cujusque nomine venerabili salutavimus. In horto fructificat ineunte Maio. 4.

$$
\text { Descriptio. }
$$

Vegetatio. Radix perennis, filiformis, obliqua, subramosa, multiceps; capitibus (stolonibus annotinis) basi foliis emarcidis obsitis, apice folioso-rosulatis, stoloniferisque. Caulis intrafoliaceus, erectus, apice corymbosus, nonnunquam a basi ramosus, paniculatus, multiflorus, foliosus, glandulosus. Stolones plures, breves, erectiusculi, foliosi, apice rosulati, canescenti-villosi. Fo-

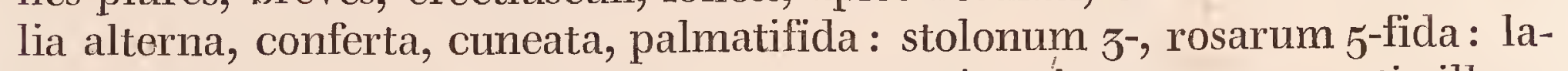
ciniis obtusis, integris, aut dentatis ; 3-, 5-nervia, viscosa, canescenti-villosa, villis apice glandulis minimis. Flores terminales, corymbosi, aut in culta saepe paniculati. Pedunculi glandulosi, ante anthesim nutantes.

Fruct ificatio. Calyx basi tubulosus, germini adnatus, ore 5-fidus, erectus, glandulosus, persistens. Corolla patens, pentapetala, aequalis. Petala oblonga, integerrima, obtusa, vix unguiculata, trinervia, alba, calyci inserta, ejusque laciniis alterna. Stamina 10, aequalia, annulo nectarifero germen tegenti inserta. Filamenta subulata. Antherae reniformes, erectae, didymae. Germen inferum. Styli 2 , breves, divergentes. Stigmata capitata, obliqua. Capsula semiinfera, stylis persistentibus birostris, bilocularis, inter apices dehiscens, polysperma, dissepimento seminifero. Semina oblonga, tuberculis asperrima, nigra.

$$
\text { Diagnosticon. }
$$

Saxifraga Steinmanni maxime affinis est S. villosae Willd., eamque et decipientem Ehrh. intercedit. Differt autem a S. villosa statura omnium partium minori, villis glandulosis, et petalis oblongis in S. villosa subrotundis; a S. decipiente villositate, viscositate, laciniisque foliorum obtusis:

$$
\text { Explicatio Tabulae. }
$$

A. Stolo autumno perfecte evolutus foliorum rosa. B. Flos magnitudine anctus. C. Capsula birostris calyce adhaerente magnitudine aucta, D. Semen. E. Idem magnitudine auctum. 


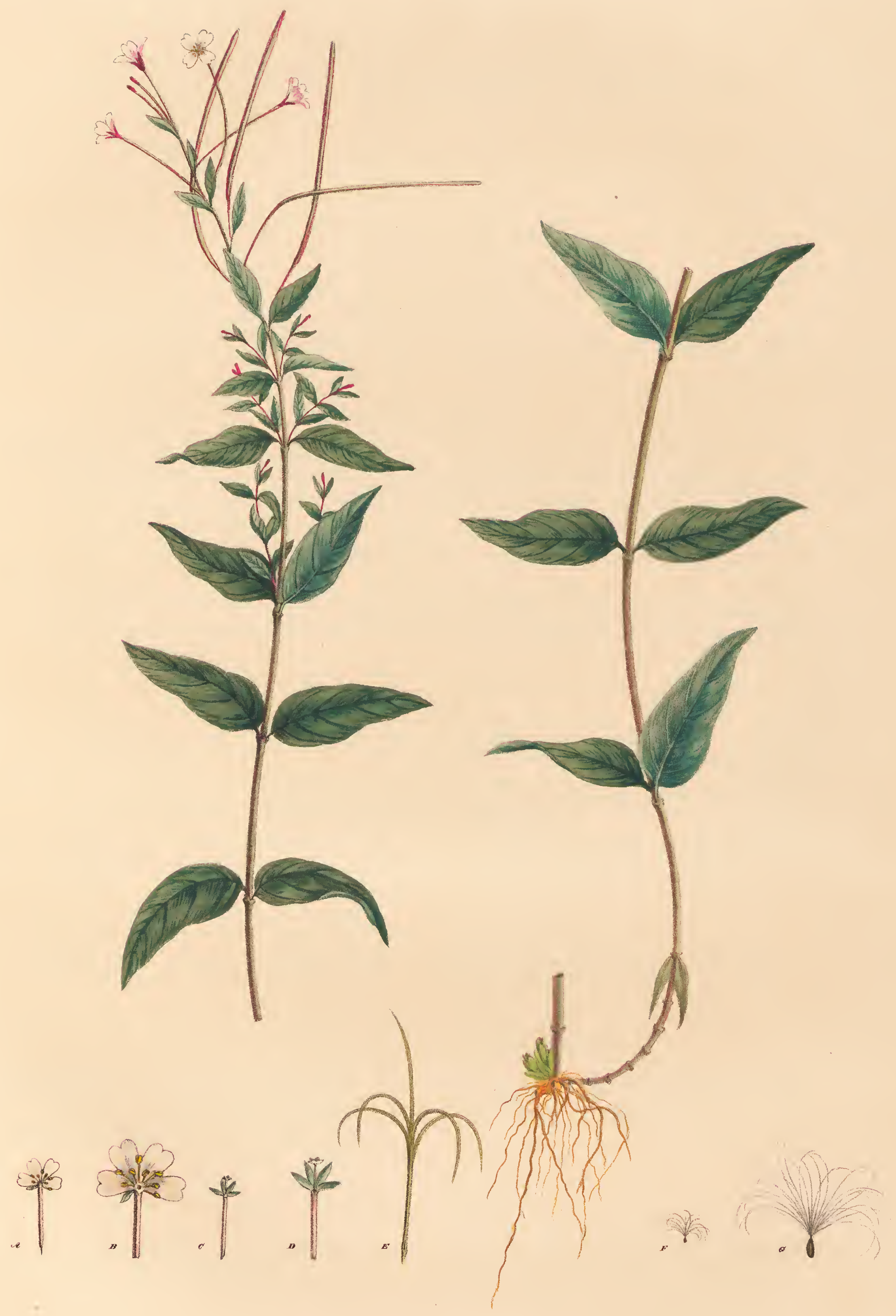

EPILOBIUM HYPERICIFOLIUM . 



\title{
EPILOBIUM HYPERICIFOLIUM.
}

\author{
E P I L O B I U M. Linne.
}

Classis, et Ordo.

Octandria: Monogynia. Linne gen.pl. Dicotyledoneae: Onagrariae. Jussieu gen. pl.

\section{Character generis.}

Fructificatio. Calyx superus, deciduus, quadripartitus. Petala quatuor. Stamina octo, alterna breviora. Germen inferum, cylindricum: Stylus terminalis. Stigma quadrifidum, aut clavatum. Capsula elongata, obtuse tetragona, quadrilocularis, quadrivalvis, polysperma. Receptaculum seminiferum, centrale, elongatum, tetragonum. Semina comosa.

Vegetatio. Herbae, aut raro suffrutices. Folia apposita, aut alterna. Flores pedunculati, axillares, conferti in racemo subnudo, aut folioso, aut raro solitarii. Racemi nutantes, post anthesim erecti. Flores diurni, rubri, aut albi.

$$
\text { Divisio generis. }
$$

Epilobium duas sectiones, a fructificatione, et vegetatione desumendas, agnoscit; nempe

I. Chamaenerion. Petala inaequalia, indivisa, patentia. Filamenta filiformia, basi dilatata. Stigma revolutum. Folia alterna.

II. Lysima chion. Petala aequalia, bifida, erecto-patentia. Filamenta subulata. Stigma erectum. Folia inferiora opposita, superiora alterna.

\section{E P I L O B I U M H Y P E R I C I F O L I U M.}

$$
\text { Differentia specifica, et Synonymia. }
$$

Lysimachion: stigmate quadrifido; foliis remotis ovatis integerrimis breve petiolatis: inferioribus oppositis; caule tereti ramoso multifloro. Hartheu-blättriges Klein-Weidenröslein.

$$
\text { Locus natalis, et tempus. }
$$

Crescit in Bohemiae monte Donnersberg, et lubenter apricatur. Fructificat in horto Junio, Julio. 4. 


$$
\text { Descriptio. }
$$

Vegetatio. Radix perennis, fibrosa, stolonifera; radiculis filiformibus, flavofuscis; stolonibus brevibus, erectis, basi radiculatis. Caulis erectus, aut basi adscendens, flexuosus, cylindricus, laevis, pilis brevissimis pubescens, saepe rubescens, foliosus, apice ramosus, fructifer ramosissimus. Folia: opposita, decussata, superiora alterna; remota, breve-petiolata, ovata, integerrima, venosa, glabra, subtus pallidiora. Flores terminales, axillares, pedunculati, in racemo folioso, ante anthesim nutante.

Fructificatio. Calyx superus, deciduus, 4-partitus, aequalis, purpurascens. Corolla 4-petala, erecto-patens, aequalis. Petala obovata, apice bifida, calyce duplo longiora, breve-unguiculata, calyci inserta, versicoloria, primo alba, serius incarnata. Stamina 8, inaequalia, petalis breviora, 4 longiora calyci, et alterna breviora petalis opposita. Filamenta subulata, flava. Antherae oblongae, incumbentes, biloculares, flavae. Germen inferum, elongatum, cylindricum, rubescens, tenuissime pubescens. Stylus terminalis, filiformis, longitudine calycis, albidus. Stigma incrassatum, 4-lobum, erectum, albidum. Capsula elongata, obtuse tetragona, 4-locularis, 4-valvis, valvis elastice dehiscentibus, et revolutis; polysperma, receptaculo seminifero, centrali, 4-gono, longitudine valvarum. Semina minuta, striata, fusca, apice comosa; coma alba, decidua.

\section{Diagnosticon.}

Epilobium hypericifolium vegetatione Hypericum montanum in mentem revocans proximum est E. montano, a quo autem foliis remotis, integerrimis, floribusque minoribus, versicoloribus abunde differt.

$$
\text { Explicatio Tabulae. }
$$
A. Flos lateraliter fissus absque stylo.
B. Ejusdem pars superior magnitudine aucta.
C. Calyx floris lateraliter fissus stylo.
D. Ejusdem pars superior magnitudine aucta.
E. Capsula.
F. Semen.
G. Idem magnitudine auctum. 


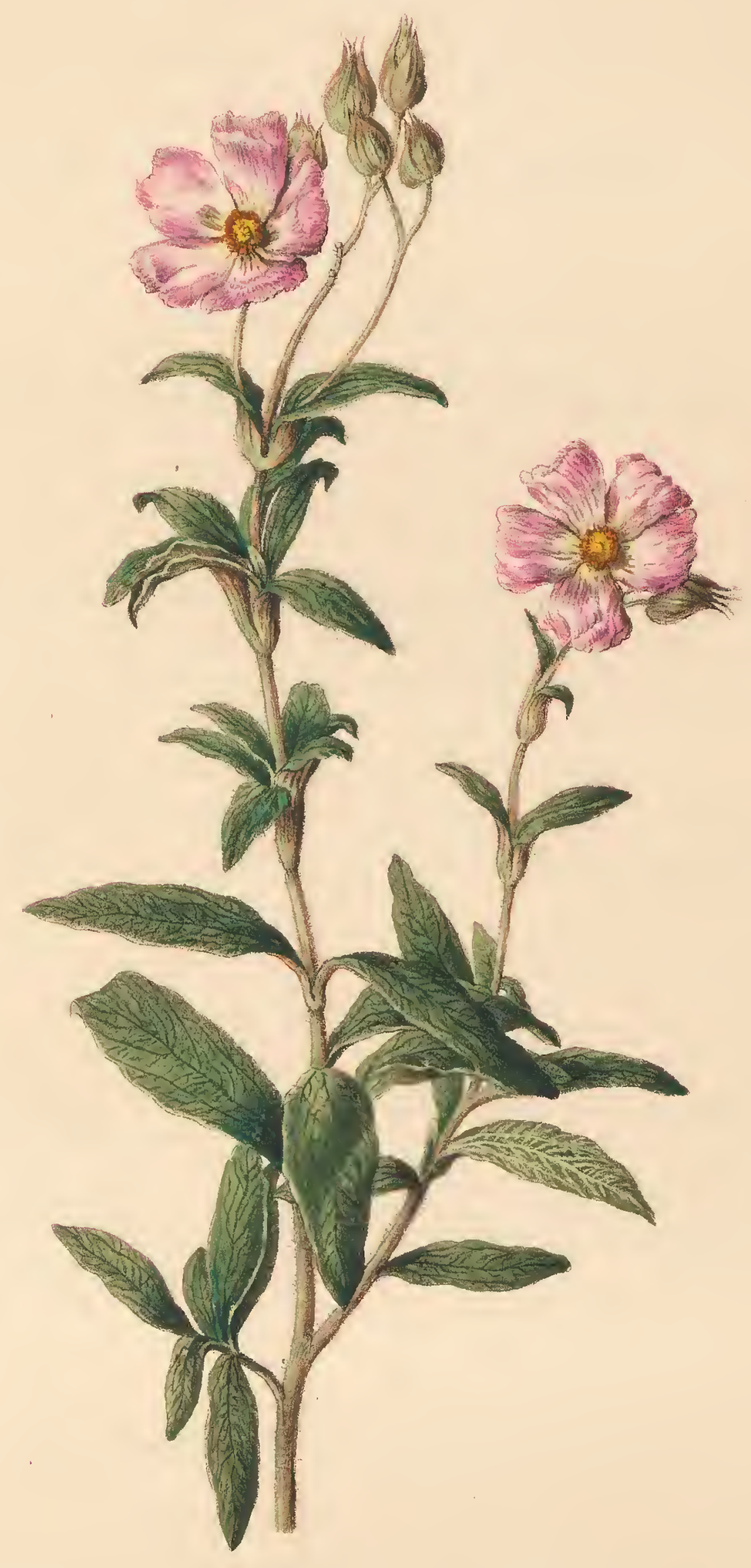

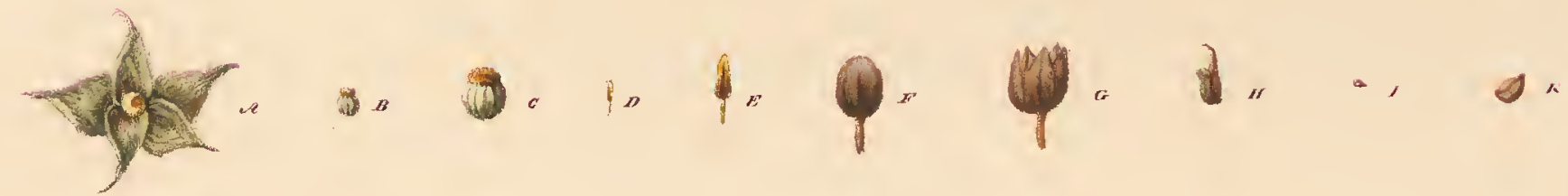

CISTUS RONEUS.

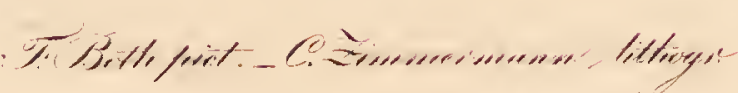




\title{
$\begin{array}{llllllllllllll}C & I & S & T & U & S & R & O & S & E & U & S .\end{array}$
}

C I S T U S. Linne. Jussieu.

\author{
Classis, et Ordo.
}

Polyandria: Monogynia. Linne gen. pl. Dicotyledoneae: Cisteae. Jussieu gen. pl.

\section{Character generis.}

Fructificatio. Calyx imbricatus, pentaphyllus, aequalis. Petala quinque. Stamina indefinita, receptaculo inserta. Germen superum. Stylus filiformis, aut nullus. Stigma orbiculatum. Capsula quinque-aut decem-locularis, quinque-aut decem-valvis, valvis medio septiferis. Semina loculorum angulo interno ad basin infixa. Corculum spiraliter tortum.

Vegetatio. Frutices. Folia opposita, exstipulata, basi connata, succum resinosum plorantia. Flores terminales, solitarii, aut in corymbo paucifloro, pedunculis fructiferis erectis.

$$
\text { Divisio generis }
$$

Cistus ex fructificatione, et vegetatione dividitur; et quidem in

I. La danum. Stigma sessile. Capsula decem-locularis, decem-valvis. Folia coriacea, facie laevia.

II. Le do n. Stigma sessile, aut stipitatum. Capsula quinque-locularis, quinquevalvis. Folia herbacea, facie rugosa.

\section{I S T U R O S E US.}

\section{Differentia specifica, et Synonymia.}

Ledon: stigmate sessili; petalis truncato-retusis; calycibus acuminatis villosis; foliis oblongo-lanceolatis, sub-petiolatis, trinerviis, rugosissimis, subtus canescentibus, superioribus vaginantibus.

Cistus roseus Tausch ind. pl. hort. Canal. anno 1821.

Rosenrothe Porst-Ciste.

$$
\text { Locus natalis, et tempus. }
$$

Habitat, prout suspicari licet, cum aliis Cisti speciebus in Europa australi; colitur autem absque nomine in frigidario horti, et fructificat Maio $\hbar$. 


$$
\text { Descriptio. }
$$

Vegetatio. Frutex (3-pedalis) a basi ramosus, ramis flexuosis, nudis, glabris, laevibus, fuscis; junioribus foliosis, canescentibus, plus, minusve villosis. Folia opposita, decussata, exstipulata, oblongo-lanceolata, lanceolatave, integerrima, subrevoluta, obtusiuscula, trinervia, facie rugosa, pilis stellatis brevibus hirta, dorso venis elevatis reticulata, canescentia; inferiora in petiolum brevem basi attenuata, superiora vaginantia, vagina turgida rubescente. Flores terminales in corymbo paucifloro. Pedunculi erecti, uniflori, villosi, saepe decidui.

Fructificatio. Calyx inferus, imbricatus, 5-phyllus, aequalis, foliolis ovatis, acuminatis, villosis, persistentibus. Corolla patens, 5-petala, aequalis, fugax. Petala oblongo - cuneata, calyce longiora, apice truncato - retusa, vix unguiculata, striato-plicata, rosea, basi flavida, receptaculo inserta. Stamina indefinita, pistillo vix longiora, lutea. Filamenta capillaria. Antherae oblongae, erectae, biloculares. Germen superum, subrotundum, striatum, tomento brevi canescens. Stylus nullus. Stigma sessile, orbiculatum, luteum. Capsula ovata, atrofusca, apice subcanescens, 5-locularis, 5-valvis, valvis medio septiferis, septis apice a valvis secretis; polysperma. Semina angulata, laevia, fusca, loculorum angulo interno ad basin infixa.

\section{Diagnosticon.}

Cistus roseus proximus est C. parvifloro Lam, a quo autem satis superque differt, floribus majoribus; calycibus acuminatis, nec acutis, longius villosis; foliis oblongo-lanceolatis, brevissime petiolatis, subtus canescentibus, nec ovatis, aut subcordato - rotundis, longe petiolatis, utrinque canescentibus.

$$
\text { Explicatio Tabulae. }
$$
A. Calyx floris pistillo,
B. Germen stigmate sessili,
C. Idem magnitudine auctum.
D. Stamen.
E. Idem magnitudine auctum,
F. Capsula inaperta.
G. Eadem valvis aperta
H. Valva septo apice secreto.
I. Semen.
K. Idem magnitudine aractum. 


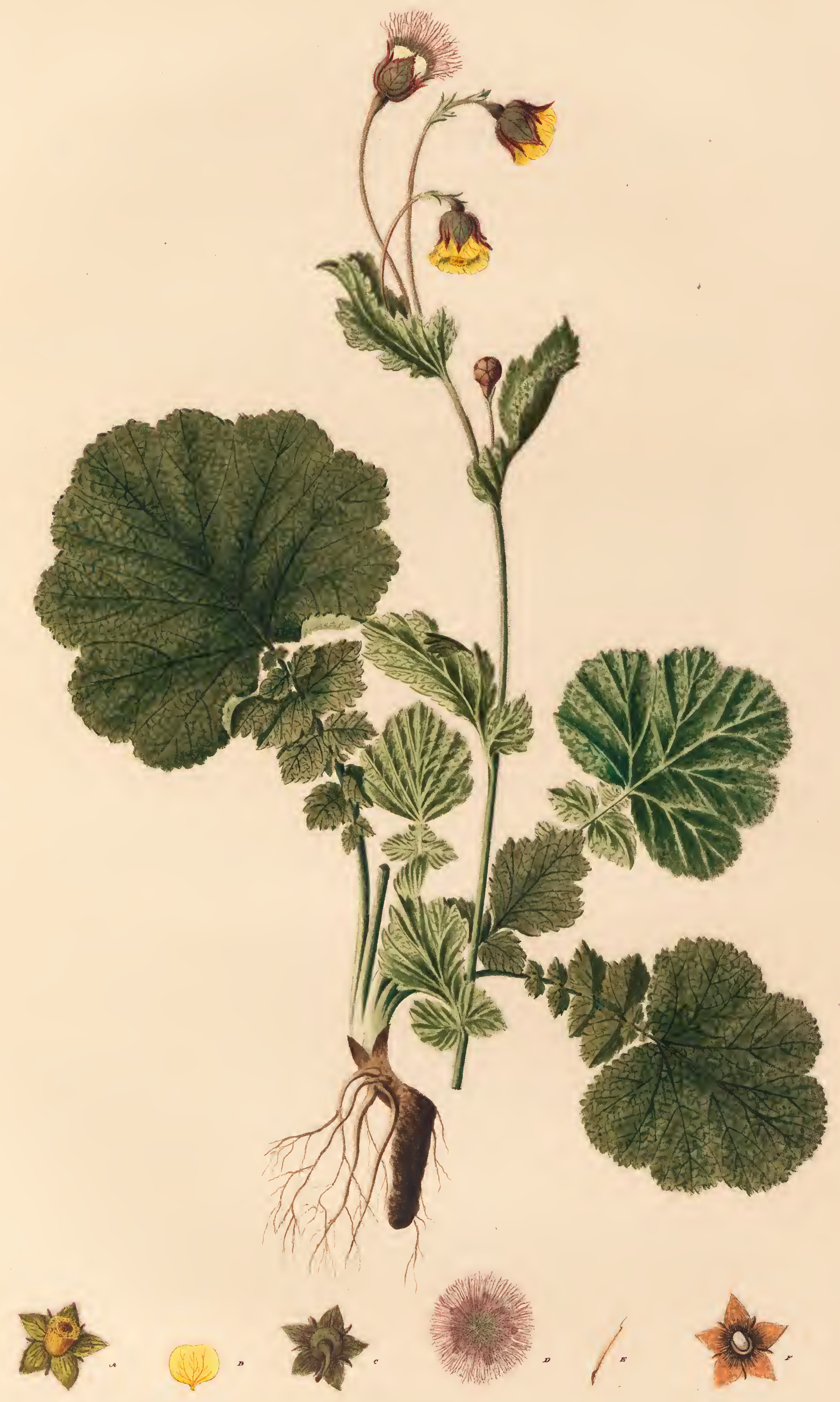

GEUM SUDETICUM.

cerrangua feo. 


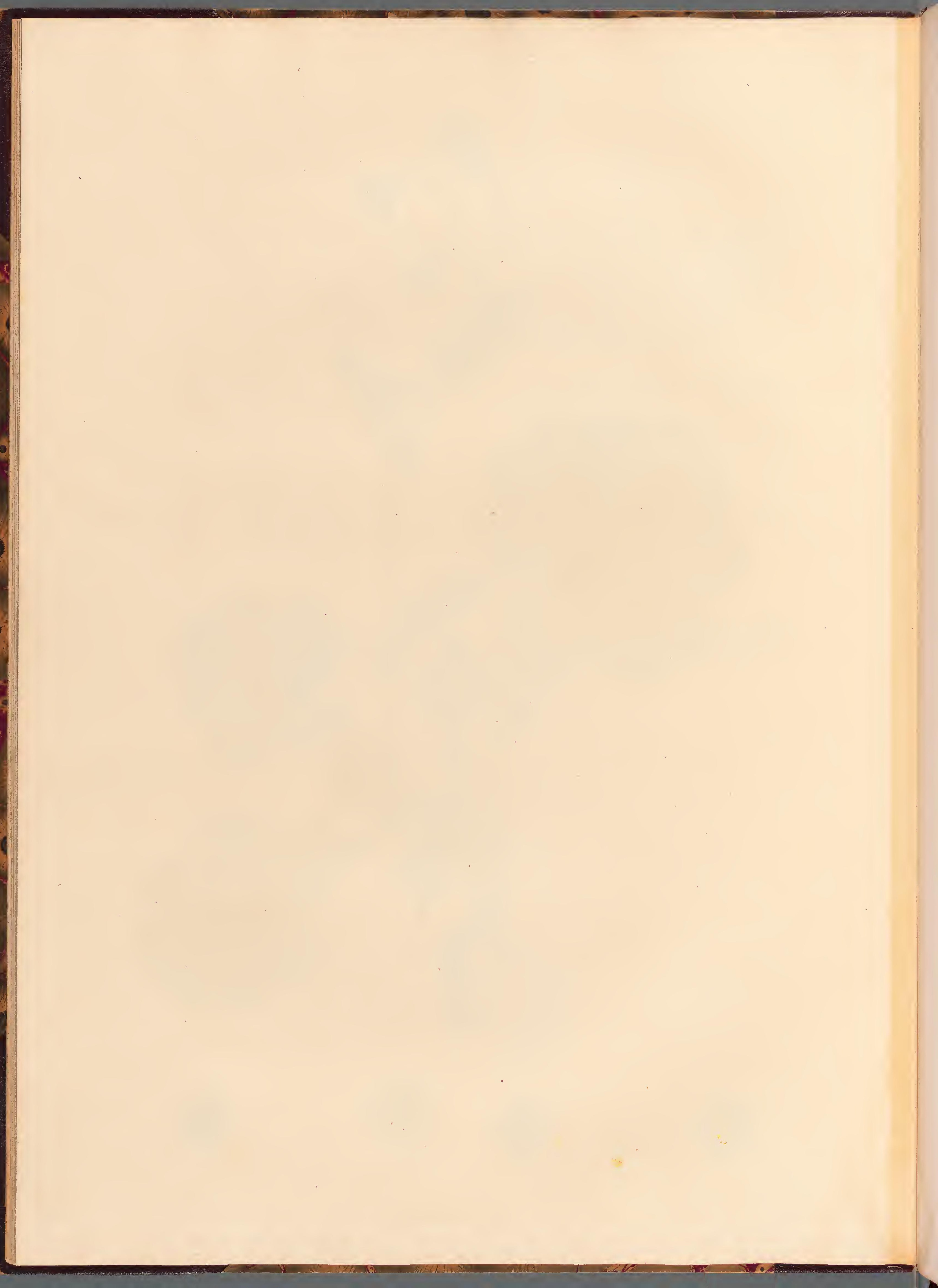




\title{
$\begin{array}{llllllllllllllllllll}G & E & U & M & S & U & D & E & T & I & C & U & M\end{array}$
}

\author{
G E U M. Linne.
}

$$
\text { Classis, et Ordo+ }
$$

Icosandria: Polygynia. Linne gen. pl. Dicotyledoneac: Rosaceae, Potentilleae. Jussieu gen. pl.

\section{Character generis.}

Fructificatio. Calyx tubo concavus, quinquefidus, extus ad incisuras bracteolatus. Petala quinque, Staminaque indefinita calyci inserta. Pistilla numerosa, in Receptaculo cylindraceo capitata, uniovaria, Stylo terminali. Caryopsides numero pistillorum, monospermae, compressae, stylo persistente, elongato aristatae; arista sub apice intorto-geniculata, et articulo superiore delapso apice uncinata; aut egeniculata, et apice recta. Receptaculum fructus saepe stipitatum.

Vegetatio. Herbae erectae, perennes, radicibus aromaticis, adstringentibus. Folia radicalia pinnata, impari maximo; caulina alterna, stipulis magnis petiolaribus. Flores dichotomo-corymbosi, aut rarius solitarii.

$$
\text { Divisio generis. }
$$

Geum ex fructificatione, et quidem ex aristae fabrica in duas sectiones separatur:

I. Caryophyllata. Arista 'rigida, intorto-articulata, et articulo superiore delapso apice uncinata. Caulis multiflorus.

II. Dryados. Arista flexilis, elongata, exarticulata. Caulis uniflorus.

\section{G E U M S U D E T I C U M. \\ Differentia specifica, et Synonymia.}

Caryophyllata: caule subbifloro, floribus nutantibus; aristis uncinatis plumosis; foliis radicalibus pinnatis: impari maximo subrotundo, inferioribus sensim minoribus; caulinis simplicibus.

Riesengebirgs - Nelken-Benedictwurz.

\section{Locus natalis, et tempus.}

Crescit rarissime in pratis editissimis declivis Sudetorum cum Geo montano, ubi mense Julio anni 1821 primo fructificantem observavimus. In horto colitur sub Dio, et fructificat ab ineunte Maio usque in Septembrem. 4. 


\section{Descriptio.}

Vegetatio. Radix perennis, rhizomatoidea. Rhizoma obliquum, cylindricum, praemorsum, hinc inde radiculatum, cicatrisatum, fuscum, vertice squamis fuscis tectum, odore aromatico, 'sapore adstringente. Caulis intrafoliaceus, erectus, cylindricus, foliosus, hirsutus, apice in pedunculos elongatos divisus, et rubescens. Folia: radicalia interrupte-pinnata, lyrata, multijuga; foliolo impari maximo, subreniformi, obsolete 5-7 lobato ; inferioribus oppositis sessilibus, cordatis, approximatis, sensim minoribus, et saepe minimis interpositis; petiolo basi nudo, semicylindrico : caulina alterna, remota, petiolata, stipulata, simplicia, cuneiformia, subtriloba: omnia rugosa, subtus pinnati-nervia, supra pinnati-plicata, dentata, ciliata, appresse pilosa, subnitentia, subtus pallidiora. Stipulae oppositae, subrhomboideae, inciso-dentatae, petiolo adhaerentes. Flores terminales, axillares, 2-4, pedunculis elongatis, subnudis, hirsutis, rubescentibus, sub flore incrassatis, nutantibus, fructiferis erectis.

Fructificatio. Calyx inferus, campanulatus, 5 -fidus, laciniis ovatis, acutis, nonnunquam dentatis, extus ad incisuras bracteolis 5 . alternantibus, obscure purpurascens, hirsutus, persistens. Corolla aequalis, rosacea, subcampanulata. Petala 5, subrotunda, apice retusa, unguiculata, calyce vix longiora, calyci inserta, flava, venis praecipue dorso purpurascentibus. Stamina plurima, erecta, longitudine pistillorum, calyci inserta. Filamenta filiformia. Antherae parvae, ellypticae, incumbentes, biloculares. Pistilla plurima, uniovaria, monostyla, in capitulum collecta. Germina compressa hirsuta, in receptaculo sessilia. Styli terminales, filiformes, plumosi, apice purpurascentes, anthesi peracta sub apice intorto-geniculati, et in fructu in aristam (rigidam) excrescentes, articulo superiore deciduo. Stigmata simplicia, vix incrassata. Fructus: caryopsides numero pistillorum, compressae, aristatae, arista plumosa apice uncinata. Receptaculum cylindricum, subsessile, albovillosum.

Observatio. Planta culta a spontanea nil nisi numero florum, quos in spontanea constanter binos observavimus, differt.

\section{Diagnosticon.}

Geum sudeticum ambigit G. montanum, et rivale, e quibus fors proles hybrida. Vegetatione nempe imitatur G. montanum, fructificatione vero G. rivale. Differt autem abunde ab illis notis indicatis, et insuper a G. rivali arista uncinata, nec incurvato-hamata.

\section{Explicatio Tabulae.}
A. Calyx floris explanatus a facie.
B. Petalum a dorso.
C. Calyx floris explanatus a tergo.
D. Calyx fructus.
E. Caryopsis aristata articulo superiore.
F. Calyx emarcidus cum receptaculo. 


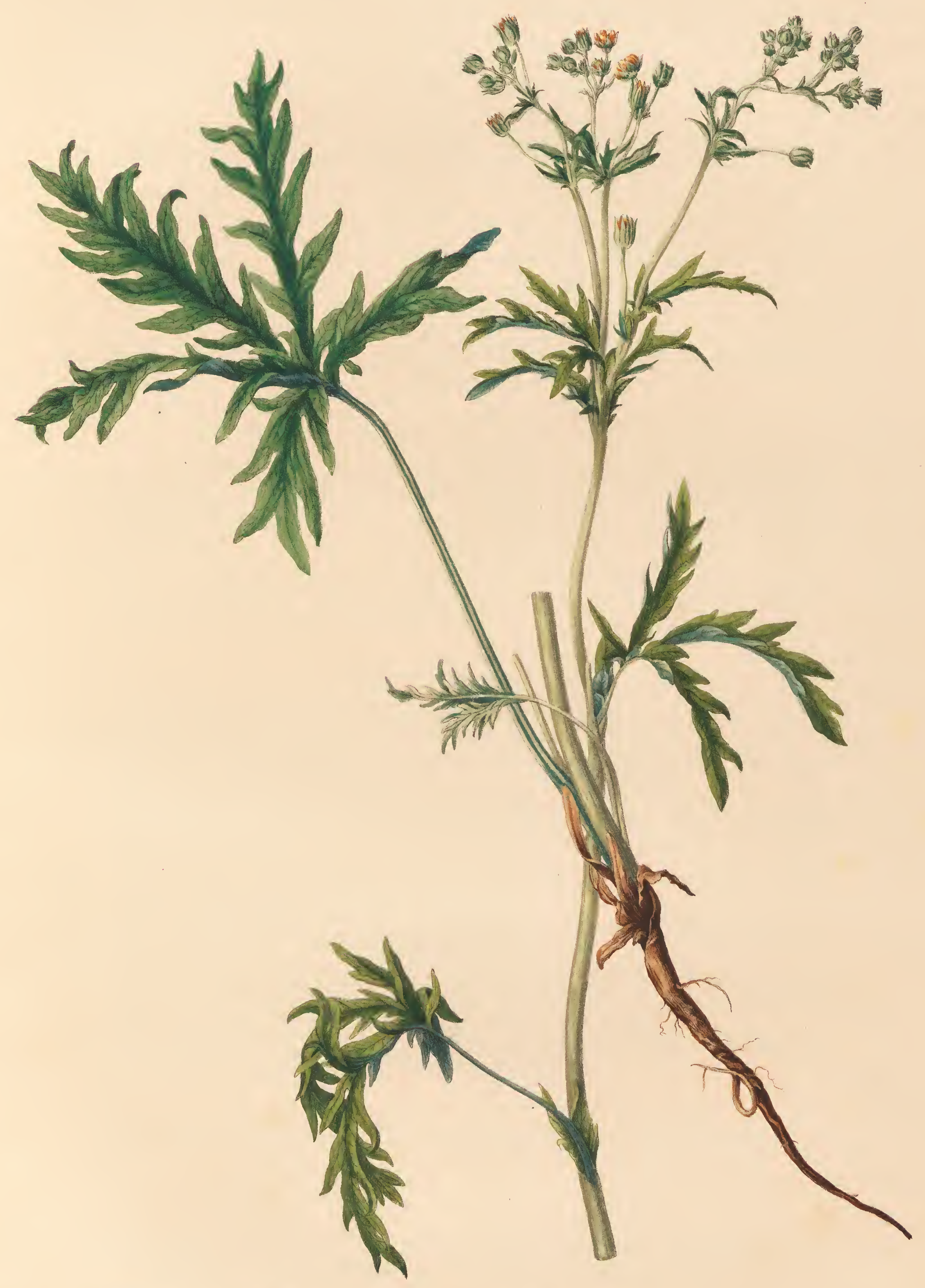

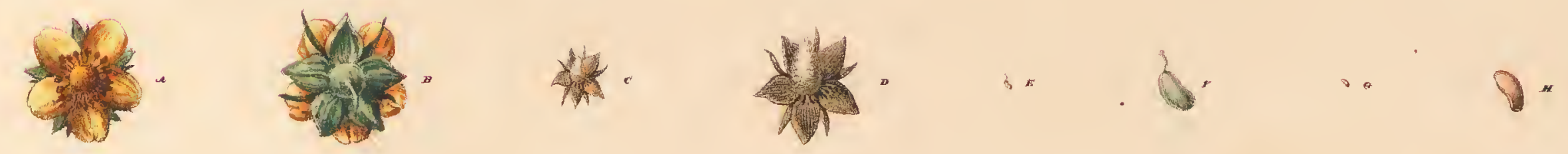




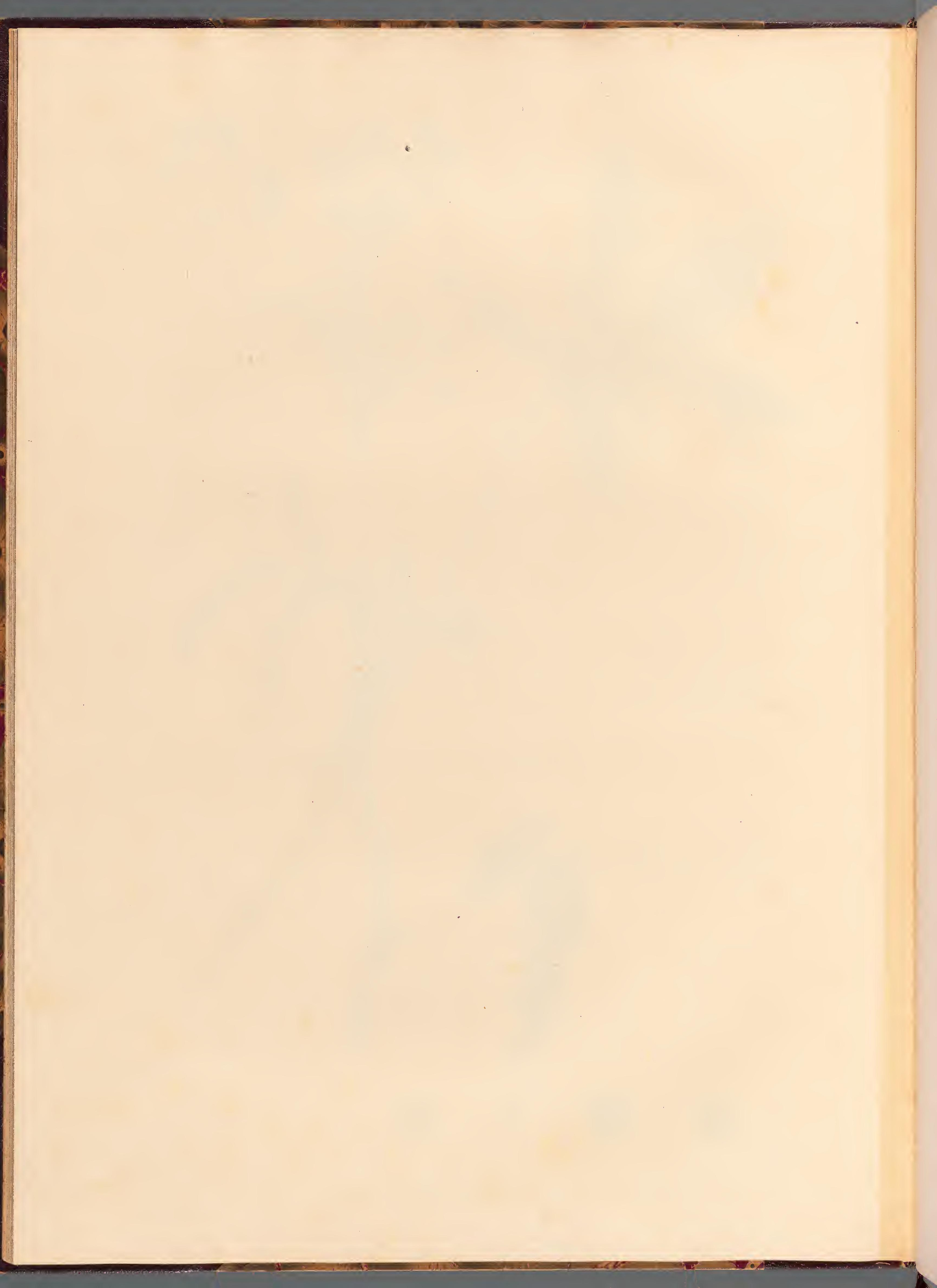




\title{
POTENTILLA ORNITHOPODA.
}

\author{
P $\quad$ O T E $\mathrm{E}$ N T I L L A. Linne. Nestler.
}

Classis, et Ordo.

Icosandria: Polygynia. Linne gen. pl. Dicotyledoneae: Rosaceae, Potentilleae. Jussieu gen. pl.

\section{Character generis.}

Fructificatío. Calyx patens, quinquefidus, extus ad incisuras bracteolatus. Petala quinque, Staminaque numerosa calyci inserta. Pistilla numerosa, in Receptaculo ovato capitata, uniovaria, Stylo laterali. Caryopsides numero pistillorum in receptaculo exsucco, monospermae, subreniformes.

Vegetatio. Herbae, aut raro frutices. Folia alterna, impari-pinnata, pinnatifidave, aut digitata, ternatave. Stipulae petiolares, aut raro caulinae. Flores dichotomo-corymbosi, aut raro solitarii.

\section{Divisio generis.}

Divisio Potentillae, generis illustratione neotericorum sat ampli potissimum ex vegetatione petitur, quaeque fructificatione nonnihil sublevatur; et quidem

I. Geoides. Folia pinnata. Stipulae petiolares. Caryopsides subreniformes, apice attenuatae. (Petala integra). e. g. P. rupestris, geoides.

II. Pentaphylloides. Folia subpinnata : foliolis extimis confluentibus,' aut decurrentibus. Stipulae petiolares. Caryopsides subreniformes. e. g. P. ornithopoda, anserina.

III. Com a rum. Folia pinnata. Petioli vaginantes: supremi stipuliferi. Caryopsides sublenticulares. e. g. P. Comarum.

IV. Quinquefolium. Folia digitata, ternatave. Stipulae petiolares. Caryopsides glabrae. e. g. P. recta, verna, grandiflora.

V. Lupinoides. Foliá digitata, ternatave, saepissime nitentia. Stipulae petiolares. Caryopsides villis deciduis obsitae. Flores albi, aut rubri. Styli elongati. Receptaculum lanatum. e. g. P. alba, alchemilloides, nitida.

VI. Tormentilla. Folia digitata, ternatave. Stipulae caulinae. Numerus floris saepissime quaternarius. e. g. P. Tormentilla.

\section{P O T E N T I L L A O R N I T H O P O D A.}

$$
\text { Differentia specifica, et Synonymia. }
$$

Pentaphylloides: foliis quinato-subpinnatis, subtus incanis; foliolis pinnatifidis approximatis; terminalibus tribus elongatis; caule adscendente.

Vogelfufsblättriges Schlitz-Fingerkraut. 


\section{Locus nditalis, et tempus.}

Crescit in montosis Caucasi, unde semina nomine P. multifidae c. r. Universitatis horto communicata fuerunt. Fructificat Maio, et Junio. 4.

$$
\text { Descriptio. }
$$

Vegetatio. Radix perennis, rhizomatoidea. Rhizoma subperpendiculare, fusiforme, subramosum, hinc inde radiculatum, laeve, fuscum, vertice squamis fuscis tectum, sapore adstringente. Caulis intrafoliaceus, adscendens, fructifer saepe declinatus, apice dichotomo-corymbosus, cylindricus, foliosus, tomento brevissimo subcanescens. Folia: radicalia subpinnata (pinnatisecta), foliolis 5 , aut raro 2 minimis accedentibus, approximatis, tribus terminalibus pari inferiore longioribus, basi decurrentibus; petiolo supra sulcato, vix piloso : caulina alterna, remota, petiolata, stipulata ; inferiora quinato-subpinnata, superiora ternata, floralia integra. Foliola oblongo-lanceolata, pinnatifida, laciniis lanceolatis, integerrimis, decurrentibus, supra rugosa, sulcata, glabra, subtus pinnati-nervia, cano-tomentosa, margine vix pilosa. Stipulae oppositae, ovatae, acuminatae, inciso-dentatae, petiolo adhaerentes. Flores parvi, terminales, dichotomo-corymbosi, conferti, pedunculis erectis, canescenti-tomentosis.

Fructificatio. Calyx inferus, patens, 5-fidus, laciniis ovatis, acutis, extus ad incisuras bracteolis 5 alternantibus, canescens, persistens. Corolla aequalis, rosacea, patens. Petala 5, obovata, emarginata, unguiculata, longitudine calycis, eoque inserta, flava. Stamina numerosa, calyci inserta. Filamenta filiformia. Antherae ovatae, biloculares. Pistilla plurima, uniovaria, monostyla, in capitulum collecta. Germina oblonga, in receptaculo sessilia. Styli laterales sub apice germinis, filiformes, decidui. Stigmata simplicia, obtusa. Fructus: cariopsides numero pistillorum, subreniformes, rugosae. Receptaculum sessile, cylindricum, villosum, exsuccum.

\section{Explicatio Tabulae.}
A. Flos magnitudine auctus a facie.
B. Idem a dorso.
C. Calyx fructus receptaculo seninilous denudato.
D. Idem magnitudine auctus.
E. Pistillum foecundatum.
F. Idem magnitudine auctum.
G. Caryopsis.
H." Eadem magnitudine aucta. 


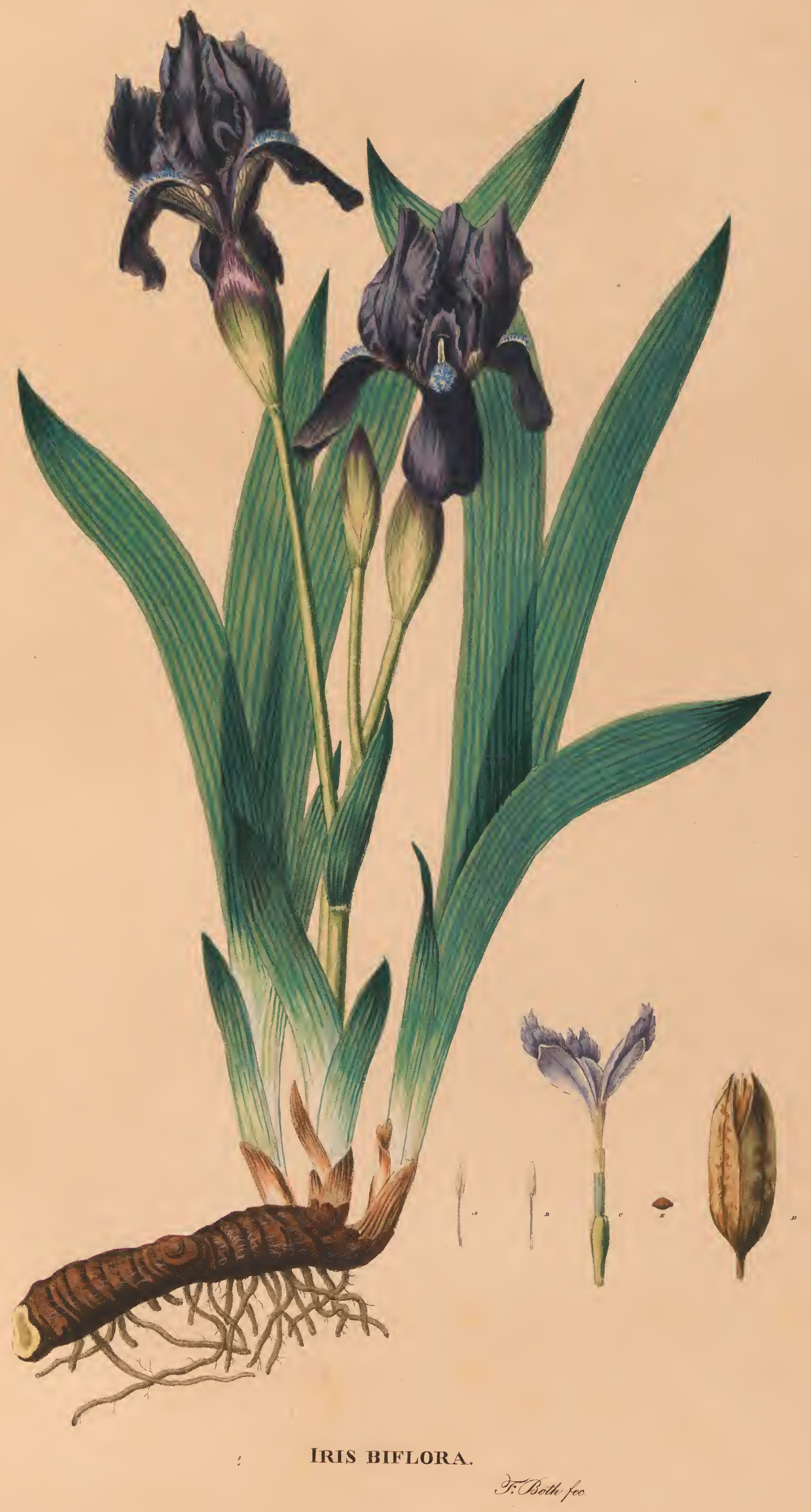




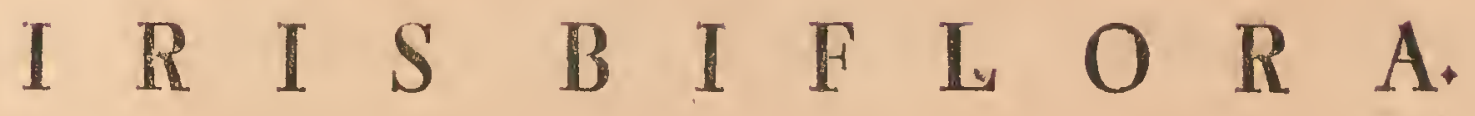 \\ Differentia specifica, et Synonymia.}

Pogiris (barbata): scapo furcato subbifloro folia falcato-gladiata subaequante; spatha herbacea ovato-inflata; perigonii laciniis concoloribus ellipticis integris undulatis, tubo germine trigono longiore.

I. illyrica, vel Iris VI. Clus. pan. 248.

I. major latifolia XXIII. Clus. hist. 1. p. 223.

Chamaeiris latifolia biflora. Besl. cyst. vern. ord. 8. fol. 1. f. 4.

Chamaeiris major saturate purpurea biflora. C. Bauh. pin. 33 .

Iridi biflorae affinis flore majore. C. Bauh. pin. $3^{2}$.

I. humilis major saturate purpurea biflora. Tournef. inst. $3^{61}$.

I. illyrica flore majore. Tournef. inst. $3^{61}$.

I. illyrica biflorae similis Clusio XXIII. flore purpureo. I. Bauh. hist. 2, p. $7^{22 .}$

I. (biflora) corollis barbatis, caule foliis breviore trifloro. Linn. spec. pl. $5^{6 .}$ (excl. loco natali.)

I. bohemica. Schmidt bohem. 4. p. 4. Roem. et Schult, syst. veg. 1. p. 466. Tausch ind. pl. hort. Can. anno 1821. Spreng, syst. veg. 1. p. 162.

I. extrafoliacea. Mikan in Pohl bohem. 1. p. 47 (excl. synon. praeter Schmidt.)

I. (hungarica) foliis ensiformibus glabris subfalcatis subaequantibus scapum multiflorum; spathis inflatis, suprema biflora. Waldst. et Kit. pl. rar. Hung. 7 . p. 251. t. 226. Willd. enum. hort. Berol. p. 64. Roem. et Schult. syst. veg. 1. p. 465 . Spreng. syst. veg. 1. p. 162.

Zweimalblühender Bart-Schwertel.

$$
\text { Locus natalis, et tempus. }
$$

Habitat in rupibus calcareis schistosisque Bohemiae, inque Hungaria. Fructificat sub Dio exeunte Aprili ineunteve Maio, altera vice saepius Octobri. 4.

$$
\text { Descriptio. }
$$

Vegetatio. Radix perennis tuberosa. Tuber fuscus repens depresso-cylindraceus articulatus annulatus, supra fibris subcapillatus, subtus radicatus, apice frondescens, basi marcescens demum abolescens. Folia fasciculata ex apice tuberis prodeuntia, fasciculis plerumque 2 sibi oppositis et scapum intercipientibus, eoque mox brevioribus mox longioribus. Folia in fasciculis alterna disticha subfalcato-gladiata, basi appresso-vaginantia, elevato-nervosa glaucescentia, superiora sensim longiora, infima squamaeformia ex albofuscescentia. Folia plus minusve falcata, latiora aut angustiora inveniuntur, et per aestatem fere duplo longiora evadunt. Scapus basi subfoliaceus e vaginis foliorum egrediens erectus tereti-compressus glaucus infra medium furcatus, ad furcationem vagina foliacea obsessus, biflorus, aut saepe pedunculo radicali una cum scapo proveniente triflorus, aut nonnunquam in culta et spontanea submultiflorus, aut simplicissimus uniflorus. Pedunculi erecti elongati tereti-compressi nudi glauci laevissimi. 
Fructificatio. Spatha 1-, suprema 2-flora, ovata inflata bivalvis, valvis subaequalibus herbaceis levissime pruinosis nervosis saepeque striis maculisque purpurascentibus notatis, tubum perigonii subaequantibus. Perigonium suaveolens superum, tubo recto subtrigono germine fere duplo longiore coerulescente, limbo 6-partito inaequali, laciniis omnibus concoloribus profunde violaceis basi utrinque glandula dentiformi albida obsitis : exterioribus 3 reflexis oblongo-spathulatis planis, basi nervis venisque albidis pictis barbatisque, barba basi flavescente apice obscure violaceo longitudine stigmatis: interioribus 3 erectis ellipticis undulatis integris, aut nonnunquam apice subemarginatis, basi canaliculato-unguiculatis, ungue venuloso. Stamina 3 , laciniis perigonii exterioribus inserta. Filamenta subulata coerulescentia anthera duplo longiora. Antherae lanceolatae erectae basi emarginatae biloculares, loculis uniserialibus extrorsum positis, polline albo farctis* Germen inferum trigonum 6-striatum. Stylus terminalis trigonus. Stigmata 3 petaliformia erecto-patentia oblonga, apice bifida et acute dentata, inverse carinata, dilute violacea, dorso lamella transversali (stigmate proprio) concolori obsita. Capsula coriacea 3 -gona 3 -valvis 3 -locularis polysperma. Semina ovata utrinque attenuata rugosa fusca.

\title{
Critica.
}

E synonymia et citata a Linnaeo icone Besleri facile evincitur nostram plantam esse I. bifloram Linn. et solum patria Lusitania male a Linnaeo indicata, et ad I. subbifloram Brotero referenda Clar. auctores terminasse videtur, eam sub propriis nominibus illustrandi. I. biflora. Willd. spec. pl. 1. p. 22\% (excl. syn. praeter Thunb.) e definitione ad I. falcatam spectat, cui quoque addi potest: Iris flore violaceo folio virente, an Clusii XXV caule foliis nudo. I. Bauh. hist. 2. p. 723 c. ic.

\author{
Explicatio Tabulae. \\ A. Stamen a facie. \\ B. Idem a dorso. \\ C. Pistillum. \\ D. Capsula. \\ E. Semen,
}




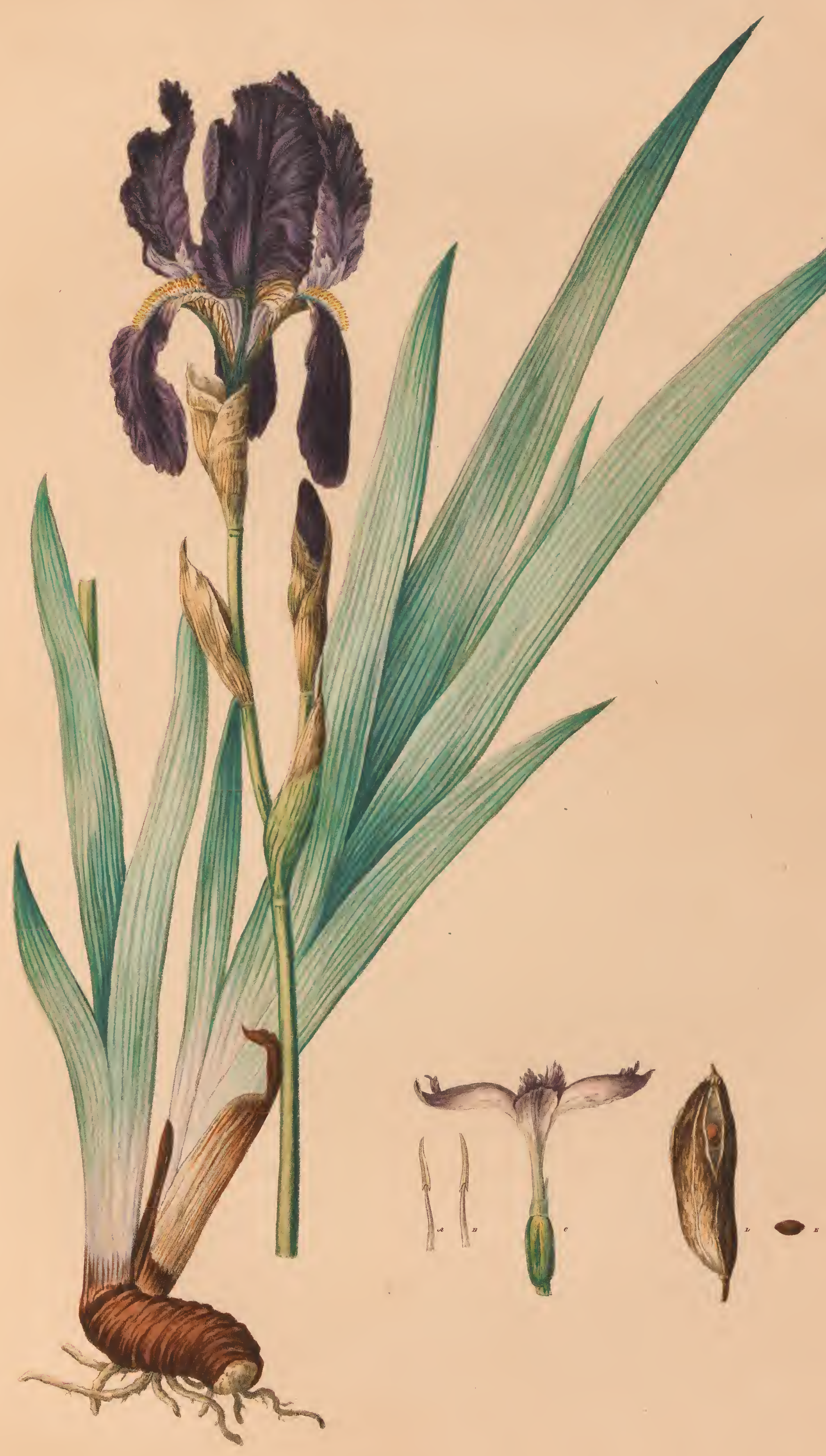

IRIS EROSA. 


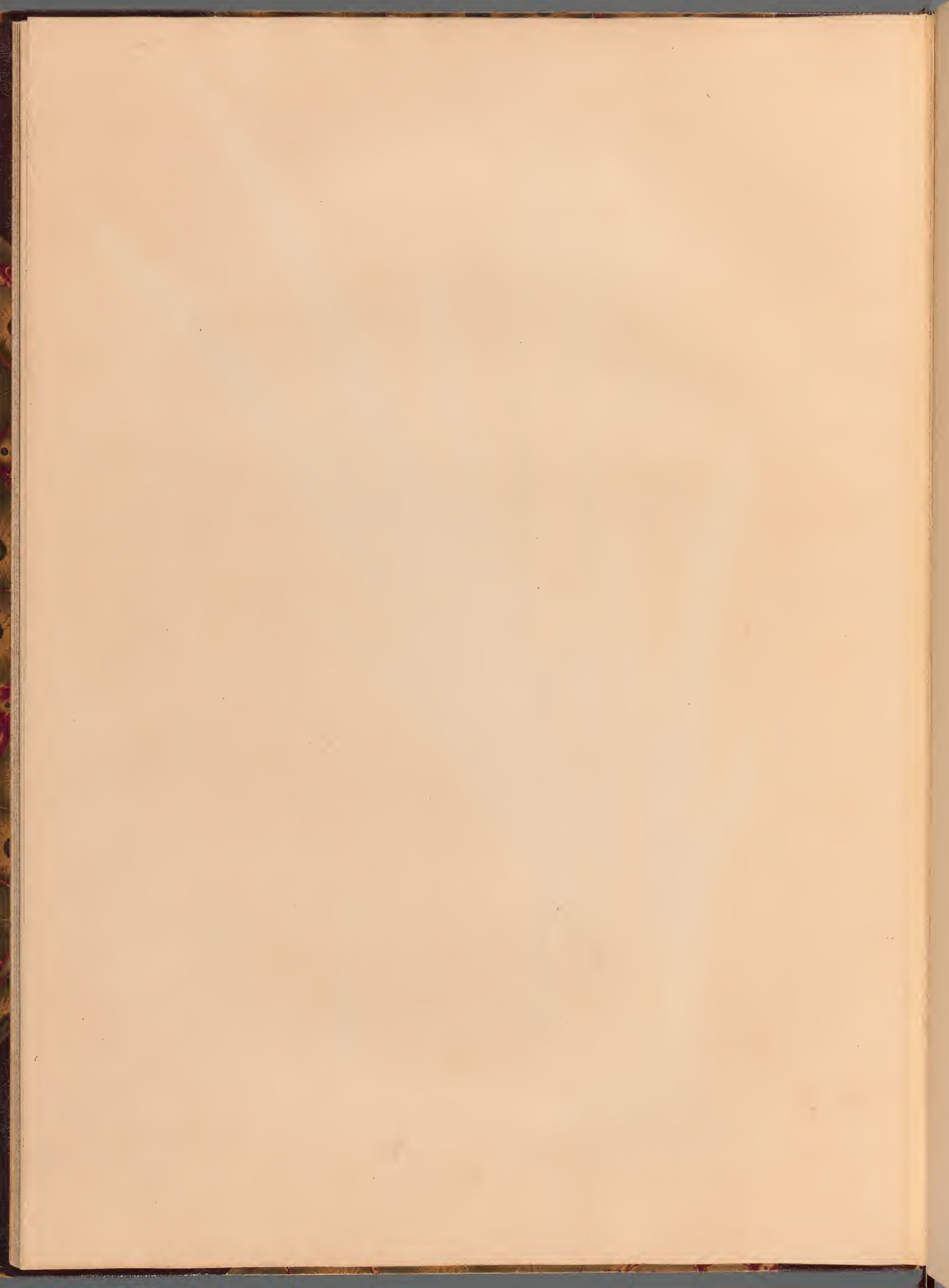




\section{$\begin{array}{llllllllll}\text { I } & R & I & S & E & R & O & S & A \text {. }\end{array}$}

Differentia specifica, et Synonymia.

Pogiris (barbata): scapo multifloro folia ensiformia glauca superante; spatha marcescente; perigonii laciniis concoloribus oblongis erosis undulatisque: erectis latioribus, tubo germine longiore.

I. undulata. Tausch ind. pl. hort. Can. anno 1821.

Benagter Bart-Schwertel.

\section{Locus, et tempus.}

Colitur in horto, quem olim nomine I. halophilae intravit. Fructificat sub Dio exeunte Maio. 4.

$$
\text { Descriptio. }
$$

Vegetatio. Radix perennis tuberosa. Tuber fuscus repens cylindraceus articulatus annulatus nudus, inferne radicatus, apice frondescens. Folia fasciculata, in fasciculis plerumque 2 sibi oppositis et scapum intercipientibus alterna disticha ensiformia stricta elevato-nervosa glauca, basi appresso-vaginantia, scapo florifero breviora. Scapus basi foliosus erectus strictus tereticompressus glaucus, apice ramosus, ramis alternis strictis unifloris ad basim vaginatis, vaginis demum marcescentibus.

Fructificatio. Spatha 1-, suprema 2-flora, cylindracea bivalvis, valvis ovatis acutis supra medium constrictis, sub anthesi marcescentibus, vix longitudine tubi perigonii. Perigonium suaveolens superum, tubo cylindrico recto coerulescente germine longiore, limbo 6-partito inaequali, laciniis omnibus concoloribus profunde violaceis: exterioribus 3 reflexis oblongis planis, basi attenuatis albido-flavescentibus venis nervisque fusco-violaceis pictis, barbaque aurea obsitis, in ambitu plus minusve eroso-crenatis undulatis: interioribus 3 erectis oblongis, reflexis latioribus magisque erosis, imo nonnunquam incisis, undulatis basi unguiculatis, ungue canaliculato flavescente fusco-venoso. Glandulae basim laciniarum perigonii interne nectentes dentiformes albidae. Stamina 3, perigonii laciniis exterioribus basi inserta. Filamenta subulata coerulescentia, anthera vix longiora. Antherae lineares erectae subsagittatae biloculares, loculis uniserialibus extrorsum positis polline albo farctis. Germen inferum obtuse 3-gonum 6-striatum. Stylus terminalis triangularis. Stigmata 3 petaliformia patentia oblonga obverse carinata, apice bifida serrulataque, dorso lamella transversali crenulata obsita, ex albo-violascentia, carina et apice violacea. Capsula coriacea 3 -gona $3_{\text {-val- }}$ vis 3 -locularis polysperma. Semina ovata utrinque attenuata rugosa fusca.

\section{Explicatio Tabulae.}

A. Stamen a dorso. B. Idem a facie. C. Pistillum. D. Capsula. E. Semen. 



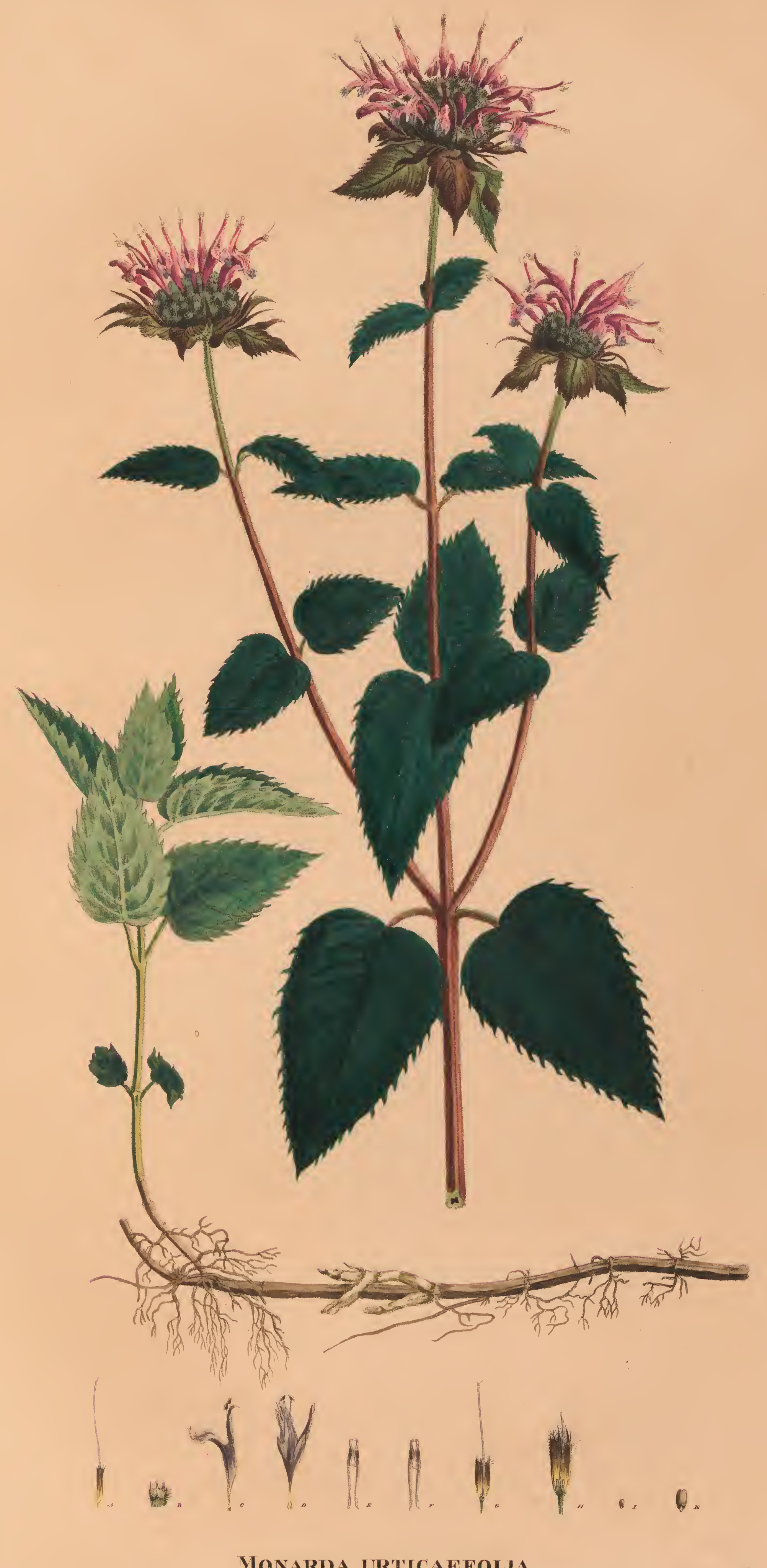

H. Bothefuctor. - Yromefer lithogr. 


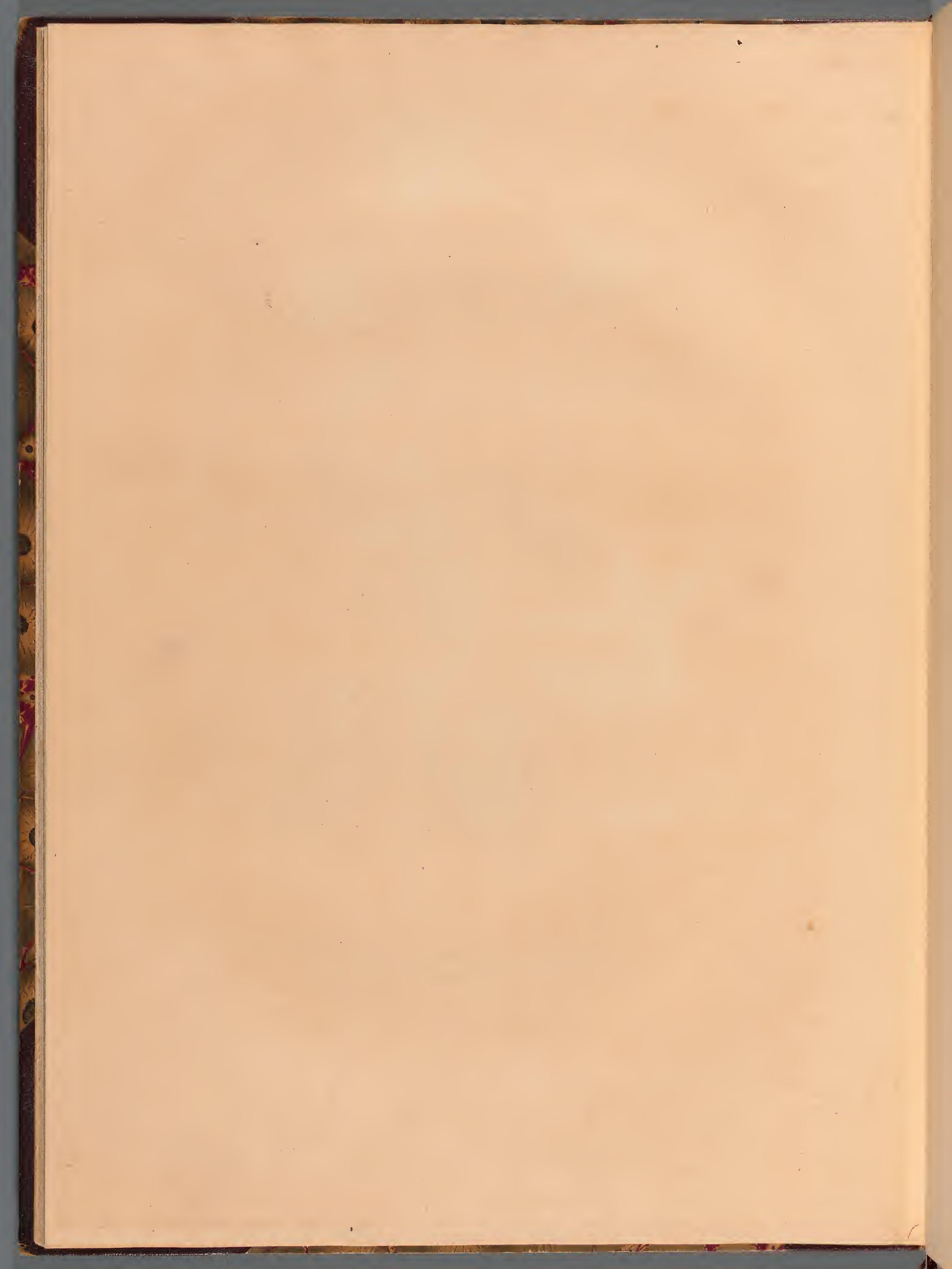




\title{
MONARDA URTICAEFOLIA.
}

\author{
M O N A R D A. Linne.
}

\author{
Classis, et Ordo.
}

Diandria: Monogynia. Linn. gen. pl. Dicotyledoneae: Labiatae (Monardeae). Juss. gen. pl.

\section{Character generis.}

Rructificatio. Calyx anguste cylindricus striatus 5-dentatus. Corolla tubulosa elongata bilabiata, labio superiore erecto angusto stamina amplexante, inferiore reflexo trilobo, lobo medio longiore.

Vegetatio. Herbae aromaticae perennes repentes, aut raro annuae. Flores capitati involucrati terminales, aut axillares verticillati, e quibus genus facile subdividendum est.

\section{O N A R D A U R T I C A E F O L I A.}

\section{Differentia specifica, et Synonymia.}

M. capitulis bracteis ovatis coloratis; corollis purpurascentibus punctatis; foliis subcordato-ovatis acuminato-patenti-serratis cauleque obtusangulo pilosis.

Nesselblättrige Monarde.

$$
\text { Locus, et tempus. }
$$

Colitur in horto promiscua cum aliis generis speciebus; sata characteres non mutavit. Fructificat sub Dio Julio, Augusto. 4.

$$
\text { Descriptio. }
$$

Vegetatio. Radix perennis rhizomatoidea. Rhizoma cinerascens repens 4-gonum articulatum nodosum, ad nodos radiculatum, turiones albidos caulesque emittens. Caulis 2-3-pedalis erectus 4-gonus obtusangulus fistulosus nodosus, ad nodos ramosus foliosusque, purpureus pilosus, ramis decussatis erecto-patentibus foliosis floribus terminatis. Folia decussata petiolata subcordato-ovata breve acuminata grosse serrata, serraturis subaequalibus remotiusculis patentibus acuminatis acumine incurvis, basi integerrima, rugosa penninervia, supra obscure viridia pilis sparsis brevibus appressis, subtus pallidiora punctata ad nervos subhirsuta. Petioli canaliculati purpurascentes hirsuti. Caulis et rami florum capitulo solitario, raro prolifero, subgloboso, basi bracteato terminati. Bracteae sessiles imbricatae, exteriores patentes ovatae acuminatae serratae, plus minusve ex viridi purpurascentes, interiores sensim angustiores lineares integerrimae purpureae. 
Fructificatio. Calyx inferus persistens cylindricus striatus glaber, punctis resinosis adspersus, plus minusve purpurascens, ore 5-dentato hirsuto, dentibus lineari-setaceis aequalibus. Corolla perigyna tubulosa bilabiata, calyce triplo longior, dilute purpurea, pubescens punctisque resinosis adspersa, labio superiore erecto lineari canaliculato-convoluto stamina involvente, labio inferiore reflexo trilobo punctato, lobis lateralibus abbreviatis obtusis, medio elongato apice dilatato emarginato. Stamina 2 aequalia exserta, corollae fauci inserta. Filamenta capillaria glabra. Antherae saepe inter se cohaerentes, erectae compressae biloculares subdidymae, polline albido repletae. Germen superum receptaculo parvo affixum, 4-lobum, interque lobos stylum exserens. Stylus filiformis staminibus longior una cum illis a corollae labio superiore involutus. Stigma bilobum, lobis linearibus inaequalibus revolutis. Fructus 4-spermus. Akenae 4 in fundo calycis ovatae lividae laevissimae.

\title{
Diagnosticon.
}

M. urticaefolia proxima est M. mediae Willd. a qua differt foliis subcordato-ovatis patenti-acuminato-serratis pilosis, nec cordato-ovatis dense appresse serratis glabriusculis; corollis majoribus dilute purpureis labio inferiore punctato, nec splendide purpureis unicoloribus; lacinia media labii inferioris apice dilatata, nec lineari.

\section{Explicatio Tabulae.}

\author{
A. Calyx integer stylo exserto. \\ B. Faux calycis magnitudine aucta. \\ C. Corolla. \\ D. Eadem tubo longitudinaliter fisso. \\ E. Stanina antheris cohaerentibus a facie. \\ F. Eardem a dorso. \\ G. Calyx longitudinaliter fissus cum pistillo. \\ H, Idem magnitudine auctus. \\ I. Akena. \\ K. Eadem magnitudine aucta.
}




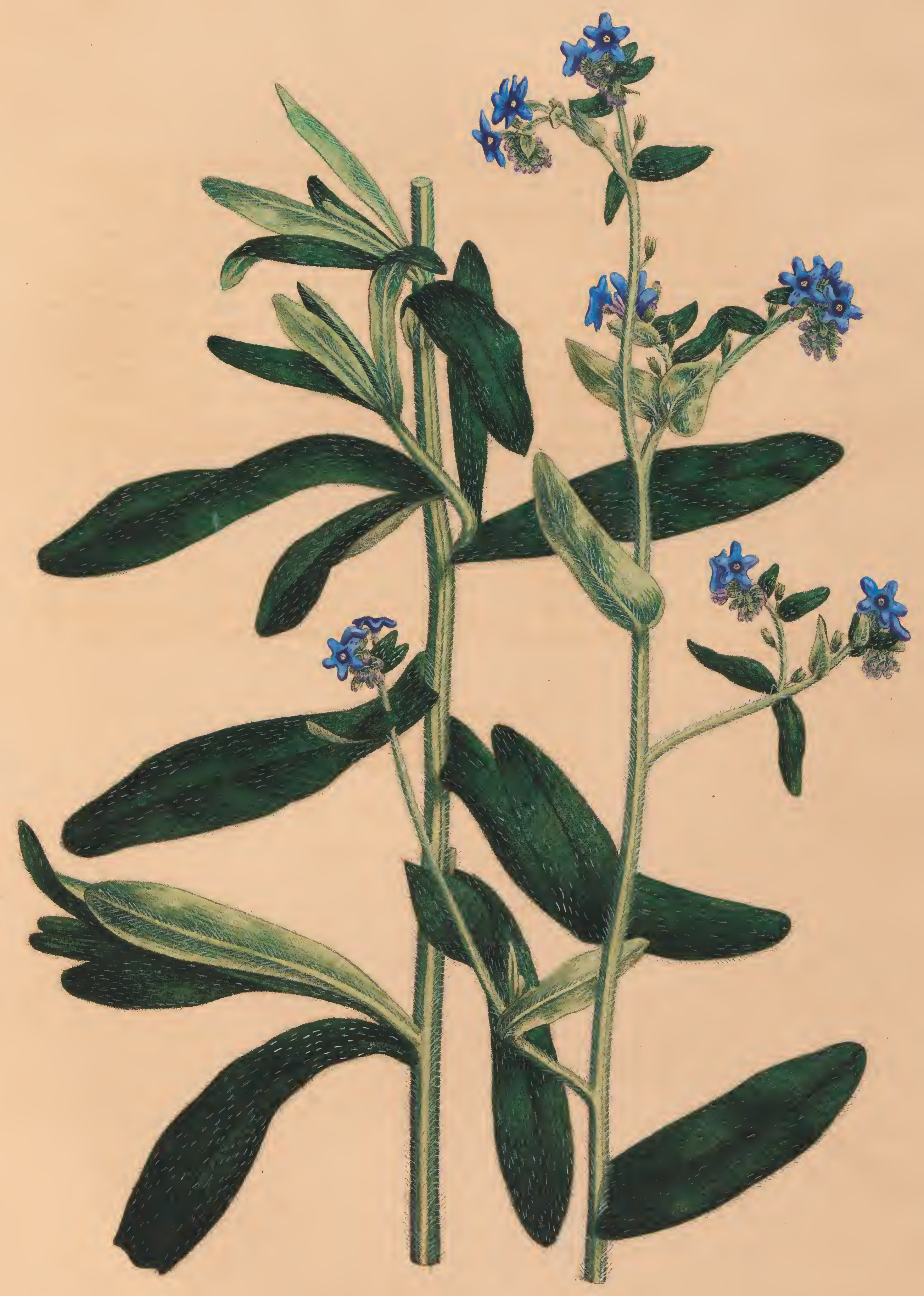

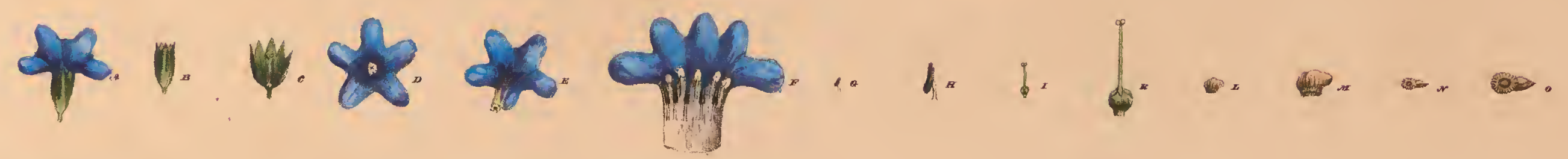





\title{
A N C H U S A A E T H E R I A.
}

\section{A N C H U S A. Linne,}

\author{
Classis, et Ordo.
}

Pentandria: Monogynia. Linn. gen. pl. Dicotyledoneae: Borragineae Gymnotetraspermae (Lycopsideae.) Juss. gen. pl.

\section{Character generis.}

Fructificatio. Calyx 5 -fidus. Corolla infundibuliformis, tubo cylindrico, limbo semiquinquefido erecto-patente, fauce clausa fornicibus 5 prominentibus papillosis. Antherae oblongae inclusae. Stigma obtusum. Nuculae 4 apice depressae, latere interno carinatae, rugosae, basi insculpta perforata receptaculo affixae.

Vegetatio. Herbae strigosae, floribus saepe spicatis unilateralibus, calycibus fructiferis inflatis cernuis.

\section{Divisio generis.}

Anchusa remotis ab illa generibus Nonea Cand. Buglosso Gaertn. et Alkanna ${ }^{*}$ ) genus admodum naturale constituit, ut nonnisi subdivisionem ex inflorescentia spicata, spicato-capitata, et sparsa admittat.

\section{A N C H U S A A E T H E R I A.}

\section{Differentia specifica, et Synonymia.}

A. spicis conjugatis secundis laxis, bracteis oblongis; corollae limbo plano, tubo longitudine calycis; foliis oblongo-lanceolatis obtusis integerrimis strigosis. Himmelblaue Ochsenzunge.

$$
\text { Locus, et tempus. }
$$

Primo innotuit haec tum magnitudine, tum colore floris elegantissima species in horto c. r. botanico Universitatis Pragensis, ubi nomine Anchusae undulatae culta fuit. Fructificat sub Dio Junio; Julio. o".

$$
\text { Descriptio. }
$$

Vegetatio. Radix biennis rhizomatoidea. Rhizoma perpendiculare cylindricum, basi ramosum, ex albo-rubescens. Caulis erectus, aut ex decumbenti 
adscendens, 2-3-pedalis flexuosus, a basi ramosus, foliosus striato-angulatus, pilis albis rigidis patentibus hispidus. Folia radicalia aggregata oblongo-lanceolata spithamaea, basi in petiolum attenuata, caulina alterna, magnitudine sursum decrescentia: inferiora laxa, basi attenuata spathulato-lanceolata, superiora basi dilatata semiamplexicaulia, summa subdecurrentia: omnia integerrima obtusa, pilis basi tuberculatis strigosa ciliataque, subtus pallidiora. Spicae terminales, axillares, et supraaxillares conjugatae laxae divaricatae, basi saepissime diphyllae, apice spiraliter convolutae. Flores in spicis remotiusculi bracteati, inferiores nonnunquam ebracteati, aut supraaxillares. Bracteae foliaceae oblongae, inferiores calyce longiores, superiores calycem aequantes.

Fructificatio. Calyx inferus tubulosus 5-dentatus, dentibus lineari-lanceolatis acutiusculis, erectus hispidus, in fructu tumidus cernuus. Corolla perigyna infundibuliformis, tubo cylindrico, basi prismatico 4-gono, longitudine calycis, limbo seniquinquefido demum fere patentissimo, margine revoluto, colore elegantissimo aetherio, fauce clausa fornicibus 5 papillosis albis. Stamina 5, tubo corollae inserta, inclusa, cum fornicibus alternantia. Filamenta subulata alba. Antherae oblongae biloculares versatiles violascentes. Germen superum 4-lobum. Stylus filiformis inclusus, inter germinis lobos enascens, albidus. Stigma obtusum emarginatum. Fructus 4-spermus. Nuculae 4, cinereae, apice depressae acumine obliquo, latere interno carinatae, superficie rugosae, basi insculpta perforata receptaculo affixae.

$$
\text { Explicatio Tabulae. }
$$
A. Flos integer a tergo.
B. Calyx integer.
C. Idem longitudinaliter fissus.
D. Limbus corollae a facic.
E. Idem a dorso una cum tubo corollae.
F. Corolla longitudinaliter fissa, et magni- tudine aucta cum staminibus.
G. Stamen.
II. Idem magnitudine auctum.
I. Pistillum.
K. Idem magnitudine auctun.
L. Nucula a latere.
M. Eadem magnitudine aucta.
N. Nucula a basi.
O. Eadem magnitudine ancta. 


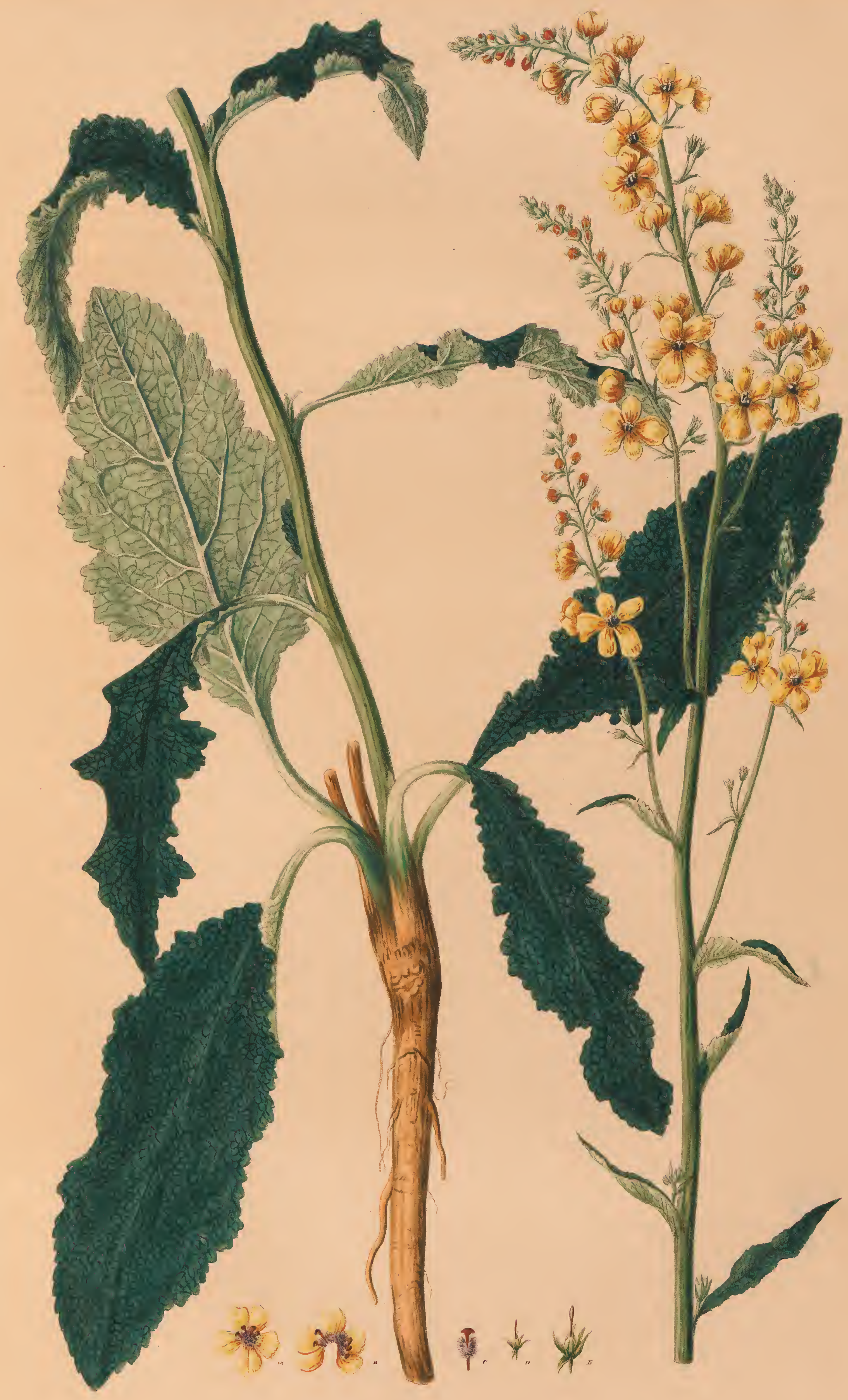

VERBASCUM IGNESCENS 


\title{
V E R B A S C U M. I G N E S C E N S.
}

\author{
V E R B A S C U M. Linne.
}

Classis, ct Ordo.

Pentandria: Monogynia Linn. gen. pl. Dicotyledoneae: Solaneae. Juss. gen. pl.

$$
\text { Character generis. }
$$

Fructificatio. Calyx 5-partitus. Corolla rotata limbo 5-partito inaequali. Stamina declinata inaequalia. Antherae 1-loculares. Capsula bivalvis bilocularis polysperma, valvis inflexis dissepimentum formantibus, in sporophorum incrassatis.

Vegetatio. Herbae, aut rarissime suffrutices. Folia alterna rugosa, pilis stellatis saepe dense tecta. Flores racemosi bracteati.

\section{Divisio generis.}

Genus admodum naturale paucas tantum praebet characteres, e quibus divisio statui potest, et quidem:

I. Lychnites. Antherae uniformes. Folia superiora saepissime sessilia.

II. Thapsus. Antherae difformes. Capsula ovata subdidyma. Folia superiora saepissime decurrentia.

III. B lattaria. Antherae difformes. Capsula subglobosa. Folia superiora sessilia.

\section{E R B A S C U M I G N E S C E N S.}

\section{Differentia specifica, et Synonymia.}

Lychnites: foliis radicalibus caulinisque inferioribus petiolatis oblongis inaequaliter crenatis undulatis subtus leviter tomentosis, superioribus lanceolatis sessilibus; racemis paniculatis, pedunculis geminis calyce vix duplo longioribus.

Glühende Brand-Königskerze.

\section{Locus natalis, et tempus.}

Habitat in arenosis subsilvaticis Bohemiae ad Lissam cum V. rubiginoso, et versifloro. Fructificat Julio. 4.

\section{Descriptio.}

Vegetatio. Radix perennis rhizomatoidea. Rhizoma perpendiculare cylindricum fuscescens, hinc inde radiculatum, basi ramosum. Caulis 2-pedalis erectus simplex flexuosus angulatus leviter tomentosus foliosus. Folia radica- 
lia plura terrae incumbentia oblonga petiolata inaequaliter crenata leviter undulata obtusa, supra rugosa obscure viridia pilosiuscula, subtus pallidiora venosa leviter tomentosa pilis stellatim congestis: caulina alterna remotiuscula, inferiora oblonga petiolata, basi attenuata, radicalibus simillima nonnisi magis undulata, superiora sensim angustiora breviusque petiolata, summa lanceolata basi ovata sessilia. Racemi terminales paniculati erecti laxiusculi. Florum fasciculi biflori, terminales uniflori, remotiusculi, bractea lineari suffulti. Pedunculi tomentosi longitudine bracteae, calyce vero vix duplo longiores.

Fructificatio. Calyx inferus persistens 5-partitus, laciniis lineari-lanceolatis acuminatis leviter tomentosis. Corolla suaveolens, ex flavo in rubrum plus minusve vergens subferruginea rotata, tubo brevissimo, limbo plano 5-partito, laciniis inaequalibus obovatis basi obscurius coloratis, inferioribus 3 majoribus. Stamina 5, tubo corollae inserta, declinata, longitudine inaequalia, inferioribus 4, subdidynamis, quinto superiore brevissimo. Filamenta subulata crocea sursum incurvata, omnia medio barba densa violacea tecta. Antherae omnes aequales reniformes erectae uniloculares, polline croceo repletae. Germen superum ovatum bisulcum tomentosum. Stylus terminalis germine longior, apice incrassatus rubescens. Stigma capitatum. Fructum antequam perfecerit, planta nostra periit, et ab hoc tempore repetitis vicibus frustra quaesita fuit.

O bservatio. Color floris valde variabilis ex flavo in rubrum plus minusve intensum vergens, quam coloris lusum quoque in V. rubiginoso et versifloro observavimus, et in $\mathbf{V}$ : ferrugineo Miller (puniceo Schrader) jam Trew et Ehret in plantis selectis t. 16.'f. 1. et 2. optime proposuerunt.

\section{Diagnosticon.}

Verbascum ignescens proximum est $V$. rubiginoso, a quo praecipue differt foliis inaequaliter crenatis undulatis: radicalibus oblongis; pedunculis calycibus vix duplo, nec multo longioribus; calycibus majoribus, ejusque laciniis lineari-lanceolatis, nec linearibus.

\section{Explicatio Tabulae.}

A. Corollae limbus cum staminibus.

B. Corolla tubo fisso.

C. Stamen magnitudine auctum.

D. Calyx cum pistillo.

E. Idem magnitudine anctus. 


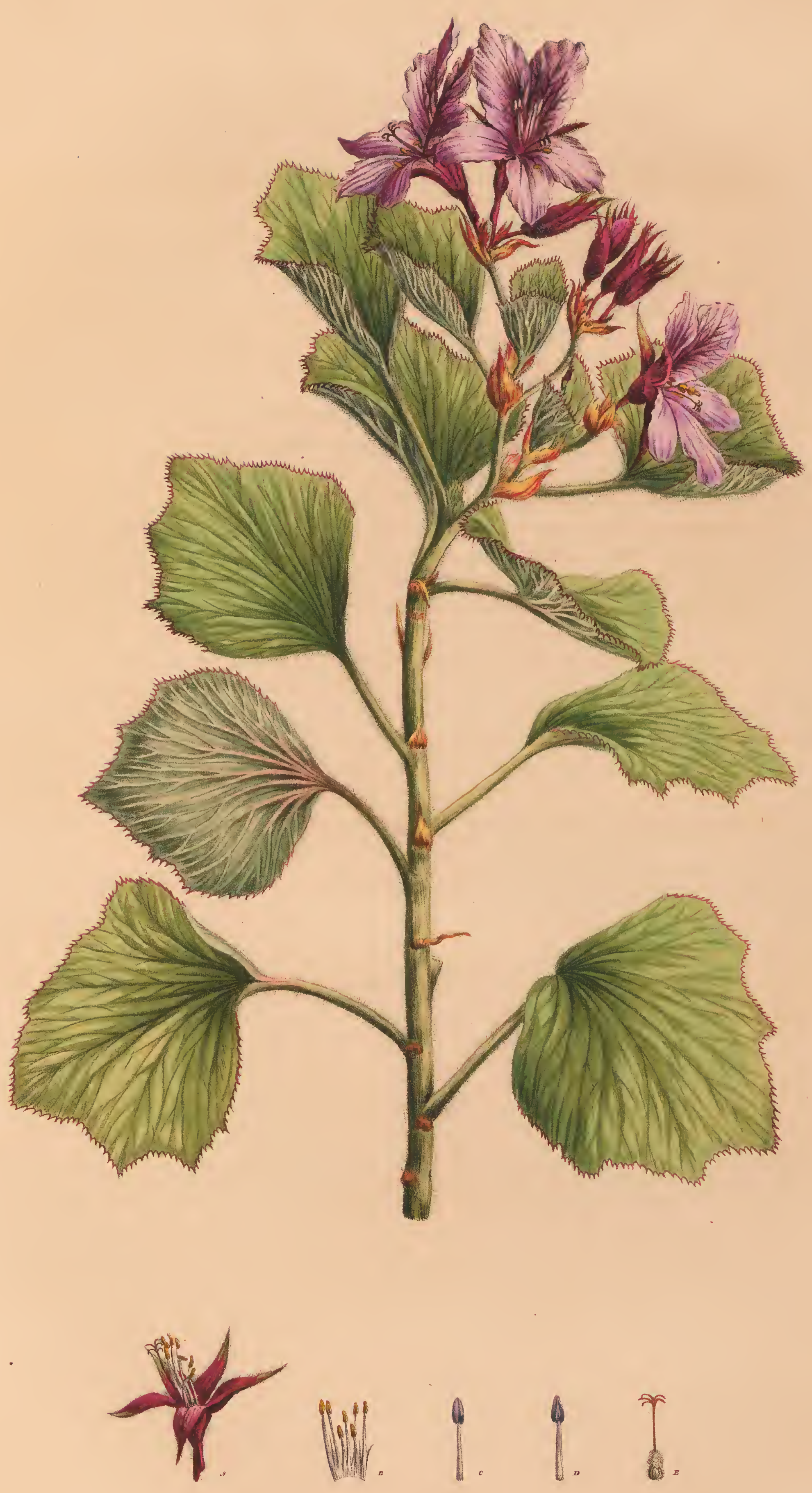

Pelargonium plicatum.

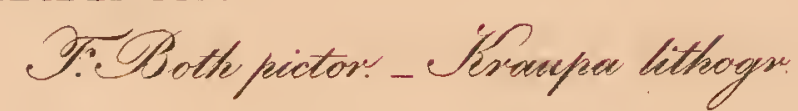




\title{
P E L A R G O I U M P L I C A T U M.
}

\author{
P E L A R G O N I U M. L'heretier.
}

Classis, et Ordo.

Monadelphia: Heptandria. Linne gen. pl. Dicotyledoneae: Geraniaceae. Juss. gen. pl. Cand. prodr.

Character generis.

Fructific atio. Calyx 5-partitus, lacinia suprema desinente in tubulum nectariferum tenuem secus pedicellum decurrentem, et huic adnatum. Petala 5, rarius 4 , plus minus irregularia. Filamenta 10 inaequalia monadelpha, 4-7 tantum fertilia, cetera castrata. Carpella 5 monosperma aristata, aristis introrsum, barbatis receptaculo rostrato arcte adnatis, demum elasticis spiraliter convolutis et secedentibus.

Vegetatio. Herbae acules tuberosae, aut caulescentes trunco saepe frutescente plus minusve carnoso. Folia stipulata petiolata alterna aut subopposita, integra aut varie dissecta spirantia. Flores umbellati involucrati.

$$
\text { Divisio generis. }
$$

Secundum divisionem Candolleanam Pelargonium plicatum ad Sectionem Pelargium Anisopetala purpurascentia foliis subindivisis cucullatis spectat, et quidem Pelargonium angulosum proxime accedit.

\section{P E L A R G O N I U M P L I C A T U M.}

$$
\text { Differentia specifica, et Synonymia. }
$$

P. foliis basi cuneatis subcucullatis subrotundis angulatis argute dentatis multinerviis plicatis cauleque patenti-villosis; umbellis paucifloris, tubo nectarifero calyce triplo breviore.

P. plicatum. Hort.

Gefalteter Kranichsschnabel.

$$
\text { Locus, et tempus. }
$$

Colitur in horto in tepidario, et ad varietates elegantissimas cultura ortas, et forte demum ad suas species reducendas spectare videtur; hinc et nomen hortense mutare noluimus, quamvis sit jam P. plicatum Thunberg. Fructificat Majo. $\hbar$. 


$$
\text { Descriptio. }
$$

Vegetatio. Frutex 3 -4-pedalis erectus ramosus, ramis flexuosis fuscescentibus citatrisatis, junioribus dilute viridibus herbaceis foliosis patenti-villosis. Folia alterna subrotunda, basi cuneata subcucullata, 5-7-angulata plicataque, angulis acutis acute dentatis, dentibus cartilagineis purpurascentibus recurvis, dilute viridia villosa, subtus pallidiora villosiora pedatinervia, nervis crassis prominentibus basi saepe purpurascentibus, odore grato impraegnata. Petiolus tereti-compressus, supra leviter exaratus, villosus, longitudine folii. Stipulae ad insertionem petioli oppositae patentes ovatae acuminatae. Umbellae terminales plures 3-4-florae involucratae pedunculatae oppositifoliae, pedunculis pedicellis calycibusque patenti-villosis. Folia involucralia ovata acuminata subincisa integerrimave. Pedicelli tubo nectarifero duplo longiores.

Fructificatio. Calyx atropurpureus inferus tubulosus 5-partitus, laciniis lanceolatis acuminatis apice patentibus, suprema in tubum nectariferum calyce triplo breviorem secus pedicellum decurrente. Corolla perigyna 5-petala irregularis bilabiata, petalis 2 superioribus majoribus labium superius, 5 inferioribus minoribus labium inferius constituentibus. Petala oblonga dilute violacea, superiora fere duplo ampliora margine undulata basi nervis tribus ramosis atropurpureis insignita. Stamina subdeclinata inaequalia. Filamenta 10 subulata basi in tubum perigynum connata, quorum $z$ fertilia longitudine inaequalia, 3 sterilia brevissima. Antherae ovatae biloculares versatiles violaceae, polline aurantiaco repletae. Germen superum 5-gonum 5 -lobum villosissimum stylum filiformem purpureum exserens. Stigmata 5 linearia revoluta purpurea. Fructum nondum perfecit.

\section{Explicatio Tabulae.}
A. Calyx cum staminibus et pistillo.
B. Tulus staminum longitudinaliter fissus et explinatus.
C. Stamen magnitudine auctum a facie.
D. Idem a tergo.
E. Pistillum. 


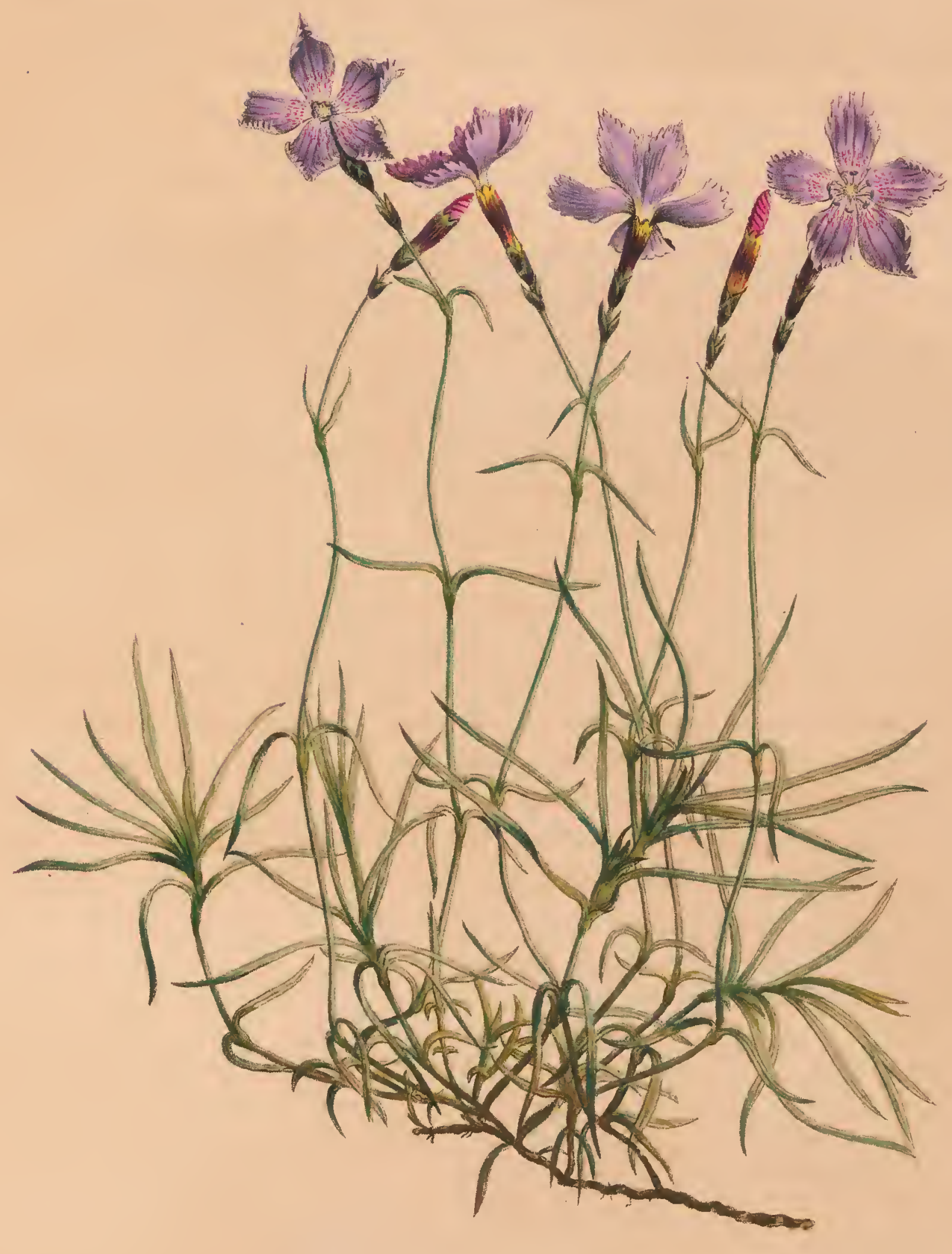

p. p. p.

Dianthus laxus.

D) Both foo. 


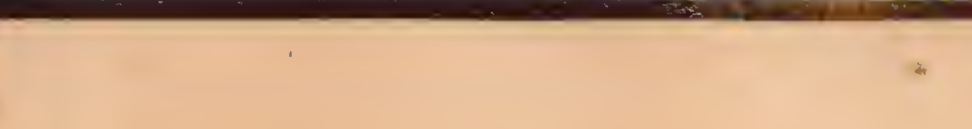




\section{I A N T H U S L A X U S.}

\section{I A N T H U'S, Linne,}

$$
\text { Classis, et Ordo. }
$$

Decandria: Digynia Linn. gen. pl. Dicotyledoneae: Caryophylleae. Juss. gen. pl. D. Caryophylleae, Sileneae. Cand. prodr.

$$
\text { Character generis. }
$$

Fructificatio. Calyx tubulosus 5-dentatus, basi squamis 2-4, aut pluribus decussatis imbricatus. Petala 5 longe unguiculata. Germen superum. Styli 2 filiformes plumosi. Capsula 1-locularis apice dehiscens sporophoro centrali columnari. Semina compressá peltata.

Vegetatio. Herbae saepissime perennes cespitosae, aut raro frutices. Caulis nodosus. Folia opposita angusta basi connata. Flores capitati fasciculati, aut solitarii sparsi, e quibus genus facile subdividitur.

\section{I A N T H U S L A X U S. \\ Differentia specifica, et Synonymia.}

D. caulibus unifloris flaccidis decumbentibus; squamis calycinis 2-4 ovatis acutis, petalis oblongo-cuneatis discretis crenatis pubescentibus; foliis glaucis anguste linearibus acutis subserrulatis.

Schlaffe Nelke.

$$
\text { Locus natalis, et tempus. }
$$

Habitat in Bohemiae rupibus ad castrum Caroli IV. cum Saxifraga Aizoone. Fructificat Maio, Junio. 4.

$$
\text { Descriptio. }
$$

Vegetatio. Radix perennis rhizomatoidea. Rhizoma obliquum tenue cylindricum elongatum flexuosum nodosum fuscum, basi radiculatum, apice multiceps, caules stolonesque ex decumbenti adscendentes numerosos, cespitemque efformantes emittens. Caulis spithamaeus debilis subfiliformis flexuosus ex decumbenti adscendens obsolete 4-gonus nodosus foliosus glaucus uniflorus aut raro 2-3-florus. Folia opposita basi connata anguste-linearia trinervia acuta tenuissime serrulata glauca patentia laxa, caulium remota, stolonum apice congesta. Folia floralia squamaeformia ovata purpurascentia. Flos terminalis erectus. 
Fructificatio. Calyx inferus anguste-tubulosus striatus purpurascens obtuse 5-dentatus, basi squamis 2 aut 4 ovatis acutis appressis auctus, persistens. Corolla 5-petala caryophyllea. Petala unguiculata, ungue elongato pallide flavescente, limbo oblongo-cuneato inaequaliter dentato saepe margine involuto, ex roseo in violaceum colorem vergente nervis obscurioribus, basi pilis sparsis saturatius coloratis barbato. Stamina 10 exserta una cum petalis annulo perigyno minimo inserta. Filamenta capillaria aequalia. Antherae ovales 2-loculares versatiles violaceae. Germen superum oblongum substipitatum. Styli 2 filiformes elongati in stigmata pilosa terminati. Capsula oblonga unilocularis polysperma, apice dentibus 4, dehiscens, sporophoro centrali columnari seminibus imbricatim tecto. Semina ovata acuta compressa, hinc convexa illinc concava peltata nigra:

\section{Diagnosticon.}

D. laxus proximus est D. caesio Smith (Dill. Elth. t. 298. f. 385) a quo praecipue differt caulibus debilibus laxissimis, foliis longioribus angustioribus acutis, squamis calycinis acutis, calyce longiore duploque angustiore, laminis petalorum oblongo-cuneatis discretis; nec rotundato-cuneatis approximatis.

$$
\text { Explicatio Tabulae. }
$$

A. Calyx integer.

B. Squamae a calyce remotae.

C. Stamina cum pistillo.

D. Petalum.

E. Capsula apice dehiscens.

F. Capsula dimidiata cum sporophoro.

G. Semen.

H. Idem magnitudine auctum a facie.

I. Idem a dorso. 


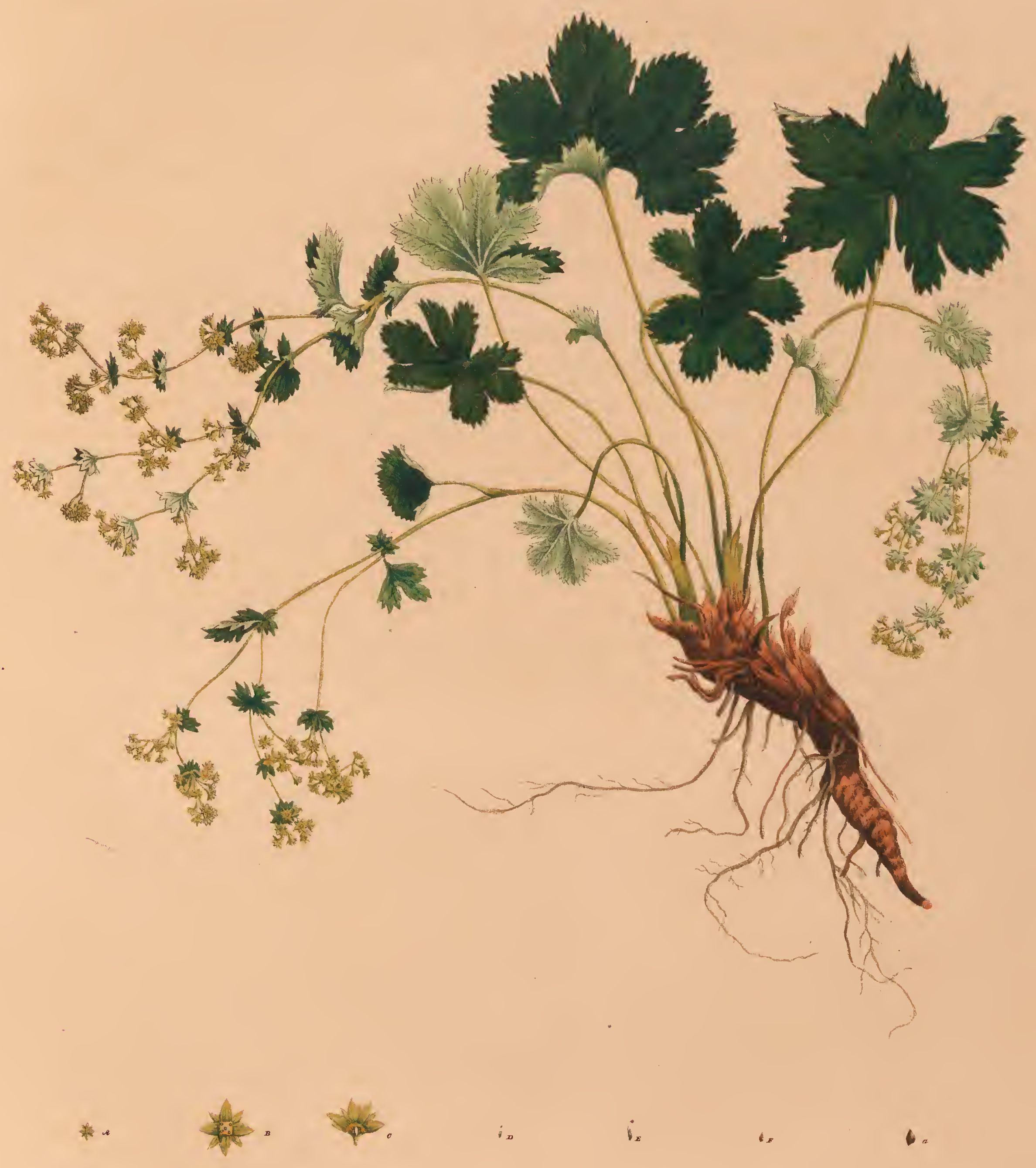

ALCHEMILLA MINOR.

Pre⿻日禸 the foa 



\title{
A L C H E M I L L A M I N O R.
}

\author{
A L C H E M I L L A. Linn. Willd.
}

Classis, et Ordo.

Tetrandria: Monogynia. Linn. gen. pl. Dicotyledoneae: Rosaceae, Sanguisorbeae. Juss. gen. pl. Cand. prod.

\section{Character generis.}

Fructificatio. Calyx tubulosus, fauce disco annulari subconstricta, limbo 8-partito plano, laciniis alternis inaequalibus. Corolla nulla. Stamina 1-4. Germina $1-6$ totque carpella in fundo calycis inclusa. Stylus basi germinis insertus stigmate capitato.

Vegetatio. Herbae foliis palmatim lobatis sectisve, floribus parvis corymbosis, aut sessilibus glomeratis spicatisve, e quibus genus praeprimis subdividendum est.

\section{A L C H E M I L L A M I N Ò R.}

\section{Differentia specifica, et Synonymia.}

A. caule debili decumbente petiolisque glaberrimis; foliis reniformibus 7 -lobis, lobis basi cuneatis discretis grosse serratis subciliatis; floribus corymbosis terminalibus.

A. perennis viridis minor. Moris. hist. 2. p. 195 .

A. minor. Tournef, inst. p. 508 .

A. vulgaris $\beta$ minor. Linn. sp. pl.ed. 1.p. 123. ${ }^{*}$ ) ed. 3. p.179. Willd. sp. pl. 1. p.698+

A. palmatifida. Tausch ind. pl. hort. Can. anno 1821.

A. fïsa. Reichenbach ic. pl. rar. Cent. 1. dec. 1. p. 6. t. 4. f. 10. Spreng. syst. veg. 1. p. 454.

Kleiner Löwenfufs.

$$
\text { Locus natalis, et tempus. }
$$

Habitat in elatis herbidis petrosis subhumidis Sudetorum, inque Alpibus Europae. Fructificat in horto sub Dio Maio, Junio, altera vice saepius Septembri. 4.

$$
\text { Descriptio. }
$$

Vegetati o. Radix perennis rhizomatoidea. Rhizoma fuscum cylindricum, rugis transversalibus exaratum, oblique descendens, undique radiculatum, verti-

*) Jrror typographicus in Linn. sp. pl. ed. 1. et quidem transpositio signaturae $\beta$ in lineam anteriorem, et hinc in Alchemillae vulgaris synonymum Bauhinianum pessime delatae in oculos cadit, qui nililo minus in subsequentibus editionibus repetitus fuit, et illustrationi hujus speciei hucdum obicem posuisse videtur. 
ce vaginis fuscis tectum, caules foliaque emittens. Caulis extrafoliaceus spithamaeus, ad summum vix pedalis, valde debilis decumbens teres glaberrimus foliosus, apice corymbosus. Folia radicalia fasciculata petiolata stipulata, petiolis teretibus glaberrimis, stipulis oppositis oblongo-lanceolatis apice inciso-dentatis; reniformia, ad medium et ultra palmatim 7 -loba, 7 -nervia plicataque, glabra, tenuissime reticulata, subtus pallidiora; lobis subrotundis, basi cuneatis discretis, in ambitu grosse et argute serratis, tenuissime ciliatis : caulina alterna remota brevissime petiolata stipulata, inferiora $5^{\text {-lo- }}$ ba basi truncata, superiora -loba basi cuneata, summa cum stipulis confluentia, stipulis oppositis ovatis inciso-dentatis'basi connatis caulemque vaginato-amplexantibus. Flores terminales racemosi, in corymbum effusum compositum congesti. Pedunculi capillares nudi glaberrimi.

Fructificatio. Calyx inferus persistens tubulosus, fauce disco annulari rubescente tenuissime ciliato constrictus, limbo plano 8-fido laciniis inaequalibus: interioribus 4 majoribus ovatis, exterioribus 4 alternantibus linearibus: omnibus glaberrimis, aut piliferis ex flavo virescentibus. Corolla nulla. Stamina 4, disco annulari inserta, laciniis calycinis exterioribus opposita. Filamenta subulata adscendentia. Antherae minimae subrotundae biloculares. Germen ovatum in fundo calycis. Stylus filiformis, ad basim germinis insertus, adscendens, longitudine staminum. Stigma capitatum. Carpellum 1 ovatum compressum laevissimum lividum, in fundo calycis inclusum.

$$
\text { Explicatio Tabulae. }
$$

\footnotetext{
A. Limlıus calycis cum staminilıs.

B. Idem magnitndine auctus.

C. Calyx longitudinaliter fissus cun germine magniludine auctus.

D. Pistillum.

E. Idenı magnitudine auctum.

F. Carpellum.

G. Hlem magnitudine auctum.
} 


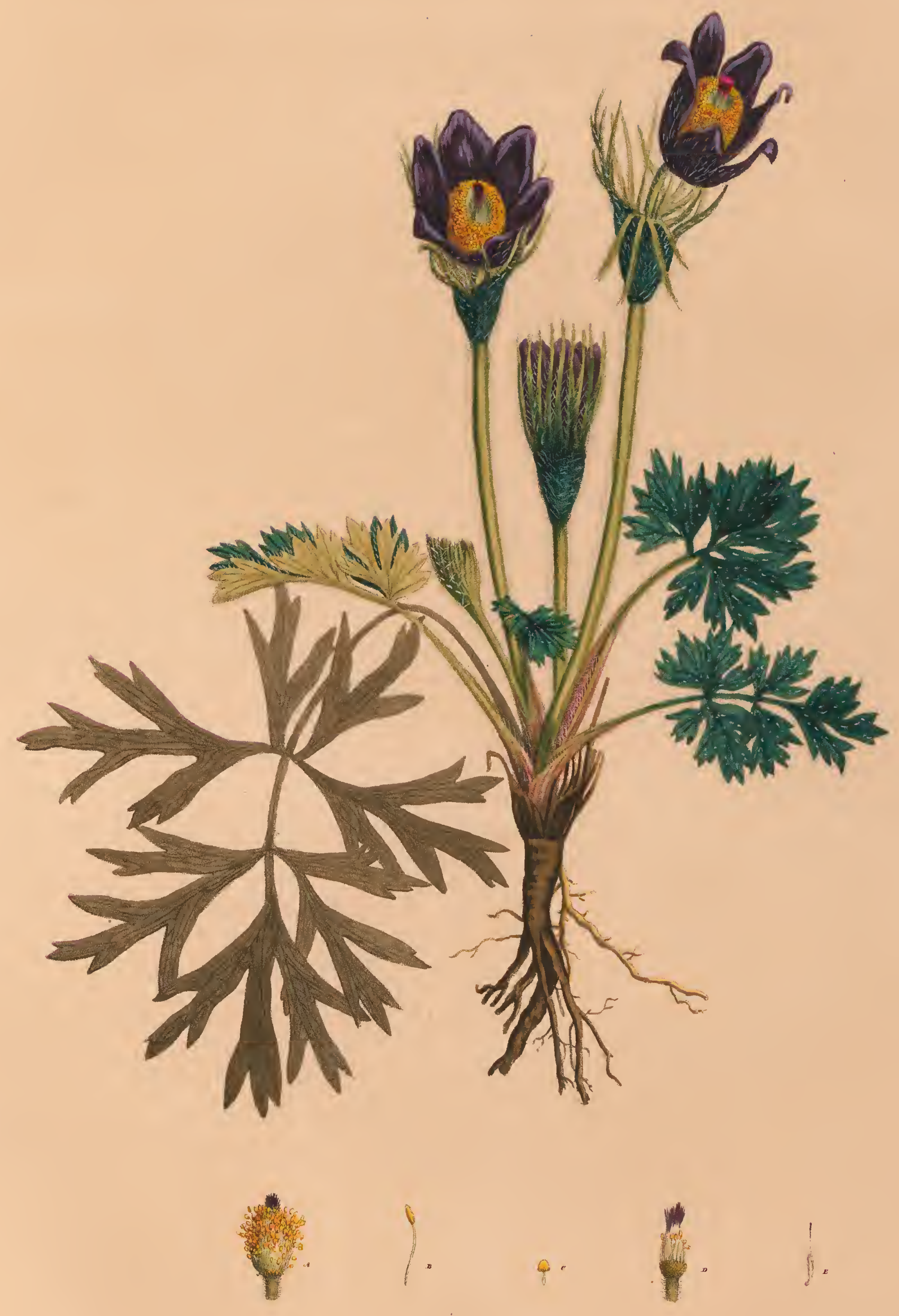

Anemone Halleri.

Tr. Doth for. 



\section{A N E M O N E H A L L E R I.}

A N E M O N E. Linn. Cand.

Classis, et Ordo.

Polyandria: Polygynia Linn. gen. pl. Dicotyledoneae: Ranunculaceae. Juss. gen. pl. D. Ranunculaceae, Anemoneae. Cand. syst. veg.

Character generis.

Fructificatio. Involucrum triphyllum varie incisum a flore distans. Calyx $5^{-1} 5^{-s e p a l u s ~ p e t a l o i d e u s . ~ P e t a l a ~ n u l l a . ~ S t a m i n a ~ p l u r i m a . ~ C a r y o p s i d e s ~ p l u r i-~}$ mae monospermae nunc in caudam longam barbatamque elongatae, nunc ecaudatae.

Vegetatio. Herbae perennes. Radix rhizomatoidea, aut carnosa tuberosa, aut fasciculata. Folia radicalia, aut rarissime caulina, petiolata, varie dissecta. Scapus apice gerens involucrum e foliis 3 varie dissectis saepeque radicalibus analogis constans. Ex involucro pedicelli uniflori solitarii, aut umbellati, aut plures inaequales, eorumque uno alterove involucrato subdiviso, quasi prolifero ramumque aemulante. Flores numero petalorum valde variabiles, facillime pleni.

\section{Divisio generis.}

Divisioni generis praeclarae a clar. De Candolle institutae sequentes liceat adjicere observationes:

3. Pulsatilla et Preonanthus sectiones nimis affines uniendae, et solum ex involucris sessilibus aut petiolatis uti Anemonanthea et Anemonespermos subdividendae sunt.

2. Anemonantheae pro charactere radix carnosa tuberosa, Anemonespermo radix rhizomatoidea, et Omalocarpo radix fasciculata addi potest, et amovendae ab Anemonanthea species sunt A. silvestris, alba, forte et baldensis, quarum altera (saltem ochotensis Hortorum), quae solum glabritie et scapo prolifero a silvestri differt, omnem Anemonespermi characterem exhibet.

\section{A N E M O N E H A L L E R I.}

\section{Differentia specifica, et Synonymia.}

Pulsatilla: foliis pinnatisectis villosis villosissimisve, segmentis tripartitis lobatis, lobulis lanceolato-linearibus acuminatis; flore erecto campanulato.

A. Halleri. Allion. pedem. n. 1922. t. 80. f. 2. (mala) Cand. syst. veg. 1. p. 19o.

A. hybrida. Mikan M. S.

Pulsatilla Hackelii. Pohl boh. 2. p. 213.

Hallers Schellen-Windblume.

Locus natalis, et tempus.

Habitat in Bohemia in vertice montis Radischken ad Litomericium, in montibus Austriae, inque Alpibus Europae australis, inque Pyrenaeis. Fructificat ineunte Aprili. 4.

$$
\text { Descriptio. }
$$

Vegetatio. Radix rhizomatoidea lignescens atrofusca cylindrica, basi ramosa, oblique recteve descendens, apice saepe multiceps cespitemque efformans, 
vertice squamis foliisque emarcidis fuscis convolutis, quorum unum in icone explanatum exhibetur, tecta. Folia coetanea: omnia radicalia petiolata pinnatisecta, segmentis 5 tripartitis, lobis lobatis, lobulis sub evolutione ovatis, aetate demum provecta elongatis lanceolato-linearibus acuminatis rigidiusculis nervosis subtus pallidioribus, in juventute villis albis praeprimis subtus tectis, demum subvillosis, imo et fere denudatis. Petioli villosi canaliculati, basi in vaginam purpurascentem dilatati. Scapi inter folia plures simul enascentes erecti spithamaei teretes solidi villosi, apice gerentes involucrum villosum e foliis 3 basi in tubum ventricosum sessilem connatis, apice in lacinias lineares palmatipartitis constans. Pedicellus ex involucro solitarius erectus uniflorus nudus villosus, sub anthesi involucro brevior, anthesi vero peracta illud bis terve superans.

Fructificatio. Calyx inferus deciduus erectus campanulatus 6-sepalus petaloideus profunde violaceus, dorso villosus, sepalis erectis ovalibus aut oblongis obtusis, demum nonnunquam apice reflexis. Petala nulla. Glandulae nectariferae subrotundae flavae breviter stipitatae calycem inter et stamina. Stamina numerosissima, sepalis duplo breviora, receptaculo subgloboso favoso nudo imposita. Filamenta capillaria. Antherae ovales biloculares adnatae, polline flavo repletae. Pistilla numerosissima, sepalis breviora; 'singulis germen lineari-oblongum, stylo terminali filiformi villoso, basi villis elongatis densissimis albo-sericeis barbato, apice purpureo. Stigma minimum capitellatum. Fructum in horto nondum perfecit, sed pedicellus elongatur, et cum flore tabescit.

Observatio. Planta bohemica cum austriaca ex asse convenit; specimina vero vallesiaca villositate multo densiore, hinc et multo candidiore argentea non magis a nostrate differunt, ac A. alpina villosissima ex Alpibus editissimis ab A. alpina subvillosa ex subalpinis.

\section{Critica.}

Planta bohemica proles hybrida ex A. patente, et pratensi enata aestimatur a Clar. Mikan, et quidem e consortio, in quo hae tres species in Bohemia proveniunt, et ex observatione, quod in hortum transplantata nunquam fructum perficiat, cui opinioni concedere non possumus ex eo, quod plures nonnunquam ejusdem generis species in consortio proveniant, quin hybridae sint; quod consortium hoc ipsum dubium aut rarissimum sit, cum A. pratensis constanter radicem, A. Halleri et patens vero verticem montis occupet; quod eadem planta in Austria absque A. patente (patre matreve) enascatur; porro quod sterilitas plantae spontaneae nondum experta sit, et in horto specimina paucissima, ut plurimum solitaria observata fuerant, quorum sterilitas potius in variis circumstantiis per mutationem loci soli inductis, et fructificationi obnoxiis fundata fuisse videtur, qua ratione sterilitatem non solum A. Halleri, sed et A. patentis in cespitibus permagnis quotannis numerosis floribus onustis in horto Canalio per 8 annos observatam explicamus.

$$
\text { Explicatio Tabulae. }
$$

A. Flos sepalis demptis glandulas nectariferas, stanina et pistilla demonstrans. B. Stamen magnitudine auctum.

$$
\text { C. Glandula nectarifera maguitudine aucta. D. Receptaculun cum pistillis. E. Pistillum. }
$$




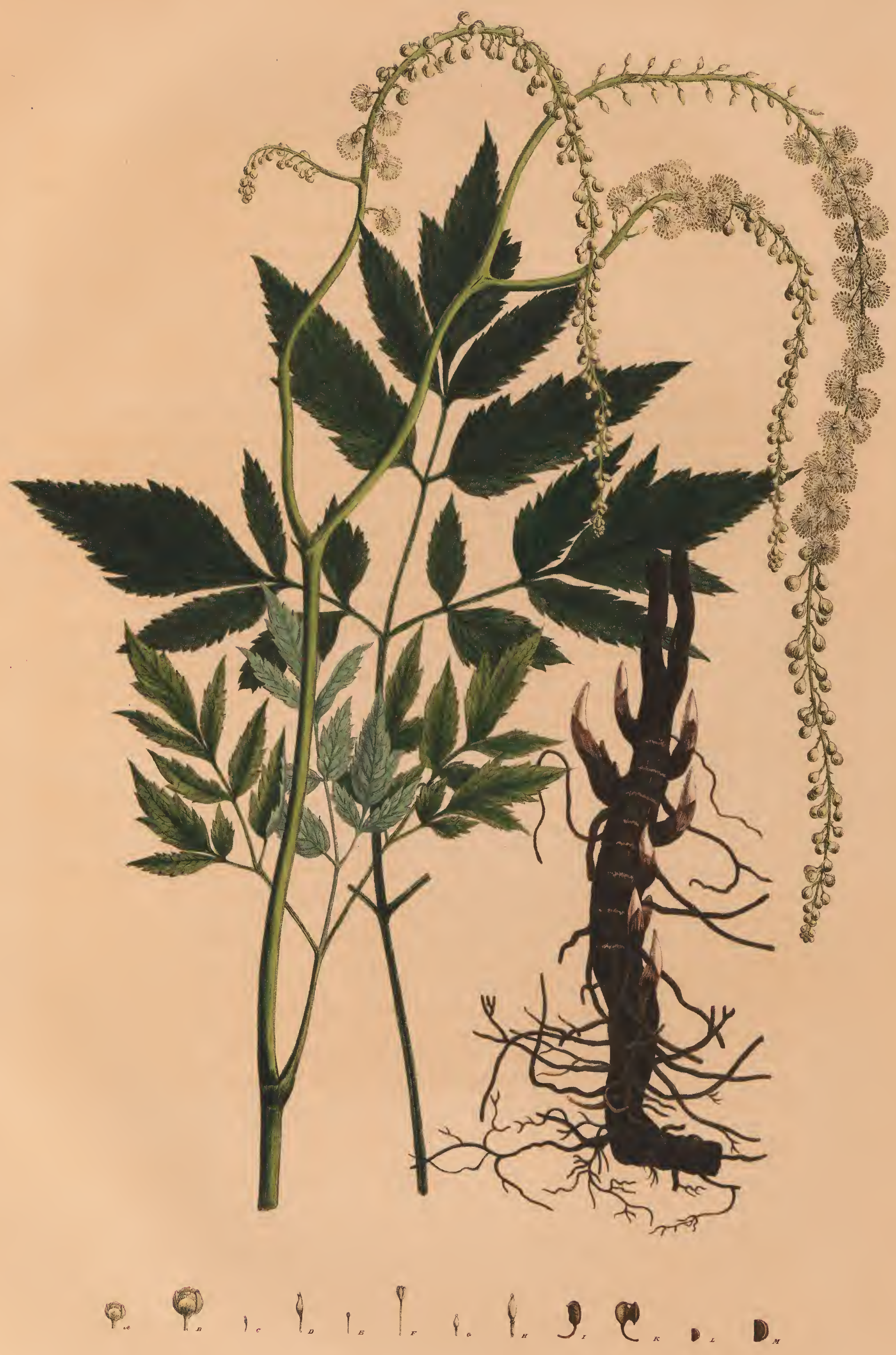

ACTAEa Nutans. 


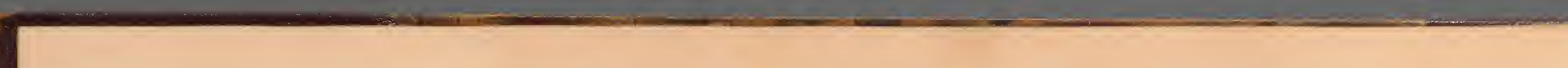




\title{
A C T A E A
}

\author{
A C T A E A. Linn. Cand.
}

$$
\text { Classis, et Ordo. }
$$

Polyandria: Monogynia. Linn. gen. pl. Dicotyledoneae: Ranunculaceae. Juss. gen. pl. D. Ranunculaceae, Paeoniaceae. Cand, prodr.

$$
\text { Character generis. }
$$

Fructificatio. Calyx 4-sepalus caducus. Petala 4. Stamina plurima antheris introrsis. Ovaria numero valde inconstantia $1-12$ ovata stigmate subsessili. Capsulae tot quot ovaria, uniloculares polyspermae 2 -valves, valvis mox siccis dehiscentibus, mox carnosis demum plus minusve dehiscentibus.

Vegetatio. Herbae perennes. Folia petiolata alterna, simpliciter aut saepe 23-ternatimdecomposita. Flores racemosi albi. Calyx et corolla caducissimi.

$$
\text { Divisio generis. }
$$

Species hucusque cognitae vegetatione et fructificatione maxime sibi affines in tanta numeri pistillorum inconstantia, tantaque pericarpiorum affinitate, cum Christophorianae pericarpium sit capsula valvis carnosis demum sua sponte dehiscens, divisionem etsi nuperrime dissentientibus viris clarissimis De Candolle et Sprengel non admittunt, et sectiones generis institutae nonnisi sunt subdivisiones habendae.

\section{A C T A E A N U T A N S.}

$$
\text { Differentia specifica, et Synonymia. }
$$

A. monogyna, capsulis exsuccis; racemis longissimis laxis nutantibus; foliis triternatim-sectis, segmentis ovato-lanceolatis acuminatis inciso-serratis.

A. pachystachya, Tausch ind. pl. hort. Can. anno 1821.

Hängendes Christophskraut.

$$
\text { Locus, et tempus. }
$$

Colitur in horto promiscua cum Actaea racemosa. Fructificat Julio. 4.

$$
\text { Descriptio. }
$$

Vegetatio. Radix perennis rhizomatoidea. Rhizoma cylindricum descendens flexuosum articulatum aterrimum undique radiculatum, apice evolutione gemmarum ramosum. Caulis 3-4-pedalis erectus flexuosus teres foliosus 
'glaber subglaucescens. Folia radicalia tongissima triternatimsecta, caulina alterna remota petiolata: inferiora radicalibus analoga, superiora biternatimsecta, summa squamosa ut plurimum caduca. Foliorum segmenta ovato-lanceolata acuminata argute inciso-serrata glabra, subtus pallidiora venosa. Petioli canaliculati basi vaginantes, vagina cauli adnata. Racemi terminales paniculati longissimi nutantes, rachi leviter tomentosa. Pedicelli laxi basi bracteati, bractea lineari pedicello breviore. Flores laxi foetidissimi. Fructificatio. Calyx inferus subglobosus 4-sepalus, sepalis subrotundis albidis glabris caducis. Petala 4 lineari-cuneata stipitata apice emarginata. Stamina numerosa receptaculo parvo subhemisphaerico imposita. Filamenta capillaria sepalis longiora. Antherae sessiles erectae ovatae biloculares, intus dehiscentes, polline albido repletae. Germen superum sessile oblongum, apice attenuatum stigmateque obliquo sessili coronatum. Capsula ovata fusca unilocularis bivalvis exsucca, sutura interiore dehiscens, polysperma ut plurimum 7 -sperma, sutura interiore seminifera. Semina biserialia, capsulam exacte replentia, fusca angulata, et quadrantem segmentumve circuli praeferentia, squamulis minimis fuscis lepidota.

\section{Diagnosticon.}

Actaea nutans differt praecipue ab A. racemosa habitu graciliore; foliorum segmentis acuminatis duplo angustioribus; racemis longissimis nutantibus laxe racemosis; pedicellis flore duplo longioribus, nec aequalibus; capsulis seminibusque minoribus. Actaeae racemosae diagnosis erit: A. monogyna, capsulis exsuccis; racemis elongatis densis sub anthesi erectis; foliis triternatimsertis, segmentis ovatis acutis serratis.

\section{Explicatio Tabulae.}
A. Flos integer sulb explicatione.
B. Idem magnitudine anctns.
C. Petahm.
D. Idem magnitudine anctum.
E. Stanen.
F. Idem magnitudine anctnm.
G. Pistillum.
H. Idem magnitudinc auctum.
I. Capsula rima dehiscente.
K. Eadem penitus aperta.
L. Semen.
M. Idem magnitndine auctum. 


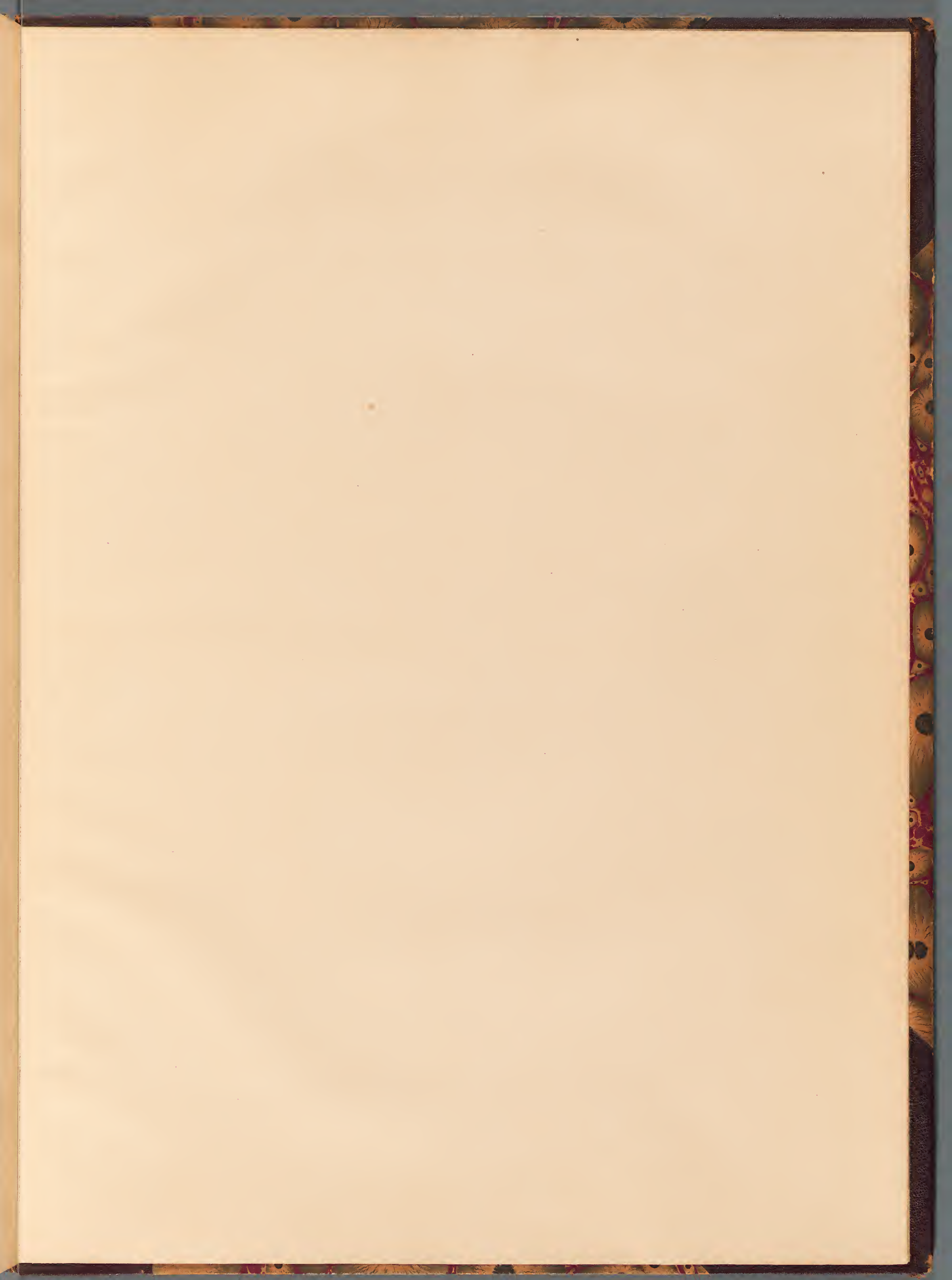





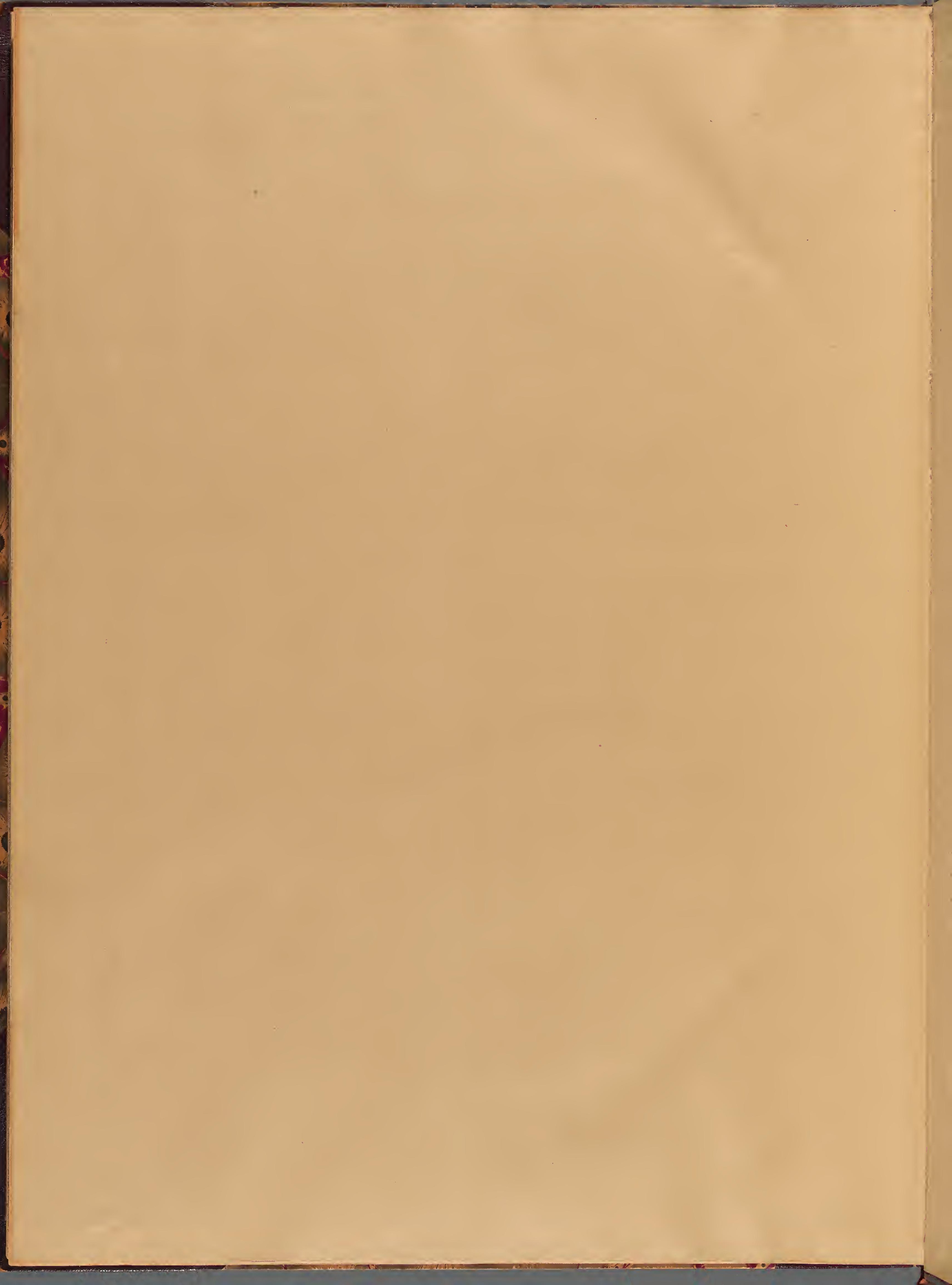




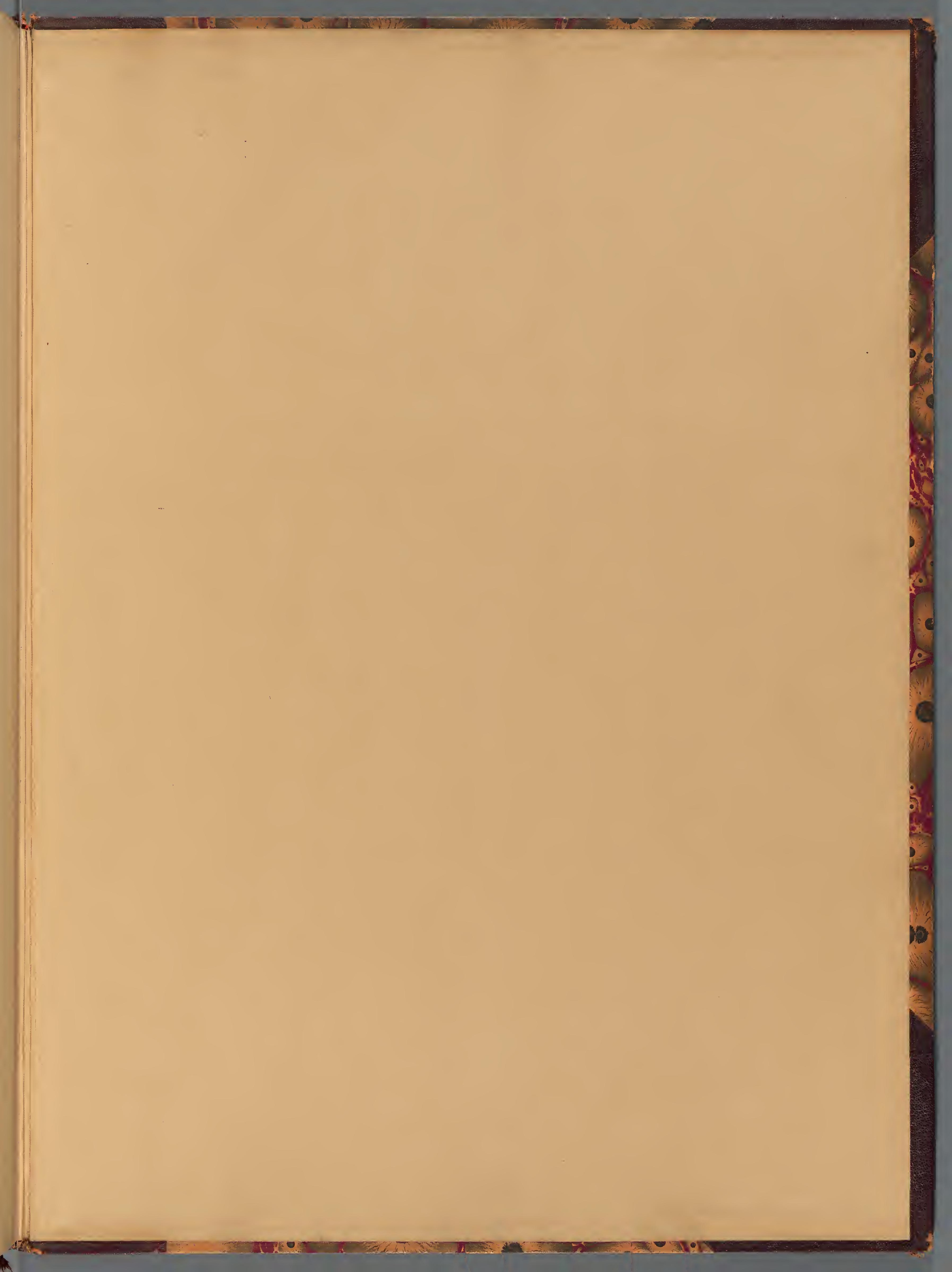




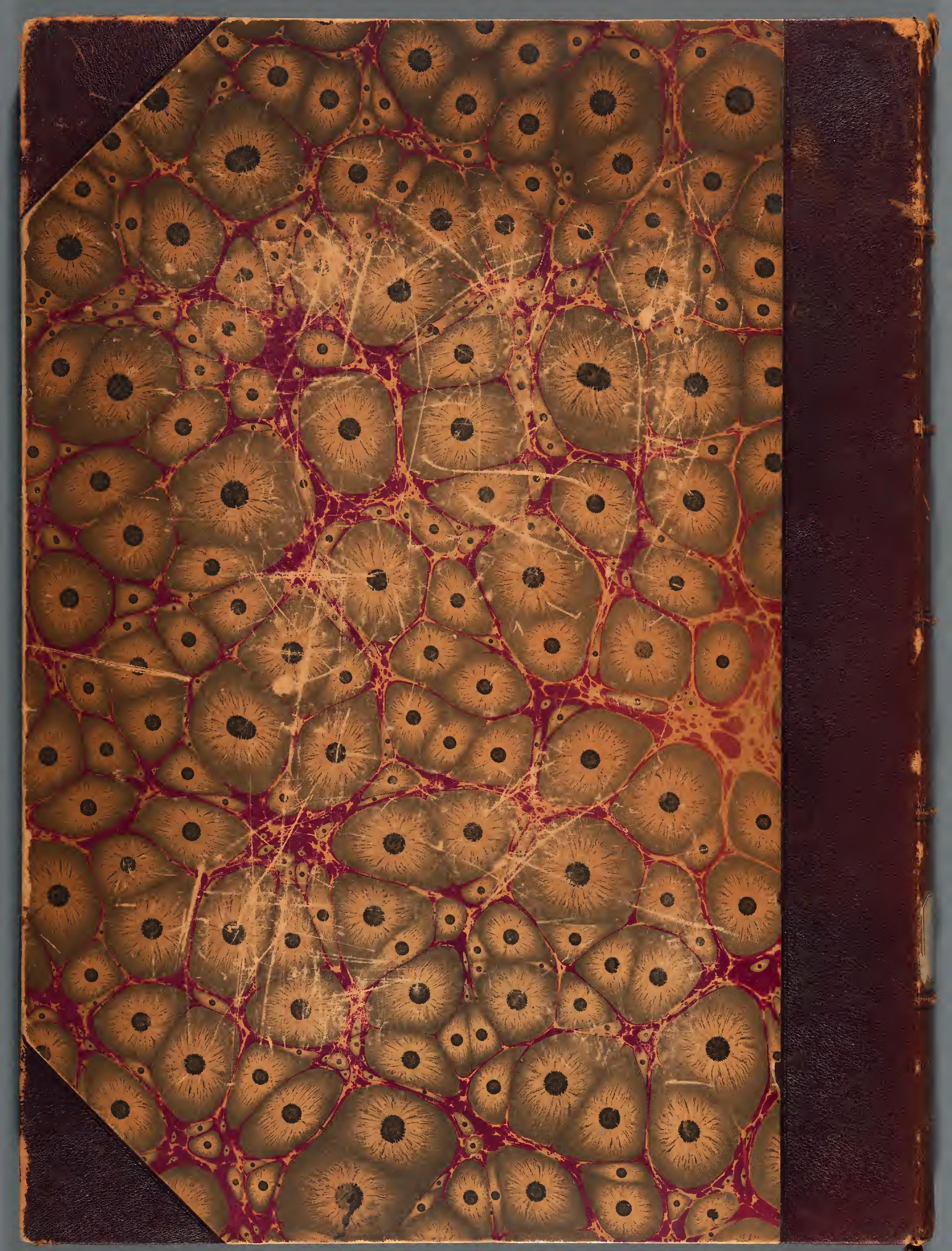

